ECONOMICS OF THE GREENSEEDER HAND

PLANTER, DISCRETE CHOICE MODELING, AND

ON-FARM FIELD EXPERIMENTATION

\author{
By \\ JOHN NEDSON NG'OMBE \\ Bachelor of Science in Agricultural Economics \\ University of Zambia \\ Lusaka, Zambia \\ 2010 \\ Master of Science in Agricultural Economics \\ University of Zambia \\ Lusaka, Zambia \\ 2013
}
Submitted to the Faculty of the
Graduate College of the
Oklahoma State University
in partial fulfillment of
the requirements for
the Degree of
DOCTOR OF PHILOSOPHY

August, 2019 


\title{
ECONOMICS OF THE GREENSEEDER HAND \\ PLANTER, DISCRETE CHOICE MODELING, AND \\ ON-FARM FIELD EXPERIMENTATION
}

\begin{abstract}
Dissertation Approved:
\end{abstract}
Dr. B. Wade Brorsen

Dissertation Adviser

Dr. Eric DeVuyst

Dr. Dayton M. Lambert

Dr. Harounan Kazianga 


\section{ACKNOWLEDGEMENTS}

I thank God the Almighty for giving me a life and fantastic opportunities all along. I would also like to thank Dr. Francis Epplin for offering me a Graduate Research Assisstantship to begin my doctoral studies at Oklahoma State, especially in the United Sates. Dr. Epplin's offer changed the trajectory of my life - it made it much better. Following his retirement, Dr. Richard Melstrom (Loyola University Chicago) briefly took over as my new advisor. I thank him wholeheartedly because he has guided me since, despite his departure to another university. Dr. Wade Brorsen became my next advisor and he has seen me through till this end. I express my full gratitude to him for "saving me from myself" most of the times. Dr. Brorsen introduced me to Bayesian analysis which I have completely come to love and enjoy doing. Thank you, Dr. Brorsen. I also acknowledge the contributions made by my other dissertation committee members: Dr. Eric Devuyst, Dr. Dayton Lambert, and Dr. Harounan Kazianga. I also acknowledge Dr. Tracy Boyer for having briefly served on my committee before she left for University of Wisconsin-Milwaukee. Without the committee's criticisms and approvals, this dissertation would not have been successfully completed. I also recognize the contributions from my classmates and friends, more especially Dr. Bart Niyibizi (University of Wisconsin-River Falls) who offered his assistance whenever my coding in R Software got so wild and messy! Additionally, I would like to express my everlasting thanks to my beloved and amazing wife - Mariah, for her unfailing encouragement, love, and for being my rock at all times. Our two sons, Yash Ivan and Ryan Nedson troubled you the most as I worked on this dissertation. They were always trying to switch off the computer so I could tend to them. I hope that they will look at this document in future with admiration. You guys are the best! I dedicate this work to you guys, including my two lovely elder sisters: Develess and Mary, as well as to my only younger brother and upcoming family's medical doctor: Rodgers Nedson! Lastly, I also affectionately dedicate this dissertation to our deceased mom and dad! 
Name: JOHN NEDSON NG'OMBE

Date of Degree: JULY, 2019

Title of Study: ECONOMICS OF THE GREENSEEDER HAND PLANTER, DISCRETE CHOICE MODELING, AND ON-FARM FIELD EXPERIMENTATION

\section{Major Field: AGRICULTURAL ECONOMICS}

Abstract: Corn yields in developing countries are lower than in developed countries partly due to planting methods that involve hand dropping of multiple seeds per hill. Researchers from Oklahoma State University (OSU) recently developed the Greenseeder Hand Planter (GHP) to replace such methods. The first essay determines economic breakeven levels of seed and labor savings, increases in corn yield, and reduced loss of $\mathrm{N}$ through reduced ammonia volatilization. Results suggest a $\$ 50 \mathrm{GHP}$ used to plant 3 hectares per year would need to increase corn yields on average by about $1.12 \%$, use $12.19 \%$ fewer seeds, or reduce labor man-days by $38.66 \%$ to equal expected net returns from traditional methods.

In the second essay, I conduct Monte Carlo experiments to measure bias in the conditional logit (CL) and independent availability logit (IAL) when there is no choice set formation and when choice sets are stochastically formed. I also compare the performance of the two models using empirical data on paddlefish angler preferences collected in Oklahoma. Both the CL and IAL work well when their own assumptions hold, but not under the alternative's assumptions. However, the IAL produces unbiased and less efficient parameter estimates when individuals actually choose from the full set of alternatives. Empirical results suggest the IAL is able to predict the attribute-cutoff.

To avoid limitations from small-scale agronomic trials, there has been a movement toward large-scale, on-farm field trials but questions remain as how best to conduct them and when it is most profitable to quit them. The third essay addresses these questions by using a fully Bayesian decision-theoretic approach. Data are from Monte Carlo simulations assuming a corn-input stochastic plateau production function. Results suggest the best way to conduct such experiments is to allocate to each of the $10 \%$ of the plots, $0 \mathrm{lb}$. of N, half of $\mathrm{N}^{*}$, and $150 \%$ of $\mathrm{N}^{*}$ under a 30-plot experimental design. Results further indicate that it optimal to quit such trials in year 2. Sensitivity analysis confirms the optimal quit period but suggests such experiments are most profitable by allocating unalike $\mathrm{N}$ levels to all of the $30 \%$ of experimental plots. 


\section{TABLE OF CONTENTS}

Chapter

I. ECONOMICS OF THE GREENSEEDER HAND PLANTER …………………....1

Abstract Introduction

II. THE EFFECT OF INCLUDING IRRELEVANT ALTERNATIVES IN DISCRETE CHOICE MODELS OF RECREATION DEMAND ………..........................25

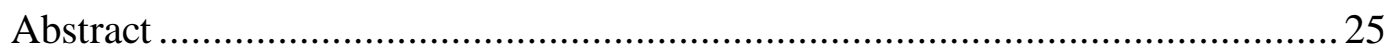

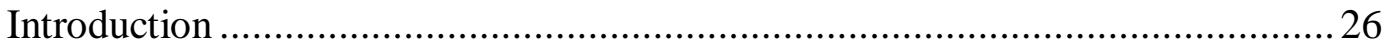

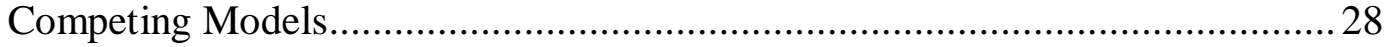

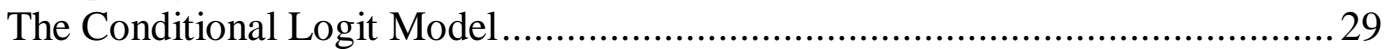

The Independent Availability Logit Model........................................................ 30

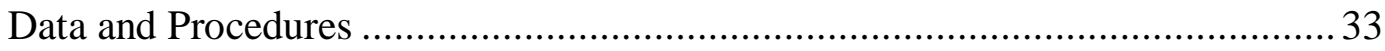

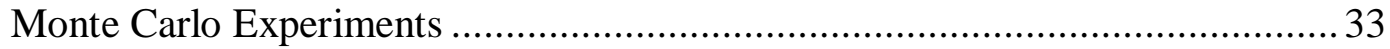

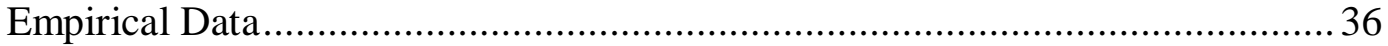

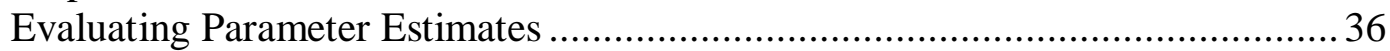

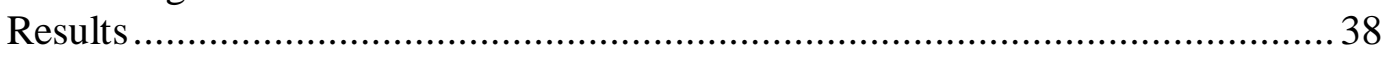

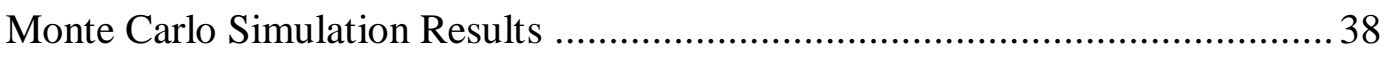

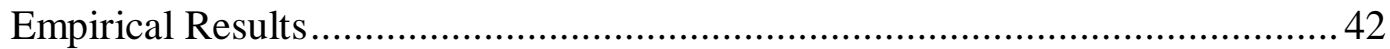

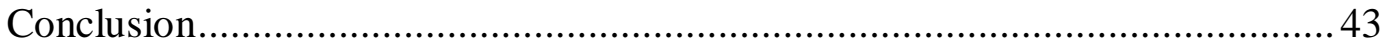

III. BAYESIAN OPTIMAL DYNAMIC SAMPLING PROCEDURE FOR ON-FARM

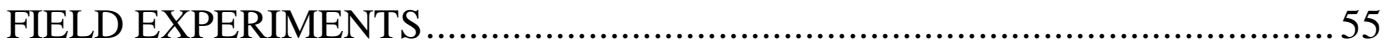

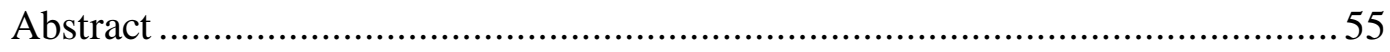

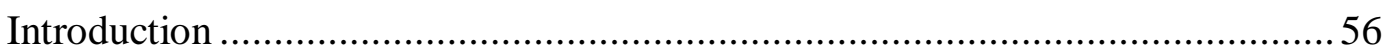

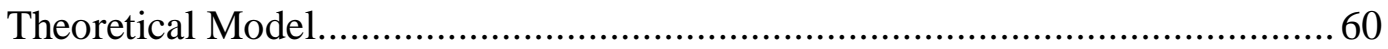

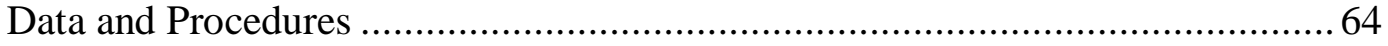

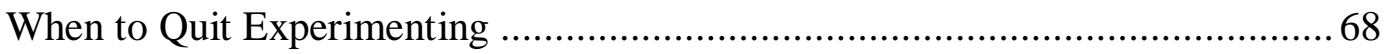




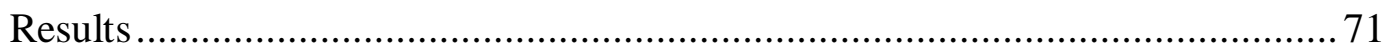

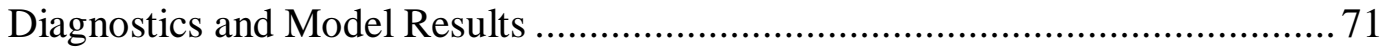

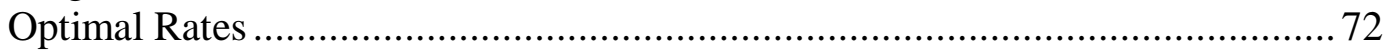

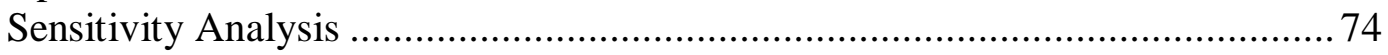

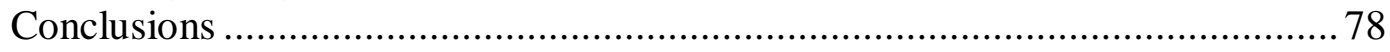

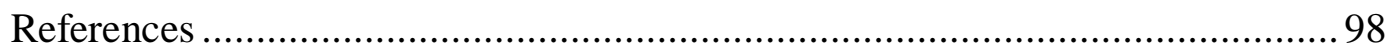




\section{LIST OF TABLES}

Table

Page

Table 1.1: Descriptive Statistics of Corn Yield $\left(\mathrm{Mg} \mathrm{ha}^{-1}\right)$ According to Planter Type Obtained in 2014, 2015, and 2016

Table 1.2: Table 2: Descriptive Statistics of Corn Yield (Mg ha-1) by Planter Type from Efaw, Lake Carl Blackwell and Stillwater Agronomy Research Stations ....... 18

Table 1.3: Linear Mixed Effects Regression Results of Corn Yield (Mg ha-1)

Response

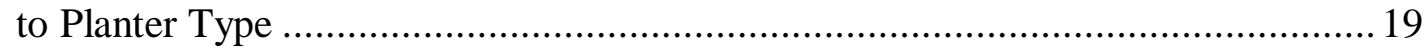

Table 1.4: Least Squares (LS) Means (Mg ha-1) of Corn Yield by Planter Type .... 20

Table 1.5: Breakeven Corn Yield (Mg/ha), Corn Seed (kg/ha) and Labor Savings (man-days).....

Table 1.6. Average Emergence Rates (\%) According to Planter Type Obtained in

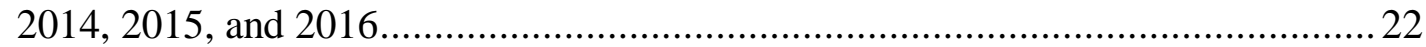

Table 2.1: The Basic Setting of the Data Generation Condition........................... 46

Table 2.2: Descriptive Statistics of Empirical Data .......................................... 47

Table 2.3: Mean Parameter Estimates of CL and IAL Models when the IAL Model is true

Table 2.4: Mean Parameter Estimates of CL and IAL Models when CL Model is true

49

Table 2.5: Mean Square Error (MSE), and Proportion of MSE by Bias and Variance

of Mean Parameter Estimates for CL and IAL when the IAL Model is true 50 Table 2.6: Mean Square Error (MSE), and Proportion of MSE by Bias and Variance of Mean Parameter Estimates for CL and IAL when the CL Model is true .............52 Table 2.7: Empirical Parameter Estimates of CL and IAL Models ........................53

Table 3.1: Experimental Designs Used in Sensitivity Analyses ............................ 83

Table 3.2: Bayesian Parameter Estimates of the Stochastic Plateau Corn Yield

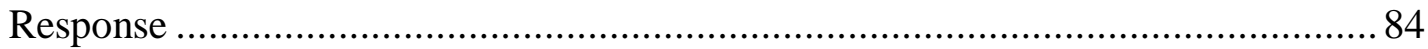

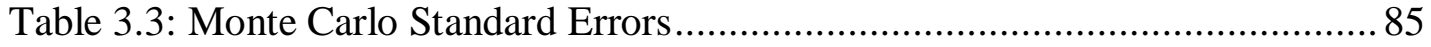

Table 3.4: Expected Profit Maximizing N, Corn-Quit, Quit and Actual Profit, and Mean Cost of Experimenting Across Years .......................................................... 86

Table 3.5: Sensitivity Analysis Results for Different Experimental Designs When Corn

Price is $\$ 2.95 / \mathrm{bu}$. and N Price is $0.45 / \mathrm{lb}$. 87

Table 3.6: Sensitivity Analysis Results for Experimental Designs When Corn and N

Prices Double 88

Table 3.7: Sensitivity Analysis Results for Different Experimental Designs When Either Corn Price or N Price Doubles 


\section{LIST OF FIGURES}

$\begin{array}{lll}\text { Figure } & \text { Page }\end{array}$

Figure 1.1: The Greenseeder Hand Planter ...........................................................2 23

Figure 1.2: Distribution of the GHP across the World by $2016 \ldots \ldots \ldots \ldots \ldots \ldots \ldots \ldots \ldots \ldots . . .24$

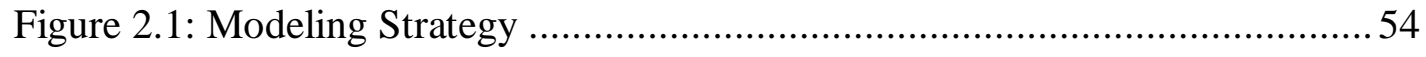

Figure 3.1: Flowchart summarizing the approach used ......................................... 90

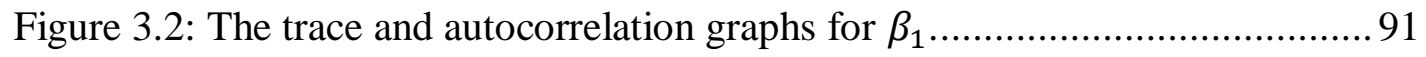

Figure 3.3: A Plot of Expected Profit Maximizing Levels of $\mathrm{N}$ in lb./acre in Each Year of Experimentation ................................................................................. 92

Figure 3.4: A Plot of Mean Quit NPV against Year of Experimentation ................ 93

Figure 3.5: A Plot of Mean Quit NPV against Year of Experimentation for 2, 4, 6, 8

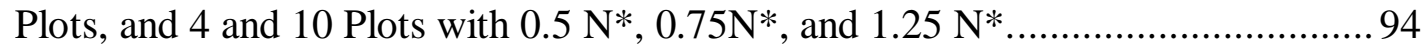

Figure 3.6: A Plot of Mean Quit NPV against Year of Experimentation for 10 and 4 Plot Designs When Corn and N Prices Double.

Figure 3.7: A Plot of Mean Quit NPV against Year of Experimentation for 12-Plot and 30-Plot Designs When Only Corn Price Doubles............................................ 96

Figure 3.8: A Plot of Mean Quit NPV against Year of Experimentation for 12-Plot and 30-Plot Designs When Only N Price Doubles. .97 


\title{
CHAPTER I
}

Citation: Ng'ombe, J. N., Brorsen, B. W., Raun, W. R., \& Dhillon, J. S. (2019). Economics of the Greenseeder Hand Planter. Agrosystems, Geosciences \& Environment, 2(1).

\section{ECONOMICS OF THE GREENSEEDER HAND PLANTER}

\begin{abstract}
Corn (Zea mays L.) yields in developing countries are lower than in developed countries in part due to planting methods that involve hand dropping of multiple seeds per hill. The Greenseeder Hand Planter (GHP) was developed to reduce seeding rates and long-term health risks from using bare hands to drop pesticide-treated seeds. When used to apply fertilizer, it can prevent loss of nitrogen $(\mathrm{N})$ from ammonia volatilization. This research determines economic breakeven levels of seed and labor savings, increases in corn yield, and reduced loss of $\mathrm{N}$ through reduced ammonia volatilization. A GHP used to plant 3 hectares per year that costs $\$ 50$ would need to increase corn yields on average by about $1.12 \%$, use $12.19 \%$ fewer seeds, or reduce labor man-days by $38.66 \%$ to equal expected net returns from traditional methods. Using the GHP to apply fertilizer would on average increase corn yields up to $10.82 \%$ per hectare due to reduced $\mathrm{N}$ loss from ammonia volatilization and thus fertilization alone could be enough to pay for the planter.
\end{abstract}

Key Words: Corn, Greenseeder Hand Planter, planting by hand, linear mixed effects, partial budgeting.

JEL Codes: Q13, Q1 


\section{Introduction}

Corn (Zea mays L.) is one of the most cultivated crops in the world. Corn originated from Mesoamerica and its production has spread throughout the world. Corn can be grown over a wide range of altitudes and latitudes (Shiferaw et al., 2011). Plant breeders have developed varieties that grow well under different biophysical environments. Thus, global corn production has increased over the years. Between 1961 and 2010, area allocated to corn production increased by more than $50 \%$ with about $73 \%$ of this growth in developing countries (Shiferaw et al., 2011). In 2010, corn was planted on about $73 \%$, 44\%, and $46 \%$ of the cultivated land in Africa, Latin America, and South Asia, respectively (Shiferaw et al., 2011) and on 35 million U.S.A. hectares (USDA, 2016).

While demand for corn in developing countries remains high (Borlaug, 2007; Shiferaw et al., 2011), its yields in developing countries are lower than in developed countries (Cairns et al., 2013; Chim et al., 2014). For example, since 1961 corn yields in the top five corn producing countries in the world (U.S.A., China, Brazil, Mexico, and Indonesia) have increased three-fold (from $1.84 \mathrm{Mg} \mathrm{ha}^{-1}$ to more than $6.10 \mathrm{Mg} \mathrm{ha}^{-1}$ ) while in developing regions of Africa, Asia, and Latin America, corn yields have stagnated at less than $2 \mathrm{Mg} \mathrm{ha}^{-1}$ (FAO, 2011; Cairns et al., 2013). These yield differences are attributed to a number of factors including access to and use of localized seed genetics, fertilizer, pest management, inefficient irrigation systems, and differences in seeding practices (Adjei et al., 2003; FAO, 2007; Aikins et al., 2010; Masasi and Ng'ombe 2019). In developed countries, mechanized planters that deliver and cover single seeds per drop at relatively precise depths and precise within row spacing, enhances yield potential (Omara et al., 2016; Mukembo et al., 2016). But, about $60 \%$ of corn area (29 million hectares) in developing countries is 
planted with multiple seeds per hill by hand (Mukembo et al., 2016; Chim et al., 2014;

Fisher, 2016; Dhillon et al., 2017).

Planting by hand usually involves using a heavy Stick Seeder Planter (SSP) and/or hand-hoe. Workers use the SSP to open a shallow hole about $5 \mathrm{~cm}$ deep; drop two to three seeds in the hole; cover the seeds with soil forming a small hill; and step on the hill enhancing soil to seed contact (Adjei et al., 2003). The typical SSP is composed of a wooden shaft and a pointed metal tip that can be used to penetrate the soil and open a slot for seed placement (FAO, 2010). Aikins et al. (2010) explain that the whole process is labor intensive and results in non-uniform plant stands often with multiple plants emerging from each hill and competing for nutrients. For equivalent seeding rates, non-uniform spacing of seeds, has been found to result in lower yields than uniform spacing (Epplin et al., 1996; Rutto et al., 2014). Whereas several hand planters have in the past been developed for corn farmers in developing countries, few of them drop one corn seed with a single strike (singulation) (Aikins, Plange, and Baffour 2010; Dhillon et al., 2017, 2018). Researchers at Oklahoma State University (OSU) developed a singulating corn Greenseeder Hand Planter (GHP) hypothesized to reduce optimal seeding rates (Omara et al., 2016). Theoretically, use of a GHP relative to a SSP could result in equivalent or greater yields from fewer seeds purchased and planted per hectare.

The GHP includes a seed box that eliminates the need for the operator to handle each seed (see Figure 1). Prior to planting, corn seeds are commonly coated with one or more pesticides such as imidacloprid (trade name Gaucho), permethrin (trade name Kernel Guard Supreme or Profound), thiamethoxam (trade name Cruiser), as well as with biological agents (Paulsrud et al., 2001). Careless handling of coated seeds may result in deleterious health 
consequences. Thus, the GHP can reduce long term health risks because it reduces operator exposure to treated seeds (Fisher, 2016; Dhillon et al., 2017). By changing the GHP's internal drum, the GHP can serve as a mid-season fertilizer applicator where the operator places fertilizer underneath the soil surface (Dhillon et al., 2017; Dhillon et al., 2018). The GHP is hypothesized to prevent loss of $\mathrm{N}$ from ammonia volatilization from urea fertilizers because it allows the operator to place fertilizer beneath the soil surface which reduces urea's exposure to direct heat from the atmosphere (Dhillon et al., 2017). Developing countries experience higher loss of nitrogen $(\mathrm{N})$ via ammonia volatilization than industrialized countries due to high temperatures and widespread use of urea and ammonium bicarbonate (Bouwman and Boumans, 2002).

The GHP is designed to release a single seed per location, which is intended to improve homogeneity of plant growth, decrease inter-plant nutrient competition, improve yield potential, and reduce seed cost per hectare (Chim et al., 2014; Fisher, 2016). To keep manufacturing costs low, the GHP does not yet meet this target. However, the most recent design comes closer than the version used in the experiments reported here.

This study seeks to determine the labor savings, seed savings, and the quantity of corn yield increase required for the GHP to be an economically viable alternative to the SSP. This study also determines the quantity of corn yield increase that would be realized due to reduced loss of $\mathrm{N}$ from ammonia volatilization if the GHP was used to apply urea fertilizer. In addition to these main objectives, we also determine the effect of using the GHP on corn yield per hectare relative to an ideal standard of near perfect seed singulation. Evaluation of the GHP technology could show whether the GHP would pay or not, which would be an important finding for farmers producing a vitally important food crop. These objectives are 
achieved by employing partial budgeting techniques and estimating a linear mixed effects model to data from designed field trials in Stillwater, Oklahoma, U.S.A.

\section{Methodology}

Theory

Farmers are expected to choose the planting method that maximizes expected net returns and improves their welfare. Biermacher et al. (2009) suggest that the expected profit maximizing framework is suitable to model behavioral decision and choice of farmers before the onset of the planting season. Assume that one of the farmer's objectives is to adopt a planting method that maximizes expected profit $\pi$ by comparing profit that is yielded by $m$ alternative methods. The farmer chooses a planting method $j$ over any alternative package $m$ such that

$$
\pi_{j}>\pi_{m}, m \neq j
$$

The adoption decision $D^{*}$ and the optimal expected profit $\pi_{j}^{*}$ from choosing a given planting method would be:

$$
D^{*}=\left\{\begin{array}{l}
\left.1 \text { iff } E\left(\underset{\mathrm{max}}{\operatorname{maj}} E\left(\pi_{j}^{*}\right)\right)>\underset{\max }{E}\left(\pi_{m}^{*}\right)\right) \text { or } \eta_{\mathrm{i} 1}>0, \text { for } \forall m \neq j \\
0 \text { otherwise }
\end{array}\right.
$$

where $\eta_{j}=E\left(\max _{\mathrm{m} \neq \mathrm{j}}\left(\pi_{j}^{*}-\pi_{m}^{*}\right)\right)>0$ (Bourguignon et al., 2007; Biermacher et al., 2009). By eqn. (2), a farmer whose objective is to maximize expected profit is expected to adopt a planting method whose expected profit is greater than all alternatives. The GHP considered here is attempting to drop a single seed per planting station as opposed to an SSP in which two or more seeds are dropped per hill. Thus, if the same number of seeds are planted per 
hectare, the theoretical expected yield would be greater for the GHP given the expected agronomic benefits of uniform plant spacing. Alternatively, if fewer seeds are planted per hectare with the GHP, total seed costs would be lower. Ignoring the potential value of farmer health benefits from using a GHP relative to a SSP, the farmer's optimization problem is mathematically $\left.c_{S S P}\right)$

$$
\max _{D} E\left(\pi_{i} \mid \boldsymbol{x}\right)=\left((D)\left(p E\left(y_{G H P} \mid \boldsymbol{x}\right)-c_{G H P}\right)+\left(( 1 - D ) \left(p E\left(y_{S S P} \mid \boldsymbol{x}\right)-\right.\right.\right.
$$

subject to

$$
y_{k}=f(\boldsymbol{x}), k=\{G H P, S S P\}, \quad D \in\{1,0\},
$$

where $p$ is the price of corn, $E\left(\pi_{i}\right)$ is expected profit $(\$)$ per hectare, $D$ is the discrete choice variable that equals 1 if the farmer uses GHP, 0 otherwise, $y_{G H P}$ is corn yield from plots where the GHP was used, $y_{S S P}$ is corn yield from plots where the SSP was used, $c_{G H P}$ is cost of production from plots where the GHP was used, $c_{S S P}$ is cost of production from plots where the SSP was used, $y_{k}$ is corn production function and $\boldsymbol{x}$ denotes a vector of inputs used in corn production.

\section{Data and Procedures}

\section{Agronomic data}

Plot-level agronomic data were generated from experiments conducted at the Efaw, Lake Carl Blackwell, and Stillwater Agronomy Research Stations in Payne County, Oklahoma, USA. Efaw has an Ashport silty clay loam soil. The Lake Carl Blackwell plots have Pulaski fine-sandy loam soils. Stillwater Agronomy Research Station has mostly Kirkland silt loam soils (Omara et al., 2016). These experiments were designed as randomized complete blocks. Each experiment comprised three replications and four plots 
per replication in each site year. The experiments were conducted at the Stillwater site in 2014, at Efaw in 2014 through 2016 and at Lake Carl Blackwell in 2015 and 2016.

Treatments consisted of planting methods: GHP, SSP, and a tractor-drawn John Deere Planter (JDP). The GHP has an internal drum that can hold up to $1 \mathrm{~kg}$ of seed. It was designed to deliver a single seed per hill at a planting depth of about $5 \mathrm{~cm}$ (Omara et al., 2016). The SSP has a metal tip like those typically used in Central and South America. Its only function is to open a planting hole into which seeds are dropped and covered by foot (Chim et al., 2014). The SSP used in these field experiments managed 100\% singulation (planter delivers a single seed with every strike) which implies that the SSP in this experiment did not simulate its actual applications in developing countries. Despite this severe limitation, the experimental dataset is used because it still provides helpful information.

Hybrid corn variety Pioneer P1498HR was planted on all plots with plant population of 74,000 seeds per hectare. Inter-row spacing at all the stations was $76 \mathrm{~cm}$ while plant spacing was uniform at $18 \mathrm{~cm}$. Plot size varied ranging from $1.5 \mathrm{~m}$ by $6 \mathrm{~m}$ to $3 \mathrm{~m}$ by $6 \mathrm{~m}$. Summary statistics of corn yield from each research station are shown in table 1.

In addition, summary statistics from the research stations according to planter type are shown in table 2. Other details of the field trials are in Dhillon et al. (2017).

\section{Economic analysis}

Partial budgeting was used to determine the economics of the GHP. Adopting a GHP would result in incremental changes at the farm and a partial budget is a useful tool for a farmer when such a situation arises (Nuthall, 2011). Partial budgeting computes the overall 
impact by netting out the negative effects from positive effects. Positive effects include the monetary value of activities that would increase revenue and/or decrease costs while negative effects are those that would decrease revenue and/or increase costs. In our partial budget, the added returns were the additional revenue that would result from using the GHP and reduced costs included seed and labor costs for SSP. The added costs included the GHP's annual operating costs whose computation relied on depreciation, interest on average value, repairs, taxes, and insurance (also called the DIRTI-5 by Lessley and Holik, 1987). Reduced revenues were zero.

The following assumptions were used in our partial budget. The market price of the GHP is assumed to range between $\$ 40$ and $\$ 100$ per unit. The $\$ 100$ is about what it costs now and the $\$ 40$ is what we hope it will cost under mass production. Omara et al. (2016) posit that if the market price of the GHP was $\$ 40$ per unit, it would be more marketable among smallholder farmers in the developing world.

We assume a useful life of 3 years and that the GHP would be used to plant corn seed on up to 5 hectares per year. Following Haggblade and Tembo (2003), Ng'ombe et al. (2017), and Ng'ombe (2017), peasant farmers in Zambia and across sub-Saharan Africa (SSA) plant up to 5 hectares of land annually - the typical holding size of land for farming by most farmers. An annual market interest rate of $6 \%$ was assumed while the repairs, taxes, and insurance for the GHP are assumed to be zero. Price of corn is assumed to be $\$ 175$ per $\mathrm{Mg}$ while labor cost was set at $\$ 2.5$ per man-day. A farmer is assumed to plant a hectare of corn in 5 days while $25 \mathrm{~kg}$ of corn seed is assumed to be planted on one hectare of land. These assumptions and variable values were pulled from the standard nationally representative smallholder corn enterprise budget from Zambia. The corn enterprise budget was prepared by 
the Zambia National Farmers' Union (ZNFU) based on production practices by representative Zambian smallholder corn farmers in 2015 (ZNFU, 2015). Zambia is a developing country in SSA where planting by hand is common (Haggblade and Tembo, 2003). In addition, Zambia is one of the countries where the GHP has been distributed (see Figure 2).

Bouwman and Boumans (2002) find that $\mathrm{N}$ loss from ammonia volatilization of urea fertilizers on average amounts to $18 \%$ and $7 \%$ in developing countries and industrialized countries, respectively. Funderburg (2009) reports a 20\% N loss from ammonia volatilization to be common when urea fertilizers are applied on the soil surface. Jama et al. (2017) determine corn yield response to nitrogen use from 940 on-farm trials and demonstration sites consisting of at least 3,220 site-year treatment combinations in southern Africa. Jama et al. (2017) classified the applied $\mathrm{N}$ rates as "half N", and "full N" based on recommended rates for each site. The "half N" and "full N" rates imply applying fertilizer containing N less than or equal to $50 \%$ and more than $50 \%$ of the recommended $\mathrm{N}$ rates, respectively (see Jama et al., 2017 for more details). Though Jama et al. (2017) did not estimate the traditional linear response stochastic plateau (Tembo et al., 2008; Boyer et al., 2013), their results corroborate the idea of the linear response stochastic plateau. They find that without N, farmers would on average realize $1.6 \mathrm{Mg}$ of corn per hectare while the expected corn plateau is $4 \mathrm{Mg}$ per hectare and that marginal physical productivity for corn is $0.025 \mathrm{Mg}$ per $\mathrm{kg}$.

Considering that agricultural producers are financially constrained and so the quantity of urea is limited, studies by Bouwman and Boumans (2002) and Jama et al. (2017) allow us to estimate the corn yield increase that would be realized due to reduced loss of $\mathrm{N}$ from ammonia volatilization if the farmer used the GHP to apply fertilizer. In our budget, the GHP 
potentially increases the amount of $\mathrm{N}$ by up to $18 \%$ (because it places fertilizer underneath the soil) and the amount of urea that a producer has is assumed to be constrained. Following Bouwman and Boumans (2002) and Jama et al. (2017), the percentage that the GHP would increase corn yield due to reduced $\mathrm{N}$ loss from ammonia volatilization $y^{*}$ is:

$$
y^{*}=[4-(1.60+0.0259 * \text { Nrem })] / 4
$$

where Nrem is amount of $\mathrm{N}$ available after $18 \%$ loss from ammonia volatilization: Nrem $=$ $\left(\right.$ Nplat - Nplat $\left.^{*} 0.18\right)$, Nplat is the amount of $\mathrm{N}$ required to produce corn at its plateau. Based on averages of Table 2 in Jama et al. (2017), Nrem is $75.95 \mathrm{~kg}$ of N per hectare while Nplat is $92.66 \mathrm{~kg}$ of $\mathrm{N}$ per hectare.

\section{Statistical analysis}

The effect of using GHP on corn yield was estimated using the plot-level agronomic data. Dhillon et al. (2017) conducted the experiment for other experimental objectives. For this study, it would have been preferred to compare the GHP with actual farmer practices rather than an ideal situation under which the SSP was used. The data are used here because they are the only experimental data available and they do show how well the GHP compares versus ideal planting methods. The data are cross-sectional time series and therefore could be prone to problems of non-spherical errors across seasons. Thus, the R-package lme4 (Bates et al., 2015) is used to estimate the linear mixed effects model. The R-package lme4 uses restricted maximum likelihood estimation (REML). For estimation of linear mixed effects models, REML is preferred to maximum likelihood estimation (MLE) because it yields unbiased covariance parameters by accounting for the loss of degrees of freedom that results from parameter estimation of fixed effects (West et al., 2007). To determine the statistical 
significance of treatment main effects, we used the R-package lsmeans developed by Lenth (2015). Our linear mixed effects model's data generating process is

$$
y_{i t k}=\mu+\tau_{i}+s_{t}+\varepsilon_{i t k}
$$

where $y_{i t k}$ is corn yield with the the $i$ th planting method, from year $t$, and site $k, \mu$ is the overall mean, $\tau_{i}$ is the effect of the $i$ th planting method, $s_{t} \sim N\left(0, \sigma_{s}^{2}\right)$ is the site-year random effect, $\varepsilon_{i t k} \sim N\left(0, \sigma_{\varepsilon}^{2}\right)$ is a random error, and $\sigma_{s}^{2}$ and $\sigma_{\varepsilon}^{2}$ are mutually independent.

\section{Results}

\section{Statistical analysis}

Several diagnostics were conducted to determine the plausibility of the linear mixed effects model selected. Based on the Shapiro-Wilk test, the null hypothesis of normality of the distribution of corn yield was not rejected at a $10 \%$ significance level $(P=0.200)$. Based on results from the Levene test, the null hypothesis of equal error variances across the treatments was not rejected $(\mathrm{P}=0.567)$. The likelihood ratio test was used to determine significance of the fixed effects (based on the ANOVA function in R software) in the model. The null hypothesis of no fixed effects was rejected $(\mathrm{P}<0.001)$. Parametric bootstrap of the p-value based on 1000 replications was used to determine statistical significance of site-year random effects. There was strong evidence to support the inclusion of site-year random effects in the model $(\mathrm{P}<0.001)$. The estimated linear mixed effects regression model is shown in table 3. The linear mixed effects model with seed size fixed effects was also estimated, but the results differed little from those reported above and therefore they are omitted. 
Furthermore, actual mean differences among treatments were determined by conducting a post-hoc analysis and results are reported in table 4. The SSP is the base treatment. Results in table 4 indicate the GHP had significantly lower corn yield than the SSP. We find no statistically significant differences between mean corn yields from using the SSP and JDP. These findings corroborate with descriptive statistics in table 1 for years 2014 and 2015, although in 2016 the GHP resulted in higher average corn yield than the JDP. Dhillon et al. (2018) document efforts to refine use of the hand planter and the improved performance in 2016 may partly result from learning in prior years.

The idealized SSP would result in about $0.742 \mathrm{Mg}$ more corn yield per hectare than the GHP. The estimated JDP advantage over GHP of $0.611 \mathrm{Mg}$ per hectare is not statistically different from zero.

\section{Economic Analysis}

Using the partial budgeting approach, breakeven values for corn yield, labor costs, the price of corn seed, and the purchased price of the GHP are discussed next. Results suggest that for a GHP priced at $\$ 50$ to be an economically viable alternative to the SSP, it should be able to increase corn yields by about $1.12 \%$ (equivalent to $28 \mathrm{~kg}$ ) per hectare. If the GHP can achieve the $20 \%$ yield increase projected by Omara et al. (2016) then it would unambiguously pay to adopt the hand planter. In terms of seed savings, results indicate that such a GHP would be an economically viable planting method if it reduced seeds by about $12.19 \%$ per hectare. This finding also implies that for the GHP that costs $\$ 50$ to result in equivalent net returns as the SSP, it should enable the smallholder farmer to save corn seeds valued at about $\$ 5.0$ per hectare (assuming seeds are valued as $\$ 1.5 / \mathrm{kg}$ ). 
In terms of labor savings, results suggest that for the GHP valued at $\$ 50$ to generate equal net returns as the SSP, it is required to reduce labor man-days for planting by $38.66 \%$. Stated differently, this implies that for the GHP to enable a farmer to break-even, it should reduce the amount of labor required for planting by at least about 39\%. Since planting is done in one motion with the GHP, it does have some potential for labor saving. Our experience, however, is that there is little or no labor saving and certainly nothing close to $38.66 \%$, so labor saving does not appear to be a sufficient motivation for adopting the GHP. In addition, the main part of the GHP is metal and contains the seeds so that it weighs more than the SSP, which makes it being a labor saving technology even more unlikely.

Since the value of the GHP depends on its production and transactions costs, its market price would perhaps be different from the one assumed above, which would ultimately alter our partial budgeting results. Considering such potential disparity and holding other factors fixed, breakeven values of corn yield, labor, and seed at varying market prices of the GHP are presented in table 5. As mentioned before, it is assumed that the GHP's market price would range between $\$ 40$ and $\$ 100$ per unit. If the price of the GHP was $\$ 95$ per unit, for it to produce the same net returns as the SSP, the GHP would need to increase corn yields by about $2.08 \%$ per hectare or result in seed savings of $23.16 \%$ per hectare, ceteris paribus.

Similarly, it would have to reduce labor man-days required for planting corn by about $74 \%$. Whereas if the market price of the GHP was $\$ 40$ per unit, the breakeven values for seeds, labor and corn yields would be $9.75 \%$ less seeds per hectare, about $30.94 \%$ less man-days per hectare, and $0.88 \%$ more corn yield per hectare. 
The smallholder farmer is assumed to be cash constrained and thus only able to purchase and apply a fixed amount of fertilizer per hectare. In terms of added corn yields due to $18 \%$ reduced $\mathrm{N}$ loss from ammonia volatilization, our findings show that a farmer would realize about $10.82 \%$ of additional corn per hectare (about $0.432 \mathrm{Mg}$ per hectare) if the GHP was used to apply fertilizer. Thus using the GHP to apply fertilizer would provide about $\$ 75.74$ per hectare, assuming fertilizer is limited. Thus, using it to apply fertilizer on only one hectare is sufficient to pay for the full cost of the GHP priced anywhere between $\$ 40$ and $\$ 70$ per unit.

Clearly from the linear mixed effects regression model, the GHP resulted in lower corn yields per hectare than the SSP, a plausible reason for its lower corn yields could be due to the way it was designed. The GHP like the SSP is not designed to ensure or enhance seed to soil contact (see video https://www.youtube.com/watch?v=VisKBsqcCWA). The SSP's operator used his/her foot to enhance soil to seed contact whereas this was not done with the GHP. Another limitation of the experiment is that unlike conventional practice in developing countries, only one seed was dropped per hill with the SSP. A third limitation is that within row spacing was uniform for all treatments. Thus, the seeding rate was held constant and findings from the experiment cannot be used to address the potential for seed savings with the GHP relative to the SSP.

Following Martin et al. (2005) and Rutto et al. (2014), lack of attention to seed to soil contact when the GHP plots were seeded or failure by the GHP to drop the seed may have contributed to lower emergence rates for GHP relative to SSP and JDP and the resultant lower crop yield on the GHP plots. As shown in table 6, the GHP had the lowest corn emergence rates among the three treatments in all the years and possibly it did not always 
place a seed. As Dhillon et al. (2018) note, these findings have already been used to modify both the design and use of the hand planter.

\section{Conclusion}

The GHP has the potential to improve yields and reduce costs for planting corn in developing countries. In terms of seed savings, a GHP valued at $\$ 50$ would be a breakeven investment if it increased corn yields by $1.12 \%$ per hectare or saved about $12.19 \%$ of seeds

per hectare. If labor reduction was its only benefit, a reduction of labor man-days by $38.66 \%$ would be required for it to be economically as viable as the SSP. Since the GHP's market price would vary, if the GHP sold at $\$ 95$, breakeven would require a $2.08 \%$ increase in yield, a $23.16 \%$ seed savings, or a $74 \%$ reduction in labor. In terms of added corn yields due to reduced loss of $\mathrm{N}$ from ammonia volatilization, the GHP seems to be a profitable venture as it would result in about $10.82 \%$ increase of corn per hectare which is a staggering $\$ 75.74$ additional corn returns per hectare. With about $\$ 74$ more added revenue, the farmer would be able to pay for the GHP from using on a single hectare. This result suggests that the economics of the GHP are more favorable for using it to apply fertilizer than for planting corn.

The GHP was compared to two ideal planting techniques. The GHP had lower corn yields than an SSP with perfect seed singulation. The GHP had lower corn emergence which may be due to the GHP failing to drop a seed or incomplete seed and soil contact. The SSP was used in an ideal situation (up to $100 \%$ seed singulation), which is different from how farmers use it. Further research is needed to evaluate the GHP versus actual farmer practice. Given the potential for the GHP to reduce seed costs, increase corn yield due to reduced loss 
of $\mathrm{N}$ from ammonia volatilization, and reduce potential health risk relative to the SSP, it is recommended that additional field trials be conducted with the following changes. First, either the GHP should be modified to enhance seed to soil contact when seeding, or the GHP operator should cover and step on the soil above each placed seed. Second, within row distance between seed drops should be doubled in the SSP plots relative to within row distance between seed drops in the GHP plots to more nearly simulate farmer practice. Third, two seeds should be dropped at each location in the SSP plots relative to one seed in GHP plots.

One limitation of our study is that consequences of physical contact between treated seed and SSP and GHP laborers were not determined. The GHP may reduce the negative consequences to operator health resulting from handling treated seed. Additional research would be required to quantify this potential benefit from using a GHP rather than SSP. Furthermore, due to uncertainty, producers may require a higher rate of return in order to adopt. Micro-dosing of fertilizer looks promising, but as Jama et al. (2017) argue, research is needed to demonstrate results in actual farmers' fields rather than only on field trials. 
Table 1.1: Descriptive Statistics of Corn Yield $\left(\mathrm{Mg} \mathrm{ha}^{-1}\right)$ According to Planter Type Obtained in 2014, 2015, and 2016

\begin{tabular}{|c|c|c|c|c|c|c|}
\hline \multirow[b]{2}{*}{$\begin{array}{l}\text { Planter } \\
\text { Type }\end{array}$} & \multicolumn{2}{|c|}{2014} & \multicolumn{2}{|c|}{2015} & \multicolumn{2}{|c|}{2016} \\
\hline & Mean & SD & Mean & SD & Mean & SD \\
\hline SSP & 6.683 & 0.511 & 4.506 & 2.140 & 5.462 & 2.320 \\
\hline GHP & 5.583 & 0.909 & 3.421 & 2.313 & 5.326 & 2.291 \\
\hline JDP & 6.433 & 1.357 & 4.488 & 1.845 & 5.221 & 2.268 \\
\hline
\end{tabular}


Table 1.2: Descriptive Statistics of Corn Yield $\left(\mathrm{Mg} \mathrm{ha}^{-1}\right)$ by Planter Type from Efaw, Lake Carl Blackwell and Stillwater Agronomy Research Stations

\begin{tabular}{lcccccccc}
\hline & Efaw & & & \multicolumn{2}{c}{ Lake Carl Blackwell } & & \multicolumn{2}{c}{ Stillwater } \\
\cline { 2 - 3 } Planter Type & Mean & SD & & Mean & SD & & Mean & SD \\
\hline SSP & 6.313 & 2.268 & & 4.067 & 1.511 & & 4.050 & 0.750 \\
GHP & 5.582 & 2.200 & & 3.106 & 2.173 & & 3.577 & 0.985 \\
JDP & 5.940 & 1.677 & & 3.706 & 2.029 & & 5.233 & 0.451 \\
\hline
\end{tabular}


Table 1.3: Linear Mixed Effects Regression Results of Corn Yield $\left(\mathrm{Mg} \mathrm{ha}^{-1}\right)$ Response to Planter Type

\begin{tabular}{lcc}
\hline Variable name & Coefficient & Std. Error \\
\hline Intercept & $5.262^{* *}$ & 0.776 \\
GHP & $-0.742^{* *}$ & 0.346 \\
JDP & -0.130 & 0.456 \\
Site-year random effect & $2.536^{* *}$ & 1.262 \\
Error variance & $3.388^{* *}$ & 1.357 \\
Log likelihood ratio & -408.344 & 193 \\
Number of observations & & \\
\hline
\end{tabular}

$* *$ Statistically significant at $1 \%$, 
Table 1.4: Least Squares (LS) Means $\left(\mathrm{Mg} \mathrm{ha}^{-1}\right)$ of Corn Yield by Planter Type

\begin{tabular}{lc}
\hline Planter $I$ vs Planter $j$ & $\begin{array}{c}\text { Difference in Least Squares Means } \\
\left(\mathrm{Mg} \mathrm{ha}^{-1}\right)\end{array}$ \\
\hline SSP vs JDP & 0.130 \\
SSP vs GHP & $0.742^{* *}$ \\
JDP vs GHP & 0.611 \\
\hline
\end{tabular}

**Statistically significant at $1 \%$ 
Table 1.5: Breakeven Corn Yield (Mg/ha), Corn Seed (kg/ha) and Labor Savings (man-days)

\begin{tabular}{|c|c|c|c|}
\hline $\begin{array}{c}\text { Price of GHP } \\
\text { (\$/unit) }\end{array}$ & $\begin{array}{l}\text { Breakeven Corn Yield } \\
\text { (Mg/ha) }\end{array}$ & $\begin{array}{l}\text { Breakeven Amount of } \\
\text { Seed }(\mathrm{kg} / \mathrm{ha})\end{array}$ & $\begin{array}{c}\text { Breakeven Amount of Labor } \\
\text { (man-days/ha) }\end{array}$ \\
\hline 40 & 0.022 & 2.578 & 1.547 \\
\hline 45 & 0.025 & 2.900 & 1.740 \\
\hline 50 & 0.028 & 3.222 & 1.933 \\
\hline 55 & 0.030 & 3.544 & 2.127 \\
\hline 60 & 0.033 & 3.867 & 2.320 \\
\hline 65 & 0.036 & 4.189 & 2.513 \\
\hline 70 & 0.039 & 4.511 & 2.706 \\
\hline 75 & 0.041 & 4.833 & 2.900 \\
\hline 80 & 0.044 & 5.156 & 3.093 \\
\hline 85 & 0.047 & 5.478 & 3.287 \\
\hline 90 & 0.050 & 5.800 & 3.480 \\
\hline 95 & 0.052 & 6.122 & 3.673 \\
\hline 100 & 0.055 & 6.444 & 3.867 \\
\hline
\end{tabular}


Table 1.6. Average Emergence Rates (\%) According to Planter Type Obtained in 2014, 2015, and 2016

\begin{tabular}{|c|c|c|c|c|c|c|}
\hline \multirow[b]{2}{*}{$\begin{array}{l}\text { Planter } \\
\text { Type }\end{array}$} & \multicolumn{2}{|c|}{2014} & \multicolumn{2}{|c|}{2015} & \multicolumn{2}{|c|}{2016} \\
\hline & Mean & SD & Mean & SD & Mean & SD \\
\hline SSP & 89.333 & 17.282 & 96.565 & 5.010 & 91.167 & 5.734 \\
\hline GHP & 82.056 & 21.421 & 80.372 & 14.372 & 86.020 & 9.411 \\
\hline JDP & 87.333 & 14.224 & 92.288 & 10.461 & 95.583 & 4.641 \\
\hline
\end{tabular}




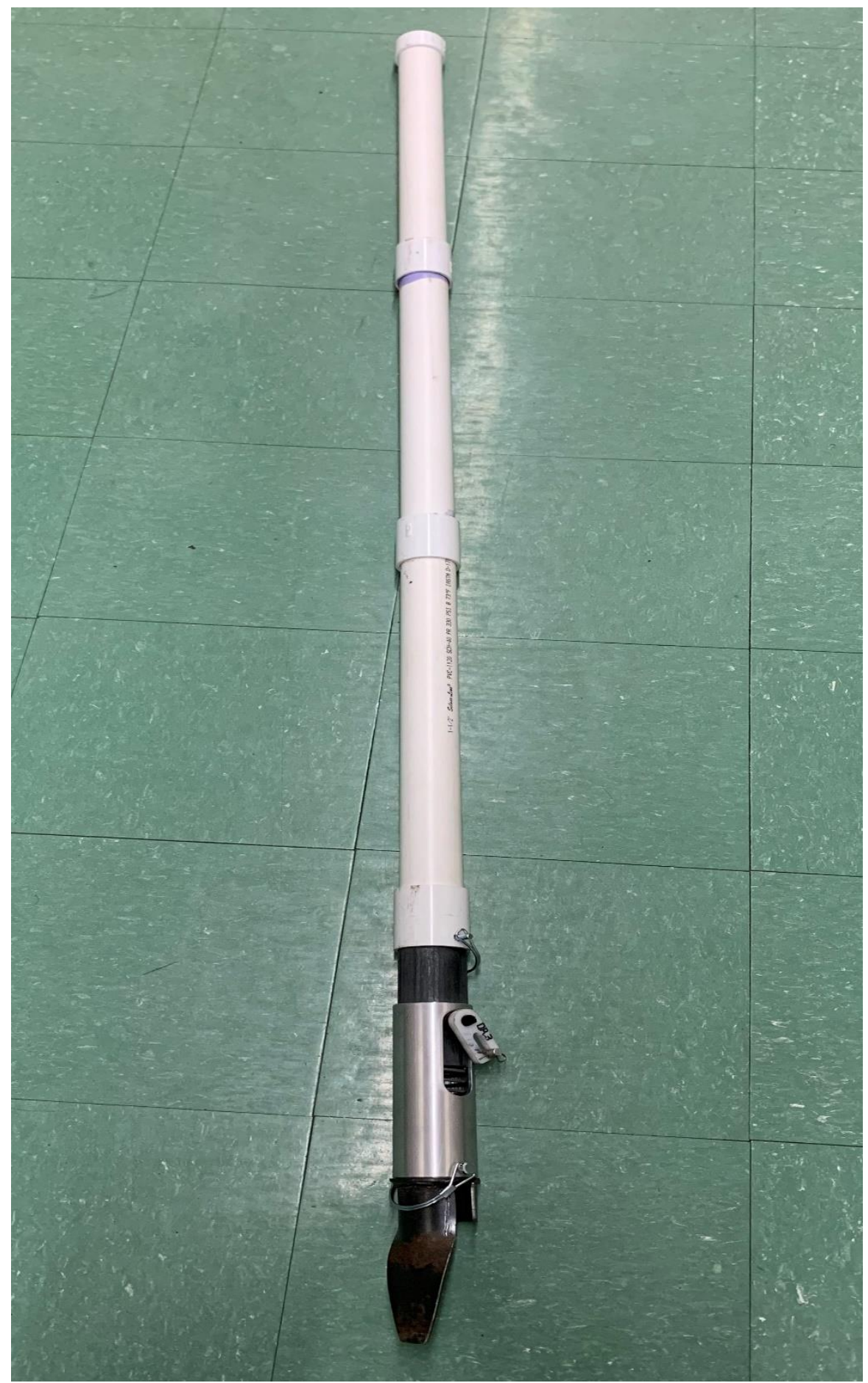

Figure 1: The Greenseeder Hand Planter

Source: Oklahoma State University's Nitrogen Use Efficiency website (www.nue.okstate.edu) 
Note: Countries marked in red had some farmers that received a GHP in previous by 2016.

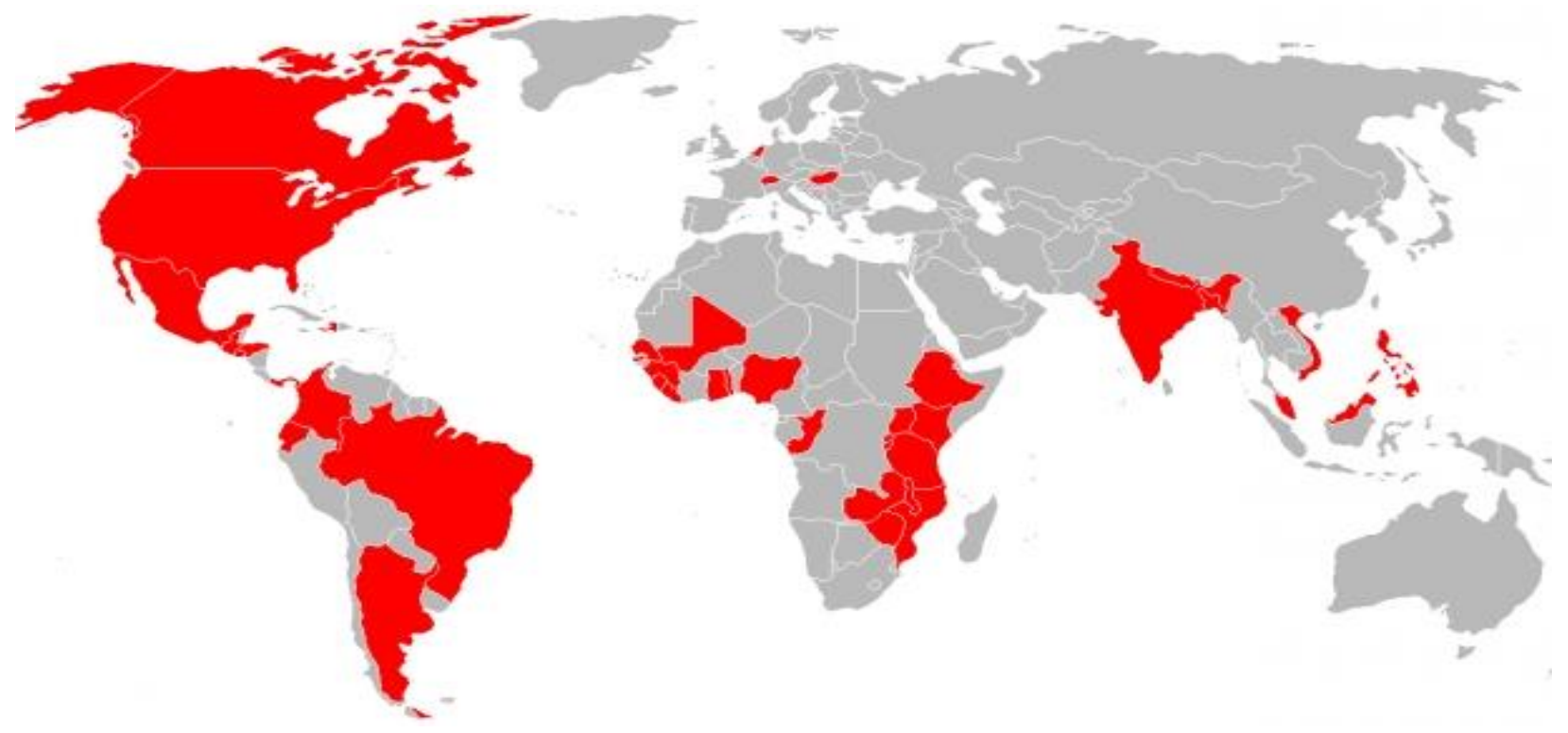

Figure 2: Distribution of the GHP across the World by 2016.

Source: Oklahoma State University's Nitrogen Use Efficiency website (www.nue.okstate.edu) 


\title{
CHAPTER II
}

\section{THE EFFECT OF INCLUDING IRRELEVANT ALTERNATIVES IN DISCRETE CHOICE MODELS OF RECREATION DEMAND}

\begin{abstract}
I extend research into choice set formation in random utility maximization (RUM) models by conducting Monte Carlo experiments to compare the performance of two plausible choice set specifications. I measure bias in the conditional logit (CL) and independent availability logit (IAL) models when there is no choice set formation and individuals choose from the full set of alternatives, and when choice sets are stochastically formed and individuals choose from a subset of all alternatives. I also compare the performance of the two models using empirical data on paddlefish angler preferences and catch-and-release regulations in Oklahoma. Both the CL and IAL work well when their own assumptions hold, but not under the alternative's assumptions. The CL produces biased parameters when the researcher ignores choice set formation and includes irrelevant alternatives in the choice set. However, the IAL produces unbiased and considerably less efficient parameter estimates when individuals actually choose from the full set of alternatives while empirical results show that the IAL predicts a distance cutoff that is closer to the true one. Since neither the IAL nor CL is universally preferred, researchers must choose between them based on knowledge about the probability of irrelevant alternatives being considered.
\end{abstract}

Keywords: Choice set specification, conditional logit, independent availability logit, Monte Carlo experiments, distance cutoffs. 
JEL: C25, C51, C52, Q5

\section{Introduction}

Choice set misspecification is an important problem in discrete choice models. Choice set misspecification occurs when irrelevant alternatives are mistakenly placed into the choice set, rather than being discarded by the researcher. Decision makers may naturally exclude certain alternatives because they are unaware of them or because one of the attributes generates substantial disutility. In practice, it is well known that parameter and welfare estimates are sensitive to choice set definitions (Peters and Adamowicz 1995; Swait and Ben-Akiva 1987). Parameter sensitivity is especially of concern in applications with a huge number of feasible alternatives, which includes models of location choice in applications to real estate and recreation demand, because the researcher may be compelled to make a subjective judgement about the composition of the true choice set (McFadden 1978; Guevara and Ben-Akiva 2013; von Haefen and Domanski 2018).

The literature on choice set misspecification offers several approaches for identifying and dealing with irrelevant alternatives. One practice common in recreation demand applications is to exclude alternatives that exceed a certain distance or price (determined by the researcher) from each decision-makers' home. Prior work shows including distant sites affects parameter estimates, although this influence may diminish past some threshold (Parsons and Hauber 1998; Whitehead and Haab 1999). Several papers examine parameter sensitivity to the inclusion of various substitute site/activity combinations in discrete choice models of recreation demand (Haab and Hicks 1997; Jones and Lupi 1999; Parsons, Plantinga and Boyle 2000; Pramono and Oppewal 2012). These papers treat choice set definitions as exogenous-i.e. the decision maker's choice set is assumed to be known deterministically. However, there is also a growing 
number of papers that treat choice set definition endogenously by modeling choice set formation in one stage and the selection of an alternative in a second stage (Manski 1977; Swait and BenAkiva 1987; Haab and Hicks 1997; Li, Adamowicz and Swait 2015; Thiene, Swait and Scarpa 2017). These papers conclude that ignoring choice set formation leads to biased parameters and welfare estimates.

This article extends research into choice set formation in discrete choice models by measuring the bias from two plausible forms of choice set specification. Our motivation comes from the practice of excluding recreational sites that the researcher thinks are too far for a decision-maker to reasonably access (for example, day-trip sites more than 200 one-way miles from an individual's home) or due to the difficulty in assessing travel costs for long distances. Specifically, unlike previous research, I examine two types of choice set formation: (1) every choice set includes the full set of alternatives and (2) each choice set is formed from a stochastic selection process that is partly a function of a choice attribute level, thereby rendering choice set formation endogenous. The two cases are used to assess the properties of two estimators of discrete choice models, one of which accounts for stochastic choice set formation. Thus, I measure the bias from including irrelevant alternatives in discrete choice models when choice set formation follows a stochastic process and when the choice set formation process is not followed.

Our primary objective is to measure the bias when an observable attribute (e.g. distance to recreation site) affects the probability that an alternative appears in the choice set. In doing so, I estimate two models: 1) the independent availability logit (IAL) model that incorporates choice set formation as a stochastic process and probabilistically imputes all possible choice sets and 2) 
the conditional logit (CL) model which assumes the choice set includes all alternatives. Our approach is illustrated in figure 2.1 .

While actual data is often used to measure potential bias in recreation demand models, I conduct Monte Carlo experiments that generate artificial data based on a known data generation process as well as empirical analyses using real data. The experiment simulates a random utility maximization (RUM) problem in which individuals choose from many recreational sites with varying attributes. Monte Carlo analysis allows us to measure the true bias when irrelevant alternatives are included in the choice set while considering stochastic choice set formation, and test how well recreational choice set definition heuristics can do in minimizing this bias. Monte Carlo-based methods are desirable in this study because (i) the two data generating mechanisms to which I compare our parameter estimates would be known, and (ii) a greater number of replications allows us to evaluate the robustness of our results. Our Monte Carlo experiments build on previous research by comparing the performance of the IAL to recreational choice set definition heuristics. Our empirical analyses mainly compare parameter estimates of the two models using real data without any known parameter estimates.

\section{Competing Models}

In this section, a description of the models estimated using both simulated and actual data. In the traditional RUM setting, choices among discrete alternatives are studied to model choice problems such as those in recreation, transportation, marketing, and agriculture. A researcher chooses the alternatives to include in the model, typically using a list of all possible alternatives, a list of the alternatives chosen by decision makers, observed levels of the attributes, or some combination of the above. However, this process has been criticized as naïve; particularly in the marketing literature where it has been argued that individuals have unique choice sets that are 
formed as part of a multistage choice process (Manski 1977; Horowitz and Louviere 1995). Haab and Hicks (1997) provide evidence that choices in recreation demand are made in a two-stage, consider-then-choose discrete choice process.

In typical discrete choice models, typically, the random utility of the $n^{\text {th }}$ individual for choosing the $i^{\text {th }}$ alternative is

$$
U_{n i}=V_{n i}+\varepsilon_{n i}
$$

where $V_{n i}$ is the deterministic utility component (i.e., systematic utility influenced by observable covariates), and $\varepsilon_{n i}$ is an independent and identically distributed stochastic component reflecting unobservable, individual specific heterogeneity. An $n^{\text {th }}$ individual would choose an $i^{\text {th }}$ alternative if and only if it provides the highest utility among all the feasible alternatives, A. Formally, utility maximization implies that the probability that the $n^{\text {th }}$ individual chooses the $i^{\text {th }}$ alternative is

$$
P_{n}(i)=\operatorname{Prob}\left(V_{n i}+\varepsilon_{n i} \geq V_{n k}+\varepsilon_{n k}, \forall k \in C\right) .
$$

Where $V_{n k}$ is the deterministic utility component from the $k^{\text {th }}$ alternative, $\varepsilon_{n k}$ is an independent and identically distributed stochastic component reflecting unobservable individual and specific heterogeneity for choosing every $k^{\text {th }}$ alternative in set $C$, and $V_{n i}$ and $\varepsilon_{n i}$ are as defined in equation (1).

\section{The Conditional Logit Model}

Assuming $\varepsilon_{n i}$ is an independent and identically distributed as a Gumbel distribution, yields the standard CL (Greene 2003). Given these assumptions, the probability $P_{n}(i)$ in equation (2) can be written as

$$
P_{n i}=\frac{\exp \left(V_{n i}\right)}{\sum_{k \in C} \exp \left(V_{n k}\right)}
$$


Equation (3) is crucial in discrete choice modeling and the deterministic part of utility $V_{n i}$ is assumed to be a linear function of $I$ attributes known to the researcher. Formally, $V_{n i}=\boldsymbol{x}_{n i}^{\prime} \beta$, where $x_{n i}$ is the vector of attributes of the $i^{t h}$ alternative for the $n^{\text {th }}$ individual (e.g., distance $d$, and perceived site quality, $q$ ) and $\beta$ a parameter vector. Through parameter estimates of $\beta$, probability of selection and marginal effects for each alternative can be easily obtained by maximum likelihood estimation. If the choice set $C$ is incorrectly specified, parameter estimates would be biased (Manski 1977).

\section{The Independent Availability Logit Model}

Applications of the CL assume the set of alternatives in the choice set is known by the analyst. Individual-specific choice sets are allowed, but the composition of these choice sets must still be known with certainty. In some cases, however, this assumption may be inappropriate, and the choice set developed by the analyst may either include alternatives that were never considered by the decision-maker or may exclude those considered by the decision-maker but overlooked by the analyst, rendering $C$ with either too many alternatives or too few alternatives. Both cases would render misspecification of the likelihood function and could lead the CL to estimate biased parameters (Swait and Ben-Akiva 1987; Li, Adamowicz and Swait 2015). When choice sets are endogenously determined it can be very difficult for the analyst to determine the exact choice set, because endogenous behavior is not typically observed. Although it may be possible to collect data about the relevant alternatives through survey methods, it has also been argued that choice set formation warrants probabilistic modeling of the choice set formation process (Wichmann, Chen and Adamowicz 2016) that prompted Manski (1977) to extend the CL model to a two-stage consider-then-choose model. 
Building on the seminal work of Manski (1977), Swait and Ben-Akiva (1987) developed the IAL that models choice set formation as a two-stage process. In the first stage, a population of $N$ individuals faces a set $B$ with $I$ alternative sites, the $n^{\text {th }}$ individual forms a non-empty choice set $B \in C$ and then chooses an alternative that maximizes utility in the second stage. Following Wichmann, Chen and Adamowicz (2016), the random utility function is defined on a feasible set $B$ and the unconditional probability that the $n^{\text {th }}$ individual chooses an $i^{\text {th }}$ alternative is

$$
P_{n}(i)=\sum_{i \in B, B \in C} P_{n}(i \mid B) Q_{n}(B)
$$

where $P_{n}(i \mid B)$ is the conditional probability that alternative $I$ is chosen given that choice set $B$ is the $n^{\text {th }}$ individual's true choice set, $Q_{n}(B)$ is the probability that $B$ is in $n^{\text {th }}$ individual's true choice set, $I$ is an alternative in $B$, and $C$ is a set of all possible non-empty choice sets. In the IAL model, $Q_{n}(B)$ is

$$
\text { (3) } Q_{n}(B)=\frac{\prod_{h \in B} A_{n}(h) \prod_{k \in(C-B)}\left[1-A_{n}(k)\right]}{1-\prod_{i \in C}\left[1-A_{n}(i)\right]}
$$

where $h, I$, and $k$ index alternatives belonging to different choice sets, $A_{n}($.$) is the probability that$ an alternative is included in the choice set. It is assumed that inclusion or exclusion of alternatives is independent of inclusion or exclusion of another alternative. For the $n^{\text {th }}$ individual, $A_{n}(i)$ denotes availability of the $i^{\text {th }}$ alternative. It is assumed that an alternative's availability is determined by a threshold for one variable (e.g. price or distance) such that

$$
A_{n}(i)=\operatorname{Prob}\left(d_{n i}<\tau+\vartheta_{n i}\right)=\frac{1}{1+\exp \left(\mu\left(d_{n i}-\tau\right)\right)}
$$

where $d_{n i}$ is a choice attribute, $\tau$ is the threshold parameter for this attributes, and $\vartheta_{n i}$ is an identically and independently logistic distributed random variable with a location of zero and a scale of $\mu$. In the context of recreation demand, equation (6) can be interpreted as the probability that the distance $d_{n i}$ to reach alternative $I$ exceeds the threshold $\tau+\vartheta_{n i}$ used by individual $n$ to 
determine which alternatives they will compare in making their final choice. In this case, the threshold is akin to the maximum distance an individual is willing to travel to access a recreation site, beyond which the site is not part of the choice set.

In the IAL model, the conditional probability that alternative $I$ is chosen given that $B$ is the $n^{\text {th }}$ individual's true choice set (included in equation (4)) is defined as

$$
P_{n}(i \mid B)= \begin{cases}\frac{\exp \left(V_{n i}\right)}{\sum_{k \in B} \exp \left(V_{n k}\right)} & \text { if } i \in B \\ 0 & \text { if } i \notin B\end{cases}
$$

where $V_{n i}$ is the systematic component of random utility $U_{n i}=V_{n i}+\varepsilon_{n i}$ where $V_{n i}=x_{n i}^{\prime} \beta($ defined in equation (3)), where $\varepsilon_{n i}$ is identically and independently distributed Gumbel with scale fixed at unity and independent of the distance cutoff error $\vartheta_{n i}$ (Swait and Ben-Akiva 1987).

Equations (4)-(7) define the IAL model and its parameter estimates are usually obtained by maximum likelihood estimation. The model has been applied in several disciplines in both methodological and applied work. For example, Wichmann, Chen and Adamowicz (2016) used it to measure the importance of social networks on choice set formation, Haab and Hicks (1997) used it to measure the value of outdoor recreation sites, and Li, Adamowicz and Swait (2015) used it to examine the effects of choice set misspecification on RUM welfare measures.

Studies by Li, Adamowicz and Swait (2015) and Wichman, Cheng and Adamowicz (2016) used Monte Carlo simulations in their settings. Though flexible and often insightful, Monte Carlo studies are subject to between-simulation variability called Monte Carlo error (Koehler, Brown and Haneuse 2009). But most simulation-based studies ignore Monte Carlo error, which informs the analyst the amount of uncertainty in their finite simulation samples (Koehler, Brown and Haneuse 2009). This approach is partly motivated by considering this 
uncertainty in simulation based results, and I report the Monte Carlo error in the mean parameter estimates.

Unlike previous studies, I also consider the performance of the CL and IAL for two scenarios shown in figure 1. In the first scenario, I estimate both the CL and IAL models from data simulated under a stochastic choice set formation (IAL model) by varying distance cutoffs to accommodate irrelevant alternatives in choice sets. In the second scenario, I estimate both models from data simulated based on the assumption that the choice set includes the full set of alternatives (CL model). I measure the bias and efficiency of parameter estimates from two discrete choice models commonly used in the literature when either choice sets are stochastically formed or when there is no choice set formation and individuals choose from the full set of alternatives. Using real databases, I vary the distances and estimate the CL model at all distance cutoffs but the IAL model is estimated once since its results are not expected to change.

\section{Data and Procedures}

In this section, I describe the data generating processes when no actual data were used. I also describe the actual data used. Specifically, I describe the Monte Carlo experiments employed besides summaries of variables from actual data set used.

\section{Monte Carlo Experiments}

Table 1 presents the basic setting of the data generation process. In both cases, there are 200 data sets (or replications, $R=250$ ), 3,000 choice tasks (or observations, $O=3,000$ ), and 10 alternatives in each choice set $(J=10)$. The alternatives are described by two attributes $(K=2)$ that reflect distance $(d)$ to the site and a measure of perceived quality $(q)$. The choice for $R=200$ and 3,000 choice tasks in both models was driven by time constraints imposed by the computational burden of estimating the IAL model rendering us not to vary the number of 
observations. The two situations correspond to discrete choice recreation demand models where either each individual is assumed to face the same set of all recreation sites in a global choice set or different individuals consider different choice sets and may not automatically choose all options because of bounded rationality (Eliaz and Spiegler 2011).

Suppose that the two attributes are, in fact, distance $(d)$ to access the alternative and the perceived environmental quality $(q)$ of the alternative. One of the reasons alternatives may become irrelevant in a recreational site choice problem is when some people lack knowledge about the sites far from their homes and may thus, consider these sites as irrelevant. Since distance and quality vary across alternatives, the two variables are randomly and independently drawn from a uniform distribution between 0 and 1 for $n=1, \ldots, 3,000$, and $i=1, \ldots, 10$.

As earlier mentioned, the IAL model has a two-stage choice set formation built on work by Manski (1977). How I accomplish this process is summarized below. In the first stage, I draw independent errors, $\vartheta_{n i}$ (see equation (6)) from a logistic distribution with mean zero and scale parameter $\mu=10$ in each replication. All alternatives or their combinations that satisfy equation (6) are included in the $n^{\text {th }}$ individual's choice set, where $\tau=0.5$. The number of alternatives and their combinations is determined by $2^{j}-1$ where $j$ represents the number of alternatives in each choice set. In the current study, $j=10$ to represent the ten categories. Thus, I considered 1023 non-empty choice sets where the universal choice set ranges from $\{1\},\{2\},\{3\},\{4\},\{5\},\{6\}$, $\{7\},\{8\},\{9\},\{10\},\{1,2\},\{1,3\}, \ldots$, and so on.

In the second stage, individuals compare the utility level from each alternative in their choice sets (as described in first stage) and select the alternative with the largest utility. I draw the random portion of utility $\varepsilon_{n i}$ from a Gumbel distribution $\mathbf{G}(0,1)$. For the sake of brevity, I assume a linear and additive form of $V_{n i}=x_{n i}^{\prime} \beta$ where $x$ includes a vector of alternative specific 
constants for alternative 1 ( $A S C 1)$ through alternative 9 (ASC9) where $A S C 10$ is the base category. The two attributes, distance and site quality, are included as regressors in both models.

Next, I estimate the CL and IAL models for 250 simulations, and I vary the distance cutoffs after each set of simulations: first 0.2 , then 0.4 , then 0.6 , and 0.8 . The IAL model is estimated when the cutoff is 0.2 while the $\mathrm{CL}$ is estimated at all distance cutoffs. Finally, I simulate the data without considering a stochastic choice set (i.e., the CL being the true model) as follows. Given the true vector of parameter estimates and an array of uniformly distributed distance and site's quality, I generate the $X \beta$ matrix and compute probabilities for each alternative based on equation (1). I then draw a Gumbel distributed random $\mathbf{G}(0,1)$ variable added to the deterministic portion of utility (equation 1). The choice is made based on random utility maximization from which individuals choose the recreation site with highest utility. I then estimate both CL and IAL models once for 250 simulated datasets. The CL framework does not assume distance cutoffs - its underlying assumption is that people would consider all recreation sites presented to them unlike in the IAL. Thus, I estimate seven models altogether: 1) IAL at distance cutoff of $0.2,2) \mathrm{CL}$ at distance cutoff of $0.2,3) \mathrm{CL}$ at distance cutoff of $0.4,4) \mathrm{CL}$ at distance cutoff of $0.6,5) \mathrm{CL}$ at distance cutoff of $0.8,6) \mathrm{CL}$, and 7) IAL when the choice set formation is not considered and individuals choose from the full set of alternatives.

What follows next for the first scenario (i.e., IAL is true model) is a comparison of mean parameter estimates from CL and IAL with the true parameter vector is $1.50,5.00,3.00,2.50$, 2.00, $0.75,1.25,2.70,4.00,4.50,-3.50,0.50$, and 10.00 for ASC1, ASC2, ASC3, ASC4, ASC5, $A S C 6, A S C 7, A S C 8, A S C 9$, site quality, distance, $\tau$, and $\mu$, respectively. Notice that $\tau$ and $\mu$ affect decision making via equation (6). 


\section{Empirical Data}

Empirical data used in the current study are part of the revealed preference (RP) data used in Cha and Melstrom (2018). The study by Cha and Melstrom (2018) focus on paddlefish angler preferences and catch-and-release regulations in Oklahoma and used choice experiment data that this study benefits from. Thus, a more detailed description of the data can be found in Cha and Melstrom (2018). Table 2 shows descriptive statistics of the empirical data used. These summary statistics show that about $2 \%$ of the anglers decided to go fishing for paddlefish while about $20 \%$ of them preferred to go fishing to at least 2 fishing sites. The average number of paddlefish anglers were able to catch was about 3 fish per day while the maximum number was about 9 fish. Furthermore, table 1 shows that about $60 \%$ of anglers preferred to fish from the river bank to other alternatives. In terms of distance to the fishing site, the average distance was about 134 miles while the maximum distance anglers could travel was 2073 miles. While there are other variables in the data, this study only uses the described variables for brevity. Similar to Monte Carlo simulations, the following are distance cutoffs in miles that were employed for empirical data: 100, 200, 300, and 400. The CL is estimated at all these cutoffs while the IAL is estimated at distance cutoff of only 100 miles.

\section{Evaluating Parameter Estimates}

To assess the efficiency of the estimates, I measure the average differences between the parameter estimates $\hat{\beta}$ from values $\beta$. This is achieved by computing the square of the differences between the parameter estimates and their true values and taking their mean values. Thus, specifically, I compute the mean square error (MSE) as

$$
\operatorname{MSE}(\hat{\beta})=\frac{1}{R} \sum_{r=1}^{R} \sqrt{\left[\hat{\beta}_{r}-\beta\right]^{2}}
$$


where $r=1, \ldots, R, R$ denotes replications, $R=250$ is the number of replications in each experiment, and $\hat{\beta}$ denotes an estimate of $\beta$. The MSE is a measure of how accurate and precise the estimate is and can thus also be decomposed as (Wackerly, Mendenhall, and Scheaffer 2014)

$$
\operatorname{MSE}(\hat{\beta})=\operatorname{Bias}^{2}(\hat{\beta})+\operatorname{Var}(\hat{\beta})
$$

where square of bias measures the accuracy of the estimate while variance measures its precision.

As earlier mentioned, I also determine bias of mean parameter estimates. Thus, for each parameter $\beta$, the average value $\bar{\beta}$ and the standard error $\sigma$ over 250 replications are computed and a hypothesis test to determine the significance of the difference between the two is conducted. I also report the Monte Carlo error of mean parameter estimates to measure the level of inter-simulation variability for all models. More details about the computation of the Monte Carlo errors can be found in Koehler, Brown and Haneuse (2009), White (2010), and Meaney and Moineddin (2014).

As mentioned before, I varied distance cutoffs at $0.2,0.4,0.6$, and 0.8 for Monte Carlo simulations. Varying distance cutoff allows us to determine the bias when the analyst potentially misjudges the deterministic portion of the cutoff. Broadly, it represents varying maximum distances that individuals may face when choosing recreation sites, they tend to visit. For example, a distance cutoff equal to 0.40 would imply that recreation sites located less or equal to 40 miles away would be considered relevant to be accessible by individuals, otherwise, they would not. Thus, without loss of generality, increasing the cutoff to .80 could mean that recreation sites located up to 80 miles away are included in the choice sets. Our empirical analyses make this clearer. A distance cutoff of 300 miles implies that recreational sites located 
more than 300 miles away from an individual would not be relevant in their consideration sets. The same implication holds for other empirical distance cutoffs used.

I used R Statistical Software version 3.5.0 (R Core Team 2018) for simulation of data and estimation of all the models. The optim function in R utilizing numerical optimization based on the Broyden-Fletcher-Goldfarb-Shanno (BFGS) algorithm was used to maximize the likelihood function for the IAL model. The BFGS algorithm was preferred because it nearly always works better than alternative algorithms (Train 2009). Additionally, the survival package in R (Therneau 2015) was used to estimate the CL model at the same time as the IAL model.

\section{Results}

In this section, first I present mean parameter estimates of the CL and IAL models obtained from the Monte Carlo experiments. I also present tests of parameter bias as well as the mean proportional root mean square errors. This is followed by empirical results.

\section{Monte Carlo Simulation Results}

Table 2.3 presents mean parameter estimates for CL and IAL models estimated from data simulated from a stochastic choice set formation process. The CL model is estimated on the complete set of alternatives, which therefore includes irrelevant alternatives in this set up. Column 2 shows the true parameter vector of the underlying data generating process while columns 3 and 4 present mean parameter estimates for IAL and their bias, respectively. The columns that follow present mean parameter estimates and respective bias of the CL model estimated at the three different distance cutoffs (i.e., at distance cutoffs of 0.4, 0.6, and 0.8)

Based on the $t$-statistics $\left(\bar{\beta}-\beta_{\text {true }}\right) / \operatorname{se}(\bar{\beta})$ and $\bar{\beta}$, where $\operatorname{se}(\bar{\beta})$ is the standard error

of $\bar{\beta}$, I test whether the mean parameter estimates are statistically different from their true ones. 
The $t$-statistics comparing the true and model values are in parentheses of table 2.3. The null hypothesis is that the estimated value is equal to the true value.

Results in table 2.3 indicate that when choice set formation is stochastic, on average the IAL model recovers the true parameter estimates since the bias between the true parameters and mean parameter estimates is significantly different from zero. This is not surprising because the IAL model describes the real data generation process underlying these results. This is the reason I do not present results for IAL at other distance cutoffs because such results are expected. However, mean parameter estimates from the CL model are not free from significant bias at every distance cutoff. At the distance cutoff of 0.2 , most parameter estimates under the CL are significantly biased. When the distance cutoff is raised to $0.4,0.6$, and 0.8 , on average, mean parameter estimates from the CL are more negatively biased. Specifically, the mean parameter estimate for the coefficient of the variable distance is less negatively biased as the distance cutoff is increased - as more fishing sites are included in the choice sets. I attribute this bias to the endogenously determined distance cutoff which seems to have a significant impact on mean parameter estimate of the coefficient for the variable distance. However, a much closer look at the distance coefficient in the CL model suggests that changing the distance cutoff has little effect on the parameter estimates, at least over the range of cutoffs considered here. This suggests there is little evidence that performance of the CL model improves as the effect of the distance cutoff is quite less on choice set formation.

I present mean parameter estimates for the CL and IAL models estimated from choice data in which the decision makers consider the full set of recreation sites in table 2.4. The true model is shown in column 2 while the following columns, as before, present mean parameter 
estimates and their bias for both CL and IAL models. Model performance statistics are presented in the lower panel.

The mean parameter estimates of the CL are very similar to the true parameter estimates. The mean parameter estimate of the coefficient of distance is -3.519 which is close to the true value of -3.500 . Based on the reported $t$-statistics, I fail to reject the null hypothesis of no difference between the true value and mean parameter estimates. Similarly, the IAL model produces significantly unbiased parameter estimates of the CL. The results in table 4 indicate that when individual choice sets include the full set of alternatives (i.e. when the CL is the true model), the IAL model still successfully recovers the true parameter estimates.

A researcher modeling choice set specification problems would also be interested in knowing the proportional deviation of estimates from their true parameters, or the efficiency of the CL and IAL parameter estimates under the two scenarios I examined. As earlier mentioned, I evaluate efficiency based on the MSEs of the mean parameter estimates. Table 2.5 reports MSEs, proportion of MSEs by bias, and proportion of MSEs by variance of the estimates, of the CL and IAL models for the estimation results in table 2.3.

Focusing first on the MSE benchmark, for which lower values are preferred, I find that the IAL model has, on average lower MSEs (i.e., 0.582) than the CL model (i.e., 2.415). Thus, in addition to the CL failing to successfully recover true parameter estimates, its parameter estimates are less efficient than the IAL's. At the distance cutoff of 0.2 , a comparison of the IAL with the CL indicates that that CL's distance parameter estimate deviates from its true value by more than $100 \%$ (indicated by the MSE). In terms of average MSEs across all distance cutoffs (shown in the third row from the last row of table 2.5), our results indicate that mean parameter estimates from the CL lose more efficiency as distance cutoff increases. I attribute this result 
from the fact that the CL does not have availability terms that are in the IAL which could hamper the former's performance. Additionally, a decomposition of MSE into variance and bias when the IAL is the true model shows that $95.8 \%$ of MSEs of IAL's mean parameter estimates emanates from variance of its estimates while $4.2 \%$ is from bias. As for the CL (assuming IAL is the true model), about $16 \%$ of its MSEs are from variance of its estimates while about $84 \%$ of the MSEs emanates from bias component. This is reasonable especially that under this scenario, IAL's mean parameter estimates are free from significant bias while majority of the mean parameter estimates from the $\mathrm{CL}$ are significantly inaccurate.

The MSEs for model parameters under CL and IAL when choice sets include the full set of alternatives are presented in table 2.6. Like in previous results, it turns out that the model that underlies the data generating process is characterized by more efficient mean parameter estimates than otherwise. On average, mean parameter estimates from the CL have MSE of 0.082 while those from the IAL model have on average MSE of 5.406. This suggests that the CL produces parameter estimates that are more than $100 \%$ more efficient than the IAL when there is no choice set formation and individuals choose from the full set of alternatives. Thus, even if the IAL model successfully recovers true parameter estimates of the CL model, it comes with the loss of efficiency rendering us not to recommend it for data characterized by deterministic choice sets if the alternative procedure, CL model can be easily implemented. After decomposing MSE into variance and square of bias, results suggest that variance of mean parameter estimates from the CL and IAL contribute $99.4 \%$ and $86.7 \%$ to their MSEs, respectively, the rest proportion of MSEs emanating from square of bias. This is unlike when the IAL is the true model. The reason for this could be that because both CL and IAL successfully recover the true parameter estimates when the $\mathrm{CL}$ is the true data generating mechanism. 
Our finding that the model of interest produces mean parameter estimates that are clearly close to the true model if the data generation process is characterized by that model's assumptions are consistent with Li, Adamowicz and Swait (2015), and Wichamn, Chen and Adamowicz (2016) despite their respective studies being totally different from the current study. Additionally, our finding that the CL model fails to successfully recover true parameters when individual decisions are made following stochastic choice set formation parallels the results of Li, Adamowicz and Swait (2015). Again, this similarity is in spite of the two studies focusing on divergent research questions — specifically, Li, Adamowicz and Swait (2015) study the effect of ignoring or misspecifying choice set formation on welfare measures in random utility models which is quite different from our study's focus.

\section{Empirical Results}

Estimation results of the CL and IAL models when the distance cutoff is varied empirically are shown in table 2.7. The variables access to sites, catch and distance to site are significantly different from zero at $1 \%$ significance level in the IAL model. At the distance cutoff of 100 miles, the IAL model attempts to estimate the true value using $\tau$ (distance threshold's estimate) in its availability function (in equation 6). As shown in table 2.7, the IAL model's distance threshold is significantly different from zero and close to the true value of 100. This implies that the IAL correctly predicts the empirical distance cutoff that is set by the researcher. These results corroborate Monte Carlo simulation results obtained in table 2.3. By magnitude, coefficients of the CL are close to those in IAL at the empirical distance cutoff of 100 miles except that the distance coefficient that is larger.

When the distance cutoff is increased to 200 miles, on average, results from the CL model change profoundly. Specifically, the coefficient of distance to site drops rapidly and 
continues to do so as the distance cutoff increases to 400 miles. However, the difference between coefficients of distance to site is only marginal when the distance cutoff is 300 miles and when it is 400 miles. This might be because a substantial number of fishing sites were in most paddlefish anglers' choice sets rendering any changes of the distance cutoffs to have inconsiderable effects on the magnitude of distance to site. These results are consistent with simulation results in table 2.3 where the coefficient of the variable distance were seemingly closer by magnitude at higher distance cutoffs. In terms of model selection, the IAL records the lowest Akaike Information Criterion (AIC) which suggests that it remains a better fit for RUM models when the researcher has some idea about the supposed attribute cutoffs. However, the IAL model's advantage over the CL model could be structural because the IAL model has the availability terms which are absent in the CL even though the two models are non-nested.

\section{Conclusion}

Choice set misspecification is an important problem in random utility maximization (RUM) models of recreation demand and several papers conclude that ignoring choice set formation leads to biased parameters and welfare estimates. In this article, I extended research into distance-based choice set formation by measuring the bias from two RUM models. Unlike previous studies, I examined two possibilities: first, a subset of alternatives appeared in the choice set based on a stochastic process and, second, the choice set included the full set of alternatives. This is novel in that I simulate choice sets with ten alternatives, and using the two plausible discrete choice models functionally increases the choice beyond a binary decision, even when irrelevant alternatives are endogenously excluded. I achieved this by carrying out Monte Carlo experiments and estimated the conditional logit (CL) and the independent availability logit (IAL) models from simulated data. I also estimated the two models using real world 
experimental data on paddlefish angler preferences and catch-and-release regulations in Oklahoma, to compare parameter estimates of the two models without any known parameter estimates.

The IAL model recovered true parameter estimates when a subset of the alternatives formed individual choice sets. I also showed that under the same conditions, the CL model failed to recover the true parameter values. Additionally, and most importantly, I found that under the CL model, the bias changed as one of the variables affecting choice set formation changedspecifically, as the distance cutoff was raised. I also found less efficient mean parameter estimates from the CL than the IAL when the underlying data generation process involved stochastic choice set formation. Thus, I recommend stochastic-choice-set-based methods such as the IAL when the analyst believes that individual choice sets do not include the full set of alternatives.

In the second scenario and as expected, I showed that the CL successfully recovers true parameter estimates when individual choice sets do include the full set of alternatives. Importantly, in this case the IAL model is also able to successfully recover the true parameter estimates. Despite relatively low Monte Carlo error, the IAL model produced considerably less efficient mean parameters than the CL. In both cases, a decomposition of the mean square error (MSE) into bias and variance components showed that biasedness of the mean parameter estimates from the CL contributed the most to their MSEs than the IAL's when the latter was the data generating process. Contrary, when the $\mathrm{CL}$ was the true data generating process, variance of the estimates under the IAL contributed more to MSEs since the IAL was able to the true parameter estimates of the CL. Thus. It is naturally better to use the CL model when there is no evidence of choice set formation and individuals choose from the full set of alternatives. 
Nevertheless, relying on a stochastic choice set formation process under IAL and allowing for the possibility of a two-stage stochastic choice set formation is conceptually appealing. It's realistic that an individual's true consideration sets may not always be known with certainty and that the IAL assumes choice sets are latent is attractive. And based on empirical results, the IAL can predict the true distance cutoff while the magnitude of the CL model's results change meaningfully as the distance cutoff is increased. Although the researcher should be cautious in pursuing such an approach because they should be concerned about the precision of the estimate, our results suggest that, in practice, the IAL model will on average recover the true parameters whether or not individual choice sets are formed stochastically.

Our study considered a situation in which an alternative such as a recreation site is considered irrelevant partly based on one observable attribute, distance to the site. This problem naturally does not generalize to all contexts. There could be other attributes that affect the probability that an alternative appears in an individual's choice set, including environmental quality and the presence of built amenities. While I recognize that the absence of the availability terms in CL model could have contributed to its poor performance vs the IAL (in some cases), employing non-nested hypothesis tests of the two models represents an important challenge for future research. 
Table 2.1: The Basic Setting of the Data Generation Condition

\begin{tabular}{lcc}
\hline & Notation & Value \\
\hline Number of data sets (replications) & $\mathrm{R}$ & 250 \\
Number of choice sets (observations) & $\mathrm{O}$ & 3,000 \\
Number of alternatives in each choice set & $\mathrm{J}$ & 10 \\
Number of attributes & $\mathrm{K}$ & 2 \\
\hline
\end{tabular}


Table 2.2: Descriptive Statistics of Empirical Data

\begin{tabular}{|c|c|c|c|c|c|}
\hline Variable name & Variable Description & Mean & Std. Dev & Minimum & Maximum \\
\hline Choice & Angler decides to fish for paddlefish, $=1$ if yes, 0 otherwise & 0.019 & 0.139 & 0.000 & 1.000 \\
\hline Access to sites & Access to 2 or more fishing sites, $=1$ if yes, 0 otherwise & 0.200 & 0.400 & 0.000 & 1.000 \\
\hline Catch (daily) & Catch rate (number of fish caught per day) & 3.349 & 2.150 & 1.400 & 9.210 \\
\hline River & Fishing site is river, $=1$ if yes, 0 otherwise) & 0.600 & 0.489 & 0.000 & 1.000 \\
\hline Distance to site (miles) & Distance to river in miles & 132.669 & 153.344 & 0.000 & 2073.100 \\
\hline Number of observations used & & & & & 70,600 \\
\hline
\end{tabular}


Table 2.3: Mean Parameter Estimates of CL and IAL Models when the IAL Model is true

\begin{tabular}{|c|c|c|c|c|c|c|c|c|c|c|c|}
\hline \multirow{3}{*}{$\begin{array}{l}\text { Dist. Cutoffs } \\
\text { Utility }\end{array}$} & \multirow{3}{*}{$\begin{array}{l}\text { True } \\
\text { model }\end{array}$} & \multicolumn{2}{|l|}{ IAL } & \multirow[t]{2}{*}{$\mathrm{CL}$} & \multicolumn{3}{|c|}{$\mathrm{CL}$} & \multirow{2}{*}{$\frac{\mathrm{CL}}{0.6}$} & \multicolumn{3}{|c|}{ CL } \\
\hline & & & 0.2 & & \multicolumn{3}{|c|}{0.4} & & \multicolumn{3}{|c|}{0.8} \\
\hline & & & Bias & & Bias & & Bias & & Bias & & Bias \\
\hline \multirow[t]{2}{*}{ ASC1 } & \multirow[t]{2}{*}{1.500} & 1.530 & 0.030 & 1.009 & \multirow[t]{2}{*}{-0.491} & 1.042 & \multirow[t]{2}{*}{-0.458} & 1.040 & \multirow[t]{2}{*}{-0.460} & 1.045 & \multirow[t]{2}{*}{-0.455} \\
\hline & & $(0.050)$ & & $(-1.281)$ & & $(-1.310)$ & & $(-1.346)$ & & $(-1.338)$ & \\
\hline \multirow[t]{2}{*}{ ASC2 } & \multirow[t]{2}{*}{5.000} & 5.251 & 0.251 & $3.683^{*}$ & \multirow[t]{2}{*}{-1.317} & $3.527 *$ & \multirow[t]{2}{*}{-1.473} & $-2.540 *$ & \multirow[t]{2}{*}{-2.460} & $-4.127 *$ & \multirow[t]{2}{*}{-9.127} \\
\hline & & $(0.255)$ & & $(-3.931)$ & & $(-3.161)$ & & $(-1.497)$ & & $(-3.538)$ & \\
\hline \multirow[t]{2}{*}{ ASC3 } & \multirow[t]{2}{*}{3.000} & 3.136 & 0.136 & $2.196 *$ & \multirow[t]{2}{*}{-0.804} & $2.149 *$ & \multirow[t]{2}{*}{-0.851} & $2.136^{*}$ & -0.864 & $2.141^{*}$ & \multirow[t]{2}{*}{-0.859} \\
\hline & & $(0.222)$ & & $(-2.935)$ & & $(-3.194)$ & & $(-3.231)$ & & $(-3.193)$ & \\
\hline \multirow[t]{2}{*}{ ASC4 } & 2.500 & 2.605 & 0.105 & $1.858 *$ & -0.642 & $1.824 *$ & -0.676 & $1.794 *$ & -0.706 & $1.800 *$ & -0.700 \\
\hline & & $(0.181)$ & & $(-2.056)$ & & $(-2.186)$ & & $(-2.474)$ & & $(-2.448)$ & \\
\hline ASC5 & 2.000 & 2.067 & 0.067 & 1.545 & -0.455 & 1.498 & -0.502 & 1.501 & -0.499 & 1.499 & -0.501 \\
\hline & & $(0.113)$ & & $(-1.331)$ & & $(-1.658)$ & & $(-1.625)$ & & $(-1.627)$ & \\
\hline ASC6 & 0.750 & 0.778 & 0.028 & 0.579 & -0.171 & 0.570 & -0.180 & 0.559 & -0.191 & 0.561 & -0.189 \\
\hline & & $(0.048)$ & & $(-0.380)$ & & $(-0.458)$ & & $(-0.497)$ & & $(-0.497)$ & \\
\hline ASC7 & 1.250 & 1.448 & 0.198 & $0.183 *$ & -0.167 & $0.114 *$ & -1.136 & $0.082 *$ & -1.168 & $0.077 *$ & -1.173 \\
\hline & & $(0.314)$ & & $(-10.042)$ & & $(-11.703)$ & & $(-12.198)$ & & $(-12.347)$ & \\
\hline ASC8 & 2.700 & 2.898 & 0.199 & $1.633 *$ & -0.168 & 1.564 & -1.136 & $1.532 *$ & -1.169 & $1.527 *$ & -1.174 \\
\hline & & $(0.315)$ & & $(10.420)$ & & $(-11.704)$ & & $(-12.199)$ & & $(-12.348)$ & \\
\hline ASC9 & 4.000 & 4.198 & 0.198 & $2.933 *$ & -0.167 & $2.864 *$ & -1.136 & $2.832 *$ & -1.168 & $2.827 *$ & -1.173 \\
\hline & & $(0.314)$ & & $(-10.042)$ & & $(-11.703)$ & & $(-12.198)$ & & $(-12.347)$ & \\
\hline Quality & 4.500 & 4.730 & 0.230 & $2.299 *$ & -2.201 & $2.323 *$ & -2.177 & $2.346^{*}$ & -2.154 & $2.355^{*}$ & -2.145 \\
\hline & & $(0.245)$ & & $(-7.536)$ & & $(-8.015)$ & & $(-7.659)$ & & $(-7.553)$ & \\
\hline Distance & -3.500 & -3.652 & -0.152 & $-7.233^{*}$ & -3.733 & $-7.039 *$ & -3.539 & $-6.942 *$ & -3.442 & $-6.933^{*}$ & -3.433 \\
\hline & & $(-0.151)$ & & $(-7.701)$ & & $(-7.711)$ & & $(-7.763)$ & & $(-7.680)$ & \\
\hline$\tau$ & 0.500 & 0.502 & 0.02 & & & & & & & & \\
\hline & & $(0.016)$ & & & & & & & & & \\
\hline$\mu$ & 10.000 & 10.246 & 0.246 & & & & & & & & \\
\hline & & $(0.207)$ & & & & & & & & & \\
\hline Average bias & & & 0.118 & & -1.183 & & -1.206 & & -1.298 & & -1.532 \\
\hline Monte Carlo & ror & 0.043 & & 0.018 & & 0.019 & & 0.024 & & 0.030 & \\
\hline Loglikelihood & value & -258.8 & & 293.9 & & -312.1 & & -305.3 & & -308.4 & \\
\hline AIC & & 543.6 & & 609.8 & & 646.2 & & 632.6 & & 638.8 & \\
\hline
\end{tabular}

Notes: $t$-statistics comparing the true and model values are in parentheses.

*biased mean parameter estimate at $5 \%$ significance level 
Table 2.4: Mean Parameter Estimates of CL and IAL Models when CL Model is true

\begin{tabular}{|c|c|c|c|c|c|}
\hline \multirow{4}{*}{$\begin{array}{l}\text { Utility function } \\
\text { ASC1 }\end{array}$} & \multicolumn{3}{|c|}{$\mathrm{CL}$} & \multicolumn{2}{|c|}{ IAL } \\
\hline & True model & & Bias & & Bias \\
\hline & 1.500 & 1.477 & -0.023 & 1.883 & 0.383 \\
\hline & & $(-0.071)$ & & $(0.152)$ & \\
\hline ASC2 & 5.000 & $\begin{array}{c}5.015 \\
(0.054)\end{array}$ & 0.015 & $\begin{array}{r}5.219 \\
(0.087)\end{array}$ & 0.219 \\
\hline ASC3 & 3.000 & $\begin{array}{c}2.993 \\
(-0.026)\end{array}$ & -0.007 & $\begin{array}{r}3.198 \\
(0.079)\end{array}$ & 0.198 \\
\hline ASC4 & 2.500 & $\begin{array}{c}2.480 \\
(-0.076)\end{array}$ & -0.020 & $\begin{array}{r}2.693 \\
(0.077)\end{array}$ & 0.193 \\
\hline ASC5 & 2.000 & $\begin{array}{l}2.023 \\
(0.090)\end{array}$ & 0.023 & $\begin{array}{r}2.217 \\
(0.086)\end{array}$ & 0.217 \\
\hline ASC6 & 0.750 & $\begin{array}{c}0.723 \\
(-0.100)\end{array}$ & -0.027 & $\begin{array}{r}1.025 \\
(0.100)\end{array}$ & 0.275 \\
\hline ASC7 & 1.250 & $\begin{array}{c}1.256 \\
(-0.019)\end{array}$ & 0.006 & $\begin{array}{l}1.620 \\
(0.145)\end{array}$ & 0.370 \\
\hline ASC8 & 2.700 & $\begin{array}{c}2.687 \\
(-0.045)\end{array}$ & -0.013 & $\begin{array}{r}3.078 \\
(0.151)\end{array}$ & 0.378 \\
\hline ASC9 & 4.000 & $\begin{array}{l}4.002 \\
(0.008)\end{array}$ & 0.002 & $\begin{array}{r}4.227 \\
(0.090)\end{array}$ & 0.227 \\
\hline Quality & 4.500 & $\begin{array}{c}4.519 \\
(0.066)\end{array}$ & 0.019 & $\begin{array}{r}4.066 \\
(-1.328)\end{array}$ & -0.434 \\
\hline Distance & -3.500 & $\begin{array}{l}-3.519 \\
(0.068)\end{array}$ & -0.019 & $\begin{array}{l}-3.023 \\
(1.563)\end{array}$ & 0.477 \\
\hline Tau & & & & $\begin{array}{c}26.143 \\
(12.795)^{1}\end{array}$ & \\
\hline $\mathrm{Mu}$ & & & & $\begin{array}{c}9.300 \\
(-9.284)^{1}\end{array}$ & \\
\hline Monte Carlo error & & 0.027 & & 0.294 & \\
\hline Average bias & & & -0.004 & & 0.228 \\
\hline Loglikelihood value & & -339.1 & & -454.6 & \\
\hline AIC & & 700.2 & & 935.2 & \\
\hline
\end{tabular}

\footnotetext{
${ }^{1}$ These are standard errors for respective parameters and not t-statistics. Their respective parameters $\tau$ and $\mu$ are not part of the true model.
} 
Table 2.5: Mean Square Error (MSE), and Proportion of MSE by Bias and Variance of Mean Parameter Estimates for CL and IAL Models when the IAL Model is true

\begin{tabular}{|c|c|c|c|c|c|c|}
\hline & & IAL & CL & $\mathrm{CL}$ & $\mathrm{CL}$ & $\mathrm{CL}$ \\
\hline Distance cutoffs & & & 0.2 & 0.40 & 0.60 & 0.80 \\
\hline \multirow[t]{3}{*}{ ASC1 } & MSE & 0.358 & 0.388 & 0.332 & 0.327 & 0.322 \\
\hline & Variance/MSE & 0.997 & 0.378 & 0.367 & 0.355 & 0.357 \\
\hline & Bias square/MSE & 0.003 & 0.622 & 0.633 & 0.645 & 0.643 \\
\hline \multirow[t]{3}{*}{ ASC2 } & MSE & 1.033 & 1.847 & 2.386 & 8.744 & 89.939 \\
\hline & Variance/MSE & 0.939 & 0.061 & 0.091 & 0.308 & 0.074 \\
\hline & Bias square/MSE & 0.061 & 0.939 & 0.909 & 0.692 & 0.926 \\
\hline \multirow[t]{3}{*}{ ASC3 } & MSE & 0.395 & 0.721 & 0.795 & 0.817 & 0.810 \\
\hline & Variance/MSE & 0.953 & 0.104 & 0.089 & 0.087 & 0.089 \\
\hline & Bias square/MSE & 0.047 & 0.896 & 0.911 & 0.913 & 0.911 \\
\hline \multirow[t]{3}{*}{ ASC4 } & MSE & 0.343 & 0.509 & 0.552 & 0.580 & 0.571 \\
\hline & Variance/MSE & 0.968 & 0.191 & 0.173 & 0.140 & 0.142 \\
\hline & Bias square/MSE & 0.032 & 0.809 & 0.827 & 0.860 & 0.858 \\
\hline \multirow[t]{3}{*}{ ASC5 } & MSE & 0.349 & 0.323 & 0.343 & 0.342 & 0.345 \\
\hline & Variance/MSE & 0.987 & 0.360 & 0.266 & 0.274 & 0.273 \\
\hline & Bias square/MSE & 0.013 & 0.640 & 0.734 & 0.726 & 0.727 \\
\hline \multirow[t]{3}{*}{ ASC6 } & MSE & 0.355 & 0.230 & 0.186 & 0.184 & 0.180 \\
\hline & Variance/MSE & 0.998 & 0.873 & 0.826 & 0.801 & 0.802 \\
\hline & Bias square/MSE & 0.002 & 0.127 & 0.174 & 0.199 & 0.198 \\
\hline \multirow[t]{3}{*}{ ASC7 } & MSE & 0.438 & 1.150 & 1.299 & 1.374 & 1.385 \\
\hline & Variance/MSE & 0.910 & 0.010 & 0.007 & 0.007 & 0.007 \\
\hline & Bias square/MSE & 0.090 & 0.990 & 0.993 & 0.993 & 0.993 \\
\hline \multirow[t]{3}{*}{ ASC8 } & MSE & 0.439 & 1.151 & 1.299 & 1.375 & 1.385 \\
\hline & Variance/MSE & 0.910 & 0.010 & 0.007 & 0.007 & 0.007 \\
\hline & Bias square/MSE & 0.090 & 0.990 & 0.993 & 0.994 & 0.993 \\
\hline \multirow[t]{3}{*}{ A } & MSE & 0.438 & 1.150 & 1.299 & 1.374 & 1.385 \\
\hline & Variance/MSE & 0.910 & 0.010 & 0.007 & 0.007 & 0.007 \\
\hline & Bias square/MSE & 0.090 & 0.990 & 0.993 & 0.993 & 0.993 \\
\hline \multirow[t]{3}{*}{ Quality of site } & MSE & 0.925 & 4.931 & 4.813 & 4.717 & 4.681 \\
\hline & Variance/MSE & 0.943 & 0.017 & 0.015 & 0.017 & 0.017 \\
\hline & Bias square/MSE & 0.057 & 0.983 & 0.985 & 0.983 & 0.983 \\
\hline \multirow[t]{3}{*}{ Distance to site } & MSE & 1.033 & 14.168 & 12.733 & 12.042 & 11.985 \\
\hline & Variance/MSE & 0.978 & 0.017 & 0.016 & 0.016 & 0.017 \\
\hline & Bias square/MSE & 0.022 & 0.893 & 0.984 & 0.984 & 0.983 \\
\hline \multirow[t]{2}{*}{ Tau } & MSE & 0.001 & & & & \\
\hline & Variance/MSE & 1.000 & & & & \\
\hline Bias s & square/MSE & 0.000 & & & & \\
\hline
\end{tabular}

Continued... 
Table 2.5. Continued

\begin{tabular}{|c|c|c|c|c|c|}
\hline & IAL & $\mathrm{CL}$ & $\mathrm{CL}$ & $\mathrm{CL}$ & CL \\
\hline Distance cutoffs & & & 0.40 & 0.60 & 0.80 \\
\hline MSE & 1.463 & & & & \\
\hline Variance/MSE & 0.959 & & & & \\
\hline Bias square/MSE & 0.041 & & & & \\
\hline Average MSE & 0.582 & 2.415 & 2.367 & 2.898 & 10.271 \\
\hline Average variance/MSE & 0.958 & 0.185 & 0.169 & 0.184 & 0.163 \\
\hline Average bias square/MSE & 0.042 & 0.815 & 0.831 & 0.816 & 0.837 \\
\hline
\end{tabular}


Table 2.6: Mean Square Error (MSE), and Proportion of MSE by Bias and Variance of Mean Parameter Estimates for CL and IAL Models when the CL Model is true

\begin{tabular}{|c|c|c|c|}
\hline & & CL & IAL \\
\hline \multirow[t]{3}{*}{ ASC1 } & MSE & 0.116 & 6.463 \\
\hline & Variance/MSE & 0.995 & 0.977 \\
\hline & Bias square/MSE & 0.005 & 0.023 \\
\hline \multirow[t]{3}{*}{ ASC2 } & MSE & 0.064 & 6.300 \\
\hline & Variance/MSE & 0.996 & 0.992 \\
\hline & Bias square/MSE & 0.004 & 0.008 \\
\hline \multirow[t]{3}{*}{ ASC3 } & MSE & 0.056 & 6.344 \\
\hline & Variance/MSE & 0.999 & 0.994 \\
\hline & Bias square/MSE & 0.001 & 0.006 \\
\hline \multirow[t]{3}{*}{ ASC4 } & MSE & 0.079 & 6.358 \\
\hline & Variance/MSE & 0.995 & 0.994 \\
\hline & Bias square/MSE & 0.005 & 0.006 \\
\hline \multirow[t]{3}{*}{ ASC5 } & MSE & 0.069 & 6.438 \\
\hline & Variance/MSE & 0.993 & 0.993 \\
\hline & Bias square/MSE & 0.007 & 0.007 \\
\hline \multirow[t]{3}{*}{ ASC6 } & MSE & 0.069 & 7.595 \\
\hline & Variance/MSE & 0.989 & 0.990 \\
\hline & Bias square/MSE & 0.011 & 0.010 \\
\hline \multirow[t]{3}{*}{ ASC7 } & MSE & 0.124 & 6.631 \\
\hline & Variance/MSE & 1.000 & 0.979 \\
\hline & Bias square/MSE & 0.000 & 0.021 \\
\hline \multirow[t]{3}{*}{ ASC8 } & MSE & 0.082 & 6.402 \\
\hline & Variance/MSE & 0.998 & 0.978 \\
\hline & Bias square/MSE & 0.002 & 0.022 \\
\hline \multirow[t]{3}{*}{ ASC9 } & MSE & 0.085 & 6.325 \\
\hline & Variance/MSE & 1.000 & 0.992 \\
\hline & Bias square/MSE & 0.000 & 0.008 \\
\hline \multirow[t]{3}{*}{ Quality } & MSE & 0.082 & 0.295 \\
\hline & Variance/MSE & 0.996 & 0.360 \\
\hline & Bias square/MSE & 0.004 & 0.640 \\
\hline \multirow[t]{4}{*}{ Distance } & MSE & 0.080 & 0.320 \\
\hline & Variance/MSE & 0.996 & 0.290 \\
\hline & as square/MSE & 0.004 & 0.710 \\
\hline & MSE & 0.082 & 5.406 \\
\hline \multicolumn{2}{|c|}{ Average variance per MSE } & 0.996 & 0.867 \\
\hline \multicolumn{2}{|c|}{ Average bias square per MSE } & 0.004 & 0.133 \\
\hline
\end{tabular}


Table 2.7: Empirical Parameter Estimates of CL and IAL Models

\begin{tabular}{|c|c|c|c|c|c|}
\hline & IAL & $\mathrm{CL}$ & $\mathrm{CL}$ & $\mathrm{CL}$ & $\mathrm{CL}$ \\
\hline Distance cutoff (miles) & \multicolumn{2}{|c|}{100} & 200 & 300 & 400 \\
\hline \multicolumn{6}{|l|}{ Utility function } \\
\hline \multirow[t]{2}{*}{ Access to sites } & $1.029 * * *$ & $0.987 * * *$ & $1.412 * * *$ & $1.615^{* * *}$ & $1.636 * * *$ \\
\hline & $(0.116)$ & $(0.105)$ & $(0.103)$ & $(0.09)$ & $(0.106)$ \\
\hline \multirow[t]{2}{*}{ Catch (daily) } & $0.102 * * *$ & $0.133 * * *$ & $0.072 * * *$ & $0.037 * * *$ & $0.037 * * *$ \\
\hline & $(0.018)$ & $(0.015)$ & $(0.015)$ & $(0.013)$ & $(0.015)$ \\
\hline \multirow[t]{2}{*}{ River } & 0.074 & 0.020 & -0.055 & 0.096 & $1.176^{* * *}$ \\
\hline & $(0.102)$ & $(0.143)$ & $(0.096)$ & $(0.091)$ & $(0.147)$ \\
\hline \multirow[t]{2}{*}{ Distance to site (miles/100) } & $-32.960 * * *$ & $-36.477 * * *$ & $-28.288 * * *$ & $-22.551 * * *$ & $-22.030 * * *$ \\
\hline & $(1.737)$ & $(1.054)$ & $(1.270)$ & $(0.995)$ & $(1.038)$ \\
\hline \multirow[t]{2}{*}{$\tau$} & $123.400 * * *$ & & & & \\
\hline & $(37.816)$ & & & & \\
\hline \multirow[t]{2}{*}{$\mu$} & 10.028 & & & & \\
\hline & (294.18) & & & & \\
\hline \multicolumn{6}{|l|}{ Model performance } \\
\hline Loglikelihood value & -1697.1 & -1860.6 & -2499.5 & -2890.9 & -3023.6 \\
\hline AIC & 3406.2 & 3729.2 & 5007.0 & 5789.8 & 6055.2 \\
\hline
\end{tabular}

Notes: standard errors are in parentheses.

*** Statistically significant at $1 \%$ level 


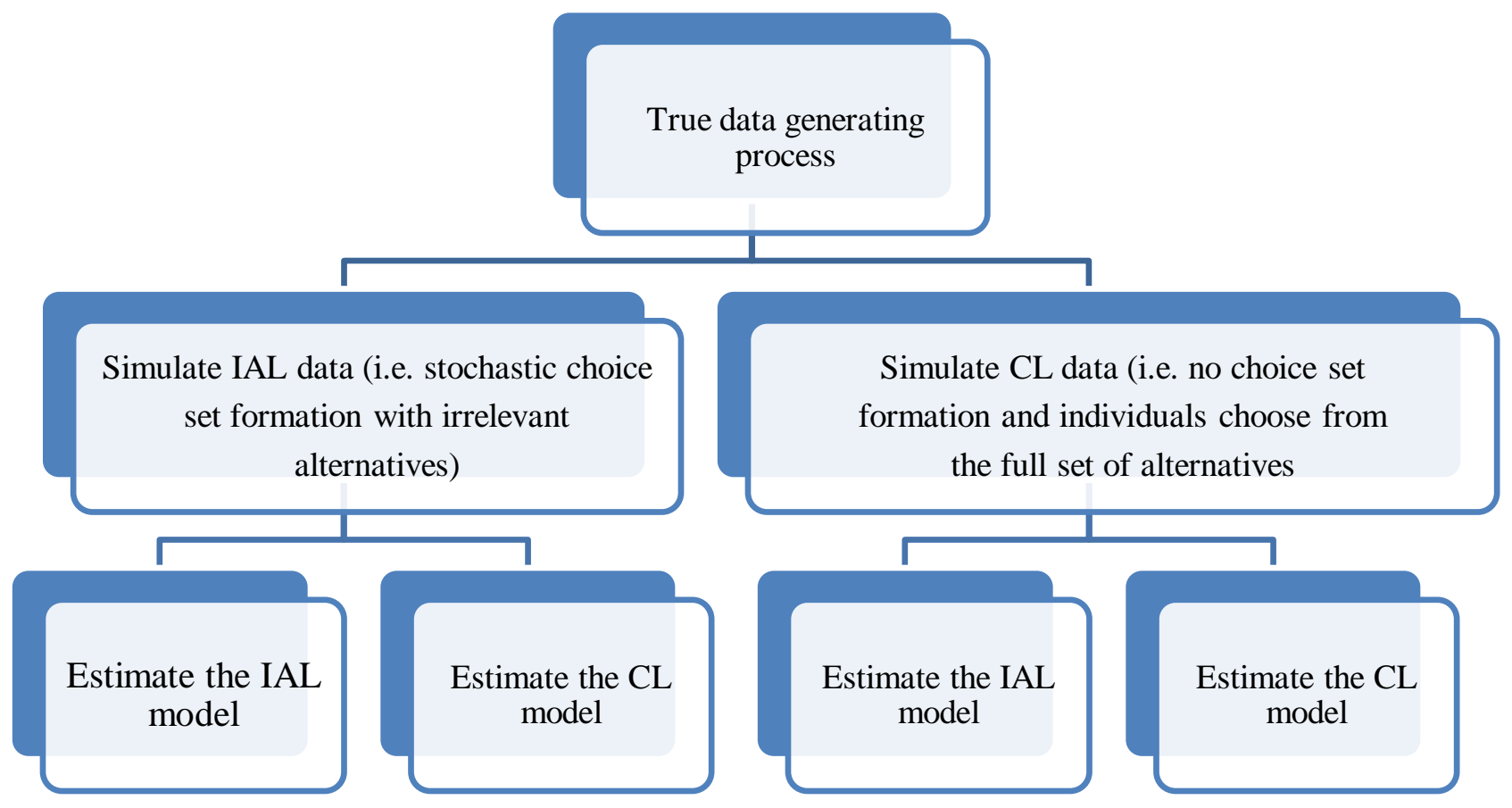

Figure 2.1: Modeling Strategy 


\title{
CHAPTER III
}

\section{BAYESIAN OPTIMAL DYNAMIC SAMPLING PROCEDURE FOR ON-FARM FIELD EXPERIMENTS}

\begin{abstract}
For many decades, researchers have relied on small-scale agronomic experiment stations to provide input management recommendations to agricultural producers. But such experiments have most often provided production functions with large standard errors in addition to the uncertainty about how well the estimates apply to different fields. To avoid such limitations, there has been a movement toward large-scale, on-farm field experiments. But questions remain as how best to conduct large-scale, on-farm field experiments and when it is most profitable to quit them. This research addresses these questions by using a fully Bayesian decision-theoretic approach. Data are from Monte Carlo simulations assuming a corn-input stochastic plateau production function from one field. When corn and $\mathrm{N}$ prices are $\$ 2.95 / \mathrm{bu}$. And $0.45 / \mathrm{lb}$, respectively, results suggest the best way to conduct such experiments is to use a 30-plot experimental design by allocating to each of the $10 \%$ of the plots, $0 \mathrm{lb}$. of $\mathrm{N}$, half of $\mathrm{N}^{*}$, and $150 \%$ of $\mathrm{N}^{*}$. Results further indicate that it is most profitable to quit such trials in year 2. Sensitivity analysis confirms the optimal quit period under similar designs but suggests such experiments are most profitable by allocating unalike $\mathrm{N}$ levels to all $30 \%$ of the experimental plots. Findings suggest designs used in large-scale, on-farm field trials should have $\mathrm{N}$ levels reduced in successive years as more information is gained.
\end{abstract}


Keywords: On-farm field experiments, Bayesian decision-theory, Monte Carlo simulation, Monte Carlo integration

JEL Codes: C11, C15, Q10

\section{Introduction}

On-farm agronomic experiments are a source of input management recommendations to agricultural producers. For many years, researchers have relied on experiments conducted on experiment stations in search of generally appropriate crop-input response functions (Bullock and Mieno 2017). The technology has been available in the U.S. and other countries to conduct on-farm field experiments. However, agronomic, economic, and statistical research on how to apply on-farm trial data is limited. In the past, and since the 1950s when Earl Heady conducted numerous field trials, the tendency has been to conduct agronomic experiments on small plots without taking advantage of using large-scale farm machinery. Conducting experiments on small plots is not only labor intensive, but also generates data not adequate for "big data statistical analyses" that would assure more statistical confidence. Such agronomic experiments have most often provided crop-yield response functions with large standard errors in addition to the uncertainty about how well the estimates apply to different fields and possibly different agricultural production methods (Rodriguez 2014; Bullock and Mieno 2017). Thus, despite a long history of surveys and scientific research, there is still substantial variation of the amount of nitrogen (N) recommended to agricultural producers to apply to their crops (Hossain et al. 2004).

To achieve a scenario where limitations from small-scale agronomic trials are avoided, there has been a movement toward large-scale, on-farm field trials - where a whole field is turned into an experiment. On-farm experiment research has gained popularity because it allows agricultural producers to test a variety of agronomic questions using their equipment and 
management practices on their own farm fields (Kyveryga, Mueller, and Mueller 2018). Wholefarm experiments are expected to generate huge amounts of data whose analyses and results could in the long run improve input management recommendations that farmers receive from small-scale field trials. Since the 1990s, large-scale, on-farm field trials have been conducted in the U.S. and Latin America to gather large amounts of data for analyses expected to improve scientific input recommendations to farmers. While using precision agricultural technology to run large-scale, on-farm field trials drops the cost of turning a whole field into a trial, the best way to conduct such experiments is not known. Bullock and Mieno (2017) report that a group of researchers conducting these trials in the U.S. and Latin America often vary $\mathrm{N}$ rates little for fear of lost yields while farmers are (or seem to be) reluctant to use check plots and replications. On the other hand, promoters of maximum return to $\mathrm{N}$ from Midwestern U.S. universities run strip trials for all of their whole-farm field experiments where they have zero yields (with zero inputs) but only experiment with a portion of the field (Bullock and Mieno 2017). Another way to conduct strip trials is where experimenters apply $\mathrm{N}$ along some strips but do not apply it on other strips. Thus, a simple but awkwardly difficult question that remains is - which way of conducting large-scale, on-farm field trials is most profitable moving forward?

Bullock and Mieno (2017) assess the value of information of conducting on-farm field trials. Their results suggest a potential profit boost exists by varying $\mathrm{N}$ rates little for large-scale, on-farm field trials relative to strip trials. But in their approach, Bullock and Mieno (2017) do not consider yearly random effects though they incorporate rainfall effects in Bullock and Mieno (2019). Including random effects could perhaps provide more realistic profit expectations for agricultural producers because such effects account for unknown events such as hail, weather, weed pressure and others (Tembo et al. 2008). The work by Bullock and Mieno (2017) is based 
on a single experimental design and neither does it clearly establish the better one nor determine the best way these experiments should be conducted to provide relevant findings.

Additionally, questions remain as what aspects of large-scale, on-farm field experiments an experimenter should change as more information is gained in subsequent years. Simply put, there is no consensus as to how the optimal experimental design of on-farm field trials should change as more information is added from preceding trials. The objective of this article is to determine if conducting large-scale, on-farm experiments is cost-effective, and if so, to determine the tradeoff between gaining information from using levels of $\mathrm{N}$ far from the optimum and the lost yield or wasted $\mathrm{N}$ from using nonoptimal levels of $\mathrm{N}$ across years. Specifically, I determine optimal profits using corn-input response functions from on-farm field trials where $\mathrm{N}$ rates are varied across four levels in different consecutive years. The four levels include: zero $\mathrm{N}$ rates on few plots for fear of lost yields, half optimal $\mathrm{N}$ rates are applied (optimal is based on current recommendations for continuous corn: see; Boyer et al. 2013), optimal N rates are allocated to plots, and $\mathrm{N}$ rates above the optimal levels are allocated to fewer portions of the field.

The choice of the functional form of the crop yield response function is key for modeling production decisions when $\mathrm{N}$ rates are varied in large-scale, on-farm field trials. It is reasonable that different functional forms of crop yield response would give dissimilar estimates in the case of variable $\mathrm{N}$ rates. Additionally, scientific research has yet to reach a consensus about a universal crop-input response function. While Bullock and Mieno (2013) assume a quadratic functional form of corn yield response function, a considerable share of literature supports the plateau-type plant yield response to N (e.g., Ackello-Ogutu, Paris, and Williams 1985; Cerrato and Blackmer 1990; Paris 1992; Llewelyn and Featherstone 1997; Babcock and Pautsch 1998). 
With the unrelenting criticisms by agronomists that crop yield potential is random, the univariate stochastic plateau model by Tembo et al. (2008) frequents the plateau-type literature and has therefore garnered wide applications in agricultural economics research measuring yield response to N (e.g., Tumusiime et al. 2011; Brorsen and Richter 2012; Boyer et al. 2013; Ouédraogo and Brorsen 2018; McFadden, Brorsen and Raun 2018; Dhaka et al. 2019). Thus, building on previous work by Bullock and Mieno (2013), the present study considers the stochastic plateau model by Tembo et al. (2008) as the underlying functional form.

Using simulated data, this study employs a fully Bayesian decision-theoretic approach to information gained from preceding trials. A fully Bayesian decision-theoretic approach is one in which the decision criterion is completely a function of the posterior distribution (Ryan et al. 2016). It is different than the classical framework where the decision is arrived at by averaging some classical criteria over the space that parameters occupy (Pronzato and Walter 1985; Ryan et al. 2016; Drovandi and Tran 2018). This article differs from Griffin et al. (2005), Bullock and Mieno (2017) and Bullock and Mieno (2019) because I model a stochastic plateau production with two random effects that typically characterize empirical agricultural production, in a fully Bayesian decision framework. This way, I am able to capture the value of field experimentation by using prior $\mathrm{N}$ recommendations in a given specific field, and update them as data from subsequent trials conducted from the same field are received. The approach used here is practically attractive because two single design years can be used to update the prior distribution and still arrive at valid inference.

A general framework of Bayesian decision theory is presented though the first step is to attempt to solve the problem analytically. But an analytical solution is not possible because of analytically intractable quantities from which I only derive first-order conditions. Thus, the 
solution must be found numerically. Several simplifying assumptions are made about the experimental plots, on which different levels of $\mathrm{N}$ are allocated, thereby providing more general results. Sensitivity analysis is conducted as a robustness check to different and plausible alternative experimental designs.

\section{Theoretical Model}

Conducting agronomic experiments is costly and time consuming. Thus, knowing the best way to conduct them could be crucial to providing value from such experiments. Determining optimal ways of conducting experiments is a decision problem for which previous research has attempted to find solutions using classical and Bayesian methodologies. Bayesian decision methodologies have dominated the literature (e.g., Han and Chaloner 2004; Muller et al. 2006; Ryan et al. 2014; Zhang et al. 2015) because establishing an optimal experiment is more often associated with nonlinear models for which classical approaches are not well suited (Ryan et al. 2016).

Following Lindley (1972), determining an optimal experiment involves defining a decision criterion $U(\boldsymbol{d}, \boldsymbol{\theta}, \boldsymbol{y})$ that captures the worth of deciding to conduct such an experiment that lies in a decision space $\boldsymbol{D}$ for a set of designed sampling locations $\boldsymbol{d}$, yielding data $\boldsymbol{y}$ with model parameters $\boldsymbol{\theta}$. In short, the solution to finding an optimal experiment can be found by maximizing the posterior expected utility over the decision space $\boldsymbol{D}$ with respect to future data $\boldsymbol{y}$ and model parameters shown below

$$
\operatorname{argmax}_{\mathbf{d} \in \mathbf{D}} E[U(\boldsymbol{d}, \boldsymbol{\theta}, \boldsymbol{y})]
$$

But the form of the utility function in equation (1) is mainly determined by the aims of the experiment. Thus, equation (1) incorporates a cost function (Overstall and Woods 2017). 
Because the aims of on-farm field trials are more inclined to producer theory, the framework above can be extended to production economic theory by making it an expected profit maximization problem. However, large-scale, on-farm field trials are conducted over a planning horizon $T$, which suggests that determining the best way to conduct them would have to encompass a time dimension. Usually, the aims of large-scale, on-farm field trials are to determine optimal input levels - input levels that would maximize profits for agricultural producers. But large-scale, on-farm field experiments can be conducted over a given planning horizon, $T$. This way, the objective function is no longer maximization of expected profit. The goal is finding optimal net present values (NPVs) of conducting experiments over $T$. This is because there would now be a flow of expected profit in successive years in which experiments are conducted. The overall objective for an experimenter would thus be a selection of optimal NPVs higher than others. Assuming the experimenter is risk-neutral, such a decision can be arrived using equation (2)

$$
\operatorname{argmax}_{\mathbf{d} \in \mathbf{D}} N P V=\operatorname{argmax}_{\mathbf{d} \in \mathbf{D}} \sum_{k=1}^{K} N P V_{k}
$$

where $\boldsymbol{d}$ is the number of plots on which nonoptimal levels of inputs are applied, NPV is the $k$ th NPV obtained from a series of NPVs, from which select only optimal NPVs are selected.

Individual NPVs of experiments can be computed by considering a flow of expected profits for every replication. Thus, a given NPV can be computed using equation (3)

$$
\begin{aligned}
& N P V=\sum_{t=1}^{T} \delta_{t}\left[P_{t} \times E\left(\boldsymbol{y}_{i t} \mid \boldsymbol{x}_{i t}, \boldsymbol{d}\right)-r_{t} \boldsymbol{x}_{i t}\right] \\
& \text { such that: } \boldsymbol{y}_{i t} \mid \boldsymbol{x}_{i t}, \boldsymbol{d}=g\left(\boldsymbol{x}_{i t} ; \boldsymbol{\theta}_{t}\right)+\boldsymbol{\varepsilon}_{i t}, \boldsymbol{x}_{i t} \geq 0
\end{aligned}
$$


where $\boldsymbol{y}_{i t} \mid \boldsymbol{x}_{i t}, \boldsymbol{d}=g\left(\boldsymbol{x}_{\boldsymbol{i} t} ; \boldsymbol{\theta}_{t}\right)+\boldsymbol{\varepsilon}_{i t}$ is the production function estimated for a specific field, $\boldsymbol{y}_{i t}$ denotes yield amounts from the $i$ th plot obtained in year $t, \boldsymbol{x}_{i t}$ are input levels from the $i$ th plot used in year $t, \boldsymbol{\theta}_{t}$ are parameters, $\delta_{t}=(1+r)^{-1}$ is the discount factor where $r$ is the interest rate representing the agricultural producer's opportunity cost of time, and $\boldsymbol{\varepsilon}_{i t}$ is a random error. First-order conditions from equation (3) are shown in equation (4). For each period from 1 through $t$ :

$$
\left\{\begin{array}{c}
\frac{\partial N P V}{\partial x_{i 1}}=\frac{\left[P_{1} \partial E\left(\boldsymbol{y}_{i 1} \mid \boldsymbol{x}_{i 1}, \boldsymbol{d}\right)\right]}{\partial x_{i 1}}-r_{1}=0 \\
\frac{\partial N P V}{\partial x_{i 2}}=\frac{\left[P_{2} \partial E\left(\boldsymbol{y}_{i 2} \mid \boldsymbol{x}_{i 2}, \boldsymbol{d}\right)\right]}{\partial x_{i 2}}-r_{2}=0 \\
\cdot \\
\cdot \\
\frac{\partial N P V}{\partial x_{i t}}=\frac{\left[P_{t} \partial E\left(\boldsymbol{y}_{i t} \mid \boldsymbol{x}_{i t}, \boldsymbol{d}\right)\right]}{\partial x_{i t}}-r_{t}=0
\end{array}\right\}
$$

which imply that in each year, the value of the posterior marginal product be equivalent to cost of the input. Value of posterior marginal product is the value of marginal product evaluated using posterior samples of the parameters.

Brorsen and Richter (2011) have shown that three different N levels are sufficient to identify a plateau. Here I select one of these points to be the current estimate of the optimal amount of inputs which should be determined. In order to maximize the value of information for conducting large-scale, on-farm field experiments - whose goal is to provide more and sufficient recommendations to agricultural producers, I use Bayesian decision theory techniques to recover a series profits in a given year. It is such profits that flow in a given year and contribute to individual NPVs. This implies that individual components of NPVs are computed by finding a solution to the following expected profit maximization problem 


$$
\operatorname{argmax}_{\mathbf{x}_{\mathrm{it}} \geq 0} \int_{\Theta} \pi_{t}\left[R_{t}\left(\boldsymbol{x}_{i t} \mid \boldsymbol{\theta}_{\boldsymbol{t}}\right)\right] p\left(\boldsymbol{\theta}_{\boldsymbol{t}} \mid \boldsymbol{x}_{i t}\right) d \boldsymbol{\theta}_{\boldsymbol{t}}
$$

where $\pi_{t}\left[R_{t}\left(\boldsymbol{x}_{i t} \mid \boldsymbol{\theta}_{t}\right)\right]$ is the profit function, $R_{t}$ is the agricultural producers' expected revenue or wealth, $\boldsymbol{\theta}_{\boldsymbol{t}}$ is a vector of relevant parameters, and $p\left(\boldsymbol{\theta}_{\boldsymbol{t}} \mid \boldsymbol{x}_{i t}\right)$ is the posterior distribution of $\boldsymbol{\theta}_{\boldsymbol{t}}$. The expected profit maximization problem in equation (5) has its first-order conditions. They are shown in equation (6) as

6)

$$
\left.\int_{\Theta} \pi_{t}^{\prime}\left[R_{t}\left(\boldsymbol{x}_{i t} \mid \boldsymbol{\theta}_{\boldsymbol{t}}\right)\right] R_{t}^{\prime}\left(\boldsymbol{x}_{i t} \mid \boldsymbol{\theta}_{\boldsymbol{t}}\right)\right] p\left(\boldsymbol{\theta}_{\boldsymbol{t}} \mid \boldsymbol{x}_{i t}\right) d \boldsymbol{\theta}_{\boldsymbol{t}}=0
$$

where $\pi_{t}^{\prime}\left[R_{t}\left(\boldsymbol{x}_{i t} \mid \boldsymbol{\theta}_{\boldsymbol{t}}\right)\right]$ is by the chain-rule the first derivative of the expected profit function, $\left.R_{t}^{\prime}\left(\boldsymbol{x}_{i t} \mid \boldsymbol{\theta}_{\boldsymbol{t}}\right)\right]$ is the first derivative of the actual profit function. Equation (6) is behavioral because it dictates optimal choices as a function of $\pi_{t}(),. R_{t}($.$) , and p\left(\boldsymbol{\theta}_{\boldsymbol{t}} \mid \boldsymbol{x}_{t}\right)$ reflecting the agricultural producers' expected, actual wealth or revenue motives, and associated risks, respectively. Equation (5) is at the heart of expected profit maximization problems but it faces a major hurdle: analytical solutions are quite difficult to derive especially for empirical estimation (Lindley 1972; Berger 2013; Ryan et al. 2016; Wu and Guan 2018). The posterior distributions in equations (5) and (6) are computed using Bayes' theorem as

$$
p\left(\boldsymbol{\theta}_{\boldsymbol{t}} \mid \boldsymbol{x}_{t}\right)=\frac{p\left(\boldsymbol{x}_{t} \mid \boldsymbol{\theta}_{\boldsymbol{t}}\right) p\left(\boldsymbol{\theta}_{\boldsymbol{t}}\right)}{p\left(\boldsymbol{x}_{t}\right)}
$$

where $p\left(\boldsymbol{\theta}_{\boldsymbol{t}}\right)$ is the prior distribution about parameters $\boldsymbol{\theta}_{\boldsymbol{t}}$ before collecting new data, $p\left(\boldsymbol{x}_{t} \mid \boldsymbol{\theta}_{\boldsymbol{t}}\right)$ is the likelihood, and $p\left(\boldsymbol{x}_{t}\right)$ is the marginal distribution or the evidence and can be regarded as a normalizing constant. In practice, due to the difficulty in computing the marginal distribution in equation (7), the posterior distribution is computed as 
where all components in equation (8) are as previously defined. Because of the reasons put forward for equation (5), alternative practical approaches exist that involve solving equation (4) directly. They involve numerical integration of quantities such as in equation (4). These methods include Gaussian or Gauss-Hermite quadrature, use of Simpson's rule, and Monte Carlo integration (Berger 2013). Under Bayesian decision theory, the solution to equation (4) can be found by evaluating the mean of the profit function evaluated at posterior draws of random parameters in the profit function. Suppose I generate an identically and independent distributed sequence of random variables $\left\{\theta_{1}, \theta_{2}, \theta_{3}, \ldots\right\}$, with a common posterior density $h\left(\boldsymbol{\theta}_{\boldsymbol{t}}\right)$ on $\boldsymbol{\Theta}$.

Then

$$
E\left[\frac{\left.\pi_{t}\left(\boldsymbol{x}_{\boldsymbol{i t}} \mid \boldsymbol{\theta}_{\boldsymbol{t}}\right)\right] p\left(\boldsymbol{\theta}_{\boldsymbol{t}} \mid \boldsymbol{x}_{\boldsymbol{i t}}\right)}{\boldsymbol{h}\left(\boldsymbol{\theta}_{\boldsymbol{t}}\right)}\right]=\int_{\Theta} E\left[\pi_{t}\left(\boldsymbol{x}_{i t} \mid \boldsymbol{\theta}_{\boldsymbol{t}}\right)\right] p\left(\boldsymbol{\theta}_{\boldsymbol{t}} \mid \boldsymbol{x}_{i t}\right) d \boldsymbol{\theta}_{\boldsymbol{t}}
$$

By the strong law of large numbers and under mild conditions (Berger 2013; Wackerly, Mendenhall, and Scheaffer 2014), it follows that

$$
\text { 10) } \lim _{n \rightarrow \infty} \frac{1}{n} \sum_{i=1}^{N}\left[\frac{\left.\pi_{t}\left(\boldsymbol{x}_{\boldsymbol{i t}} \mid \boldsymbol{\theta}_{\boldsymbol{i t}}\right)\right] p\left(\boldsymbol{\theta}_{\boldsymbol{i t}} \mid \boldsymbol{x}_{\boldsymbol{i t}}\right)}{\boldsymbol{h}\left(\boldsymbol{\theta}_{\boldsymbol{i t}}\right)}\right]=\int_{\Theta} E\left[\pi_{t}\left(\boldsymbol{x}_{i t} \mid \boldsymbol{\theta}_{\boldsymbol{t}}\right)\right] p\left(\boldsymbol{\theta}_{\boldsymbol{t}} \mid \boldsymbol{x}_{i t}\right) d \boldsymbol{\theta}_{\boldsymbol{t}}
$$

which can be used to approximate equation (4) as follows

$$
\cong \sum_{i=1}^{N} E \pi_{t}\left(\boldsymbol{x}_{i t} \mid \boldsymbol{\theta}_{i t}\right)
$$

where $\boldsymbol{\theta}_{\boldsymbol{i t}}$ is a vector of posterior estimates from an $i$ th draw.

\section{Data and Procedures}


Data used for this study are simulated to represent different ways in which large-scale, on-farm field experiments are conducted at a typical farmer's field. Because of the complexity of the problem and lack of actual data, there is no actual field data available for this study. This approach only allows four levels of nitrogen (N) to a corn (y) field. The four levels are (i) the optimal based on the current recommendations and distribution - $156 \mathrm{lb}$./acre (Boyer et al. 2013), (ii) half the optimal - 78 lb./acre, and (iii) zero N level, and (iv) a level substantially above the optimum - $256 \mathrm{lb} . / \mathrm{acre}$.

Boyer et al. (2013) compare the stochastic plateau production functions with their deterministic counterparts to determine the most appropriate response function for continuous corn and rotation of corn with other crops. They find the stochastic response function the more appropriate response function than its deterministic counterparts in all cases. Since our study's focus is on continuous corn, and assumes the stochastic plateau function as the appropriate functional form, I use $\mathrm{N}$ rates found in Boyer et al. (2013) to guide the design of my experiments. For the sake of brevity, the total number of plots assumed are 100. Thus, the choice variable is how many plots use levels (ii), (iii), and (iv) described above. For simplicity, I assume that levels (ii), (iii), and (iv) are equal - each is equal to 10 plots while level (i) is 70 . The response variable for corn is generated by Monte Carlo simulations using the stochastic plateau as the underlying data generating process for each round of replication. The procedure is illustrated in figure 1.

\section{\{Figure 3.1\}}


As mentioned before, posterior samples are used to determine the expected optimal $\mathrm{N}$ levels in the continuing period. The stochastic plateau crop response function (Tembo et al. 2008) is

$$
y_{i t}=\min \left(\beta_{0}+\beta_{1} N_{i t}, P_{t}+u_{t}\right)+s_{t}+\varepsilon_{i t}
$$

where $y_{i t}$ is corn yield from the $i$ th plot in year $t, \beta_{0}$ and $\beta_{1}$ are model parameters to be estimated, $N_{i t}$ is the amount of $\mathrm{N}$ applied on $i$ th plot in year $t, P_{t}$ is the plateau yield, $s_{t} \sim N\left(0, \sigma_{u}^{2}\right)$ is the plateau year random effect, $s_{t} \sim N\left(0, \sigma_{u}^{2}\right)$ is the intercept year random effect, $\varepsilon_{i t} \sim N\left(0, \sigma_{\varepsilon}^{2}\right)$ is the random error term assumed to be independent from the plateau year random effect, and intercept year random effect. Thus, equation (11) is the assumed functional form for the production presented in equation (3). This implies that a vector of parameters of interest is actually: $\boldsymbol{\theta}=\left(\beta_{\mathbf{0}}, \beta_{\mathbf{1}}, \boldsymbol{\sigma}_{\boldsymbol{u}}^{\mathbf{2}}, \boldsymbol{\sigma}_{\boldsymbol{s}}^{\mathbf{2}}, \boldsymbol{\sigma}_{\varepsilon}^{\mathbf{2}}\right)^{\prime}$. Following (Ouedraogo and Brorsen 2018), the Bayesian approach to providing the solution to equation (4) involves a maximization of equation (13)

$$
E\left(\pi_{t} \mid N_{i t}\right)=p\left[(1-\Phi)\left(\theta_{0}+\theta_{1} N_{i t}\right)+\Phi\left(P_{t}-\frac{\sigma_{u} \varphi}{\Phi}\right)\right]-r N_{i t}
$$

where $p$ is corn price, $r$ is price of $\left.N_{i t}, \varphi=\left[\varphi \theta_{0}+\theta_{1} N_{i t}-P_{t}\right) / \sigma_{u}\right]$ is the standard normal probability density function, and $\Phi=\Phi\left[\left(\theta_{0}+\theta_{1} N_{i t}-P_{t}\right) / \sigma_{u}\right.$ is the standard normal cumulative distribution. Thus, under Bayesian decision theory, equation (4) is evaluated as an optimization problem using Monte Carlo integration whereby using posterior samples in the preceding Bayesian estimation, the resulting value is obtained as the average (as illustrated in equation (10)). Once the optimal value of $\mathrm{N}$ is known in a given period, I use levels of $\mathrm{N}$ as well as prior information about the distribution of parameters in the Monte Carlo simulations to 
generate the values of corn, $y_{i t}$ to be used in the current period's Bayesian estimation. For brevity, the assumption of no spatial correlation between errors is retained. The true model assumed in all Monte Carlo simulations to generate corn levels is

$$
y_{i t} \sim \min \left(39.84+0.86 N_{i t}, 157.93+u_{t}\right)+s_{t}+\varepsilon_{i t}
$$

where $y_{i t}, N_{i t}$, and everything else is as defined in equation (11). Assuming corn price of 2.95/bu. And N price of $\$ 0.45 / \mathrm{lb}$, the true expected profit function is

$$
E\left(\pi_{t} \mid N_{i t}\right)=2.95 \times E\left(y_{i t}\right)-0.45 N_{i t}
$$

such that: $y_{i t} \sim \min \left(39.84+0.86 N_{i t}, 157.93+u_{t}\right)+s_{t}+\varepsilon_{i t}, N_{i t} \geq 0$

Once corn levels are generated, I estimate posterior means of the parameter vector $\boldsymbol{\theta}=$ $\left(\boldsymbol{\theta}_{0}, \boldsymbol{\theta}_{1}, \boldsymbol{\sigma}_{u}^{2}, \boldsymbol{\sigma}_{s}^{2}, \boldsymbol{\sigma}_{\varepsilon}^{2}\right)^{\prime}$ following Bayes' theorem by using Markov chain Monte Carlo (MCMC) methods. Because the distribution of $y_{i t}$ is conditional on both plateau year and intercept random effects, equation (8) is estimated in a Bayesian hierarchical framework. All simulations of data are conducted in $\mathrm{R}$ software while all Bayesian estimations are carried out using runjags, an $\mathrm{R}$ software package that utilizes JAGS - Just Another Gibbs Sampler (Denwood 2016; R Core Team 2018). The following informative priors were imposed in all the model estimations. The assumption is that these priors are not accurate or else there would not be any value in experimenting

$$
\begin{gathered}
y_{i t} \sim \min \left(\beta_{0}+\beta_{1} N_{i t}, P_{t}+u_{t}\right)+s_{t}+\varepsilon_{i t} \\
\beta_{0} \sim N(40,6.25), \quad \beta_{1} \sim N(1,0.0625), \\
\sigma_{u}^{2} \sim G(0.0025,2.500), \sigma_{s}^{2} \sim G(0.0025,2.500), \sigma_{\varepsilon}^{2} \sim G(0.00375,2)
\end{gathered}
$$


In each Bayesian estimation phase, the MCMC techniques that I employed involved two chains with a burn-in phase of 5,000 to enable the chains forget their initial regions, with the remaining iterations set at 20,000 per chain. I specifically use Gibbs Sampler because it is more efficient than Metropolis-Hastings especially that the latter generates potentially correlated sequences (Ntzoufras 2009; Ng'ombe and Boyer 2019). Autocorrelation and trace plots, and the Gelman-Rubin test of the remaining parts of each parameter's MCMC chains were used to check whether the chains converged successfully (Gelman and Rubin 1992; Gelman et al. 2013). Autocorrelation plots display the level of correlation between MCMC sequences while trace plots assess mixing of the chains. Additionally, the Gelman-Rubin test checks convergence of a parameter's Markov chain to its posterior distribution. In other words, the Gelman-Rubin test statistic checks whether parameter estimates are stationary, by comparing the within- and between-chain variation using equation (19)

$$
\hat{R}=\sqrt{\frac{W+\frac{1}{n}(B-W)}{W}}
$$

where $\hat{R}$ is the Gelman-Rubin test statistic - also known as the scale reduction statistic, $W$ is within-chain variance, $B$ is the variance between chains, and $n$ is the size of the post-burn-in MCMC samples. Gelman and Rubin's idea is that if $B \rightarrow W$, then $\widehat{R} \rightarrow 1$, which would be strong evidence that the Markov chains converged. In practice, $\widehat{R}$ should be estimated across all parameters until all their respective $\widehat{R}$ 's satisfy $\widehat{R}<1.10$ (Gelman and Rubin 1992, Gelman et al. 2013; Lambert 2018; Plastina and Lence 2019).

When to Quit Experimenting 
Following a Monte Carlo integration in which expected optimal $\mathrm{N}$ levels are determined, 10 plots are allocated zero of optimal $\mathrm{N}$ (expected profit maximizing level of $\mathrm{N}$, labelled $\mathrm{N}^{*}$ ), while half of $\mathrm{N}^{*}$ are allocated to 10 other plots, and $1.5 \times \mathrm{N}^{*}$ are allocated to other 10 plots while $\mathrm{N}^{*}$ is allocated to 70 plots. Based on this, corn levels are generated in a Monte Carlo simulation discussed above. A trivial example below illustrates this point. Consider a field trial conducted in year $k$ from which, a Monte Carlo integration using posterior samples from a preceding year's Bayesian estimation generates $\mathrm{N}^{*}$ to be $194.50 \mathrm{lb}$./acre. This implies that: $0 \mathrm{lb} . / \mathrm{acre}$ of $\mathrm{N}^{*}$ would be allocated to 10 plots, half of $\mathrm{N}^{*}=97.25 \mathrm{lb} . /$ acre would be allocated to other 10 plots, $1.5 \times \mathrm{N}^{*}=291.75 \mathrm{lb}$./acre would be allocated to other $10 \mathrm{plots}$, and $\mathrm{N}^{*}=194.50 \mathrm{lb}$./acre would be allocated to the remaining 70 plots.

As discussed above, corn levels would then be generated in a Monte Carlo simulation using the stochastic plateau function as the true data generating mechanism from which another Bayesian estimation to recover the true parameter vector is conducted. In this approach, a Bayesian estimation is conducted on a cumulative sample in every upcoming year so as to account for yearly random effects. For example, a Bayesian estimation for year 2 has 300 observations generated by appending each 100 observations from year 0,1 , and 2 . This practice was maintained up to year 10. However, once corn levels are generated, actual profit is computed using 100 observations using corn and $\mathrm{N}$ levels from that particular year. It is assumed that corn and $\mathrm{N}$ prices are $\$ 2.95$ per bushel (bu.) and 0.45 per pound (lb.), respectively. The actual cash flows for each year are discounted to year 1 and then used to compute the actual NPV for that year. 
But there is another corn that is vital at determining when to quit experimenting - called "corn-quit". Corn-quit is the expected yield at a given year's optimal $\mathrm{N}^{*}$. If the experiment is quit in year $k$, corn-quit is the amount of corn simulated based on $\mathrm{N}_{k}^{*}$ in year $k+1$ through year 10 . Using the previous example of year $k^{\prime} \mathrm{s} \mathrm{N}^{*}$ being $194.5 \mathrm{lb} . / \mathrm{acre}$, it means that corn-quit for years $k+1$ through 10 would be corn simulated at $\mathrm{N}_{k}^{*}=194.5$ by considering only plateau's random effects. This is plausible because once the experiment is quit in year $k$, the recommendation would be that agricultural producers use $\mathrm{N}_{k}^{*}$ in future years. Using corn-quit, another cash flow is computed named "quit-profit". Since it would be a series of profit flows from the year the experiment is quit to year 10, quit-profit is used to compute another component of NPV, I called "quit-NPValue".

All these procedures for each year are conducted 250 times. Thus, to determine the optimal period to quit experimenting, another quantity I called "Mean Quit-NPV" (MQNPV) is computed using equation (24)

$$
M Q N P V_{k}=\text { Mean Actual NPV }{ }_{k}+\left(\text { Mean Quit }-N P \text { Value }_{k}\right)
$$

where Mean Actual $N P V_{k}$ is the average actual NPV for year $k$ from 250 replications, and Mean Quit - NPValue ${ }_{k}$ is the average NPV from 250 replications if the experiment is quit in year $k$. Mean Quit - NPValue ${ }_{k}$ is computed based on quit profit alone. I also compute the cost of experimentation to determine the additional average cost of an experiment. The $k$ th year's cost of experimentation is computed using equation (25)

25) Cost of experimentation $\left.k_{k}={\text { Mean Actual } N P V_{k}-\left(\text { Mean }_{\text {Quit }}-N P V a l u e_{k-1}\right.}\right)$ 
where Mean Actual $N P V_{k}$ is the average actual NPV for year $k$ from 250 replications, and Mean Quit - NPValue ${ }_{k-1}$ is the average NPV from 250 replications if the experiment is quit in the immediate year preceding the $k$ th year. An interest rate of $6 \%$ is assumed in all NPV computations. A summary of scenarios considered in the sensitivity analysis is shown in table 3.1.

\{Table 3.1\}

\section{Results}

Diagnostics and Model Results

Because I estimated stochastic plateau functions for 250 times for each year, a snapshot of model results for the ninth year (out of preference) are presented in table 3.2.

\section{\{Table 3.2\}}

The last column in table 3.2, presents Gelman-Rubin test statistics for each parameter in the production function. The Gelman-Rubin test statistics for all parameters are smaller than 1.1, providing strong evidence that my chains converged successfully. A check on the $250^{\text {th }}$ estimation results for the slope parameter using trace and autocorrelation plots shown in figure 3.2 also suggests MCMC sequences mixed well, which is in agreement with the Gelman-Rubin test statistics. I only show autocorrelation and trace plots for the slope's posterior mean to conserve space.

\section{\{Figure 3.2\}}

The posterior medians in table 3.2 show that the posterior median estimate for the intercept term is $40.815 \mathrm{bu}$./acre, which is close to the true value of $39.84 \mathrm{bu}$./acre. The posterior 
median for the slope is 0.916 which is also close to the true value of 0.860 . The slope value implies that an additional pound of nitrogen would result in 0.916 bushels per acre with $95 \%$ probability, when other factors are held fixed. The expected posterior plateau yield is 167.313 bushels of corn per acre, a value which is also close to the true one. Variance terms of the plateau year random effect, intercept random effects, and error terms are also on average close to their true values. All of these estimates are statistically significant since the credible intervals do not span zero. I also report Monte Carlo standard errors for the $250^{\text {th }}$ estimation for all parameter estimates for year 9. They are presented in table 3.3. Results in table 3.3 indicate relatively low error from Monte Carlo methods employed because the average Monte Carlo standard error is around $0.018 \%$ which is less than $5 \%$, the standard rate at which one would have to get concerned (Denwood 2016).

\section{\{Table 3.3\}}

\section{Optimal Rates}

Based on the main experimental design with 30 plots with each of the 10 plots allocated zero N, half of $\mathrm{N}^{*}$, and $1.5 \times \mathrm{N}^{*}$, figure 3 shows average optimal $\mathrm{N}$ levels from years 0 through 10 . As can be seen, both year 0 and 1 have the same expected optimal level of $\mathrm{N}$ (i.e., 208.741 lb./acre). I use the same level of $\mathrm{N}^{*}$ in both years since I do not have any posterior samples yet to determine the new $\mathrm{N}^{*}$. However, this changes in year 1 when I have 200 observations with varying random effects associated with year 0 and 1. Thus, after a Bayesian estimation in year 1, new $\mathrm{N}^{*}$ is generated for year 2 using posterior samples from year 1. From year 2 onwards, average optimal $\mathrm{N}$ levels decline substantially to $169.991 \mathrm{lb}$./acre and $167.256 \mathrm{lb}$./acre in years 9 and 10 , respectively. In terms of variability, the $95 \%$ confidence interval of average $\mathrm{N}$ estimates are narrower as more information is gained over time. Average optimal $\mathrm{N}$ rates decline further. 
In short, the estimates become more precise. This suggests that as experiments are conducted successively over the years, the expected optimal levels of $\mathrm{N}$ become less variable. In particular, the experimental design also changes because lower levels of $\mathrm{N}^{*}$ are attained which then changes allocations to other 30 plots in subsequent years.

\section{\{Figure 3.3\}}

Notice that the original experimental design keeps on being updated and therefore changes each year. For example, each year has a different level of $\mathrm{N}^{*}$ and other $\mathrm{N}$ levels depend on $\mathrm{N}^{*}$ in that specific year. That is in year 10 , the final experimental design would be 10 plots with 0 lb./acre allocated, 10 plots with $83.627 \mathrm{lb}$./acre, 10 plots with $250.883 \mathrm{lb}$./acre and 70 plots with $167.256 \mathrm{lb}$./acre. A clearer illustration of the changes in $\mathrm{N}^{*}$ besides figure 3 is shown in table 3.4. Table 3.4 presents the expected profit maximizing $\mathrm{N}$, corn-quit, quit-profit, actual profit and the expected cost of experimenting across years. The average corn-quit is around 156 bu./acre across the years while the average quit-profit is between $\$ 369.70$ and $\$ 385.96 /$ acre .

\section{\{Table 3.4\}}

Average actual profit realized for every field trial would be around \$340/acre while the average cost of experimentation would be the lowest in year 2. After year 2, the average cost of experimentation would be higher across the years suggesting that the optimal year to quit experimentation would be year 2. This finding corroborates the results in figure 3.4. Figure 3.4 shows a plot of MQNPV across time. As shown in figure 3.4, the optimal time to quit conducting on-farm field trials is year 2 - the year with the highest MQNPV of $\$ 2,703.99 /$ acre relative to other years. This value implies that, other things held fixed, the value of returns in the next 8 years if conducting field experiments for continuous corn is quit in year 2 would be $\$ 2,703.99 /$ acre. This is the most that would be realized relative to quitting experimentation in 
other years. Thus, for a rational experimenter, it would be most profitable to quit on-farm field trials in year 2. After year 2, MQNPVs decline, which suggests that quitting experiments in later years would be less profitable, ceteris paribus.

\section{\{Figure 3.4\}}

The MQNPV findings indicate that the best sampling procedure to conduct on-farm field trials is one that involves varying different levels of $\mathrm{N}$ on $30 \%$ of the plots by equally distributing the number of plots without $\mathrm{N}$, half $\mathrm{N}^{*}$, and $1.5 \times \mathrm{N}^{*}$. While these results are plausible in the given context, checking how robust they are, is of utmost importance for relevant practical implications. This is because these results may largely depend on their basic parameter values and assumptions. Thus, as explained before, a sensitivity analysis over a wider range of potential scenarios was conducted.

\section{Sensitivity Analysis}

Moving away from the context discussed above, next I discuss results from sensitivity analysis. Since I have twelve experimental designs presented in table 3.1, throughout the next discussion, I have named them based on the total number of experimental plots allocated with varying $\mathrm{N}$ levels out of a total of 100. An illustration makes this clearer: Results presented above focus on the design with 10 plots, each allocated with 0 of $\mathrm{N}^{*}$, half of $\mathrm{N}^{*}$, and $1.5 \times \mathrm{N}^{* 2}$ while 70 plots were allocated with $\mathrm{N}^{*}$. From now onwards in the present study, without loss of generality, such a design is called a 30-plot design, the same classification is extended to other procedures. Table 3.5 presents sensitivity analysis results for 24 -plot ( 8 plots each with $0 \mathrm{~N}, 0.5 \mathrm{~N}^{*}$, and $\left.1.5 \mathrm{~N}^{*}\right), 18$-plot (6 plots each with $0 \mathrm{~N}, 0.5 \mathrm{~N}^{*}$, and $\left.1.5 \mathrm{~N}^{*}\right), 12$-plot (4 plots each with $0 \mathrm{~N}, 0.5 \mathrm{~N}^{*}$,

\footnotetext{
${ }^{2}$ I will drop the multiplication sign from now onwards for simplicity. Thus, instead of $1.5 \times \mathrm{N}^{*}$, I will use $1.5 \mathrm{~N}^{*}$.
} 
and $1.5 \mathrm{~N}^{*}$ ), 6-plot (2 plots each with $0 \mathrm{~N}, 0.5 \mathrm{~N}^{*}$, and 1.5N*), 10-plot-new (10 plots each with $0.5 \mathrm{~N}^{*}, 0.75 \mathrm{~N}^{*}$, and $1.25 \mathrm{~N}^{*}$ ), and 12 -plot-new (4 plots each with $0.5 \mathrm{~N}^{*}, 0.75 \mathrm{~N}^{*}$, and $1.25 \mathrm{~N}^{*}$ ) designs. Results show that despite the change in the number of plots allocated to experiments, average profit maximizing $\mathrm{N}$ and corn-quit levels do not differ considerably from results associated with a 30-plot experimental design. Even over the years, profit maximizing mean $\mathrm{N}$ levels converge to $167 \mathrm{lb} . /$ acre while their standard errors become smaller and smaller, as indicated by narrower confidence intervals.

\{Table 3.5\}

While even average actual and quit-profit behave likewise, the average cost of experimentation declines as the number of plots allocated to experiments declines. Based on table 3.5 and among all designs that are based on $0 \mathrm{~N}$, half of $\mathrm{N}^{*}$, and $1.5 \mathrm{~N}^{*}$, a 6 -plot experimental design would have least costs of experimentation (about \$1.97/acre). This occurs in year 3. For a 6-plot experimental design, unlike other designs, the optimal year to quit experimenting would be year 6 because it is associated with the highest MQNPV (i.e., $\$ 2,757.2 / a c r e)$. MQNPVs for these designs are shown in figure 3.5. Consistent with the 30-plotnew experimental design, MQNPV and average costs of experimentation results from the 12plot, 18-plot, and 24-plot experimental designs suggest that the optimal quit period for experimentation is year 2, a finding that is consistent with the 30-plot sampling procedure.

\section{\{Figure 3.5\}}

In general, assuming corn and $\mathrm{N}$ prices of $\$ 2.95 / \mathrm{bu}$. And $\$ 0.45 / \mathrm{lb}$, the best experimental design is a 12-plot-new experimental design because it is associated with a higher MQNPV (i.e., $\$ 2,781.5 /$ acre) than the rest. When I include 30-plot-new and 12-plot-new experimental designs into analysis, a 12-plot-new would be the most profitable sampling procedure with MQNPV of 
$\$ 2,782.9 /$ acre. This is closely followed by a 30-plot-new design whose MQNPV value is

$\$ 2,781.5 /$ acre. As defined before, in a 30-plot-new or 12-plot-new design, not even a single plot is allocated with zero $\mathrm{N}$, but rather $\mathrm{N}$ levels are varied substantially, that is $0.5 \mathrm{~N}^{*}, 0.75 \mathrm{~N}^{*}$, and $1.25 \mathrm{~N}^{*}$. This means that there are no corn plants or seedlings subjected to zero $\mathrm{N}$ in a field under these experimental designs, when other factors are held fixed. Even excess $\mathrm{N}$ levels that are applied $\left(1.25 \mathrm{~N}^{*}\right)$ are less than the excess $\mathrm{N}\left(1.5 \mathrm{~N}^{*}\right)$ in other procedures. That is, plot-new designs involve $16.67 \%$ lower excess $\mathrm{N}$ than the other designs considered here. I attribute these reasons to why both the 30-plot-new and 12-plot-new designs would be more profitable than other designs. Consistent with each other, but fundamentally different from other designs, their most profitable quit period is year 6 .

Random changes in economic conditions affect both corn and input prices. I therefore consider such stochastic economic behavior by adjusting corn and $\mathrm{N}$ prices as part of sensitivity analysis. I consider 30-plot and 12-plot experimental designs under three scenarios: when both corn and $\mathrm{N}$ prices double, when corn price alone doubles, and when $\mathrm{N}$ price alone doubles. Table 3.6 shows sensitivity analysis results for respective designs when corn and $\mathrm{N}$ prices double (i.e., corn price is $\$ 5.90 / \mathrm{bu}$. And N price is $\$ 0.90 / \mathrm{lb}$.).

\section{\{Table 3.6\}}

Results in table 3.6 suggest expected profit maximizing $\mathrm{N}$ and average corn-quit do not deviate from the main results presented for a 30-plot design at initial corn and $\mathrm{N}$ prices. Only monetary variables such as average quit-profit, actual profit, and cost of experimentation increase by $100 \%$. This implies that both corn-quit supply and $\mathrm{N}$ demand functions are consistent with economic theory of being homogenous of degree zero in output and input prices. Similarly, the profit functions are homogenous of degree 1 in input and output prices (Jehle and Reny 2001, 
Mas-Colell, Whinston, and Green 1995) since doubling corn-quit and N prices results in average optimal quit-profit, actual profit, and cost of experimentation to double as well. Average cornquit is around 156 bu./acre across the years while the average quit-profit is between $\$ 739.41$ and $\$ 773.64 /$ acre. In both cases, the average cost of experimentation is the lowest in year 2 while it is higher in later years, which agrees with MQNPVs (shown in figure 3.6) for both experimental designs.

\section{\{Figure 3.6\}}

A closer look at figure 3.6 suggests that if prices of both corn and $\mathrm{N}$ double (i.e., $\$ 5.90 / \mathrm{bu}$. And 0.90/lb., respectively), a 12-plot experimental design would be more profitable than a 30-plot design because it would have a higher MQNPV ( $\$ 5,483.90 /$ acre) than the latter $(\$ 5,407.30 /$ acre) . This is possibly because the 12-plot design would result in lower yield losses from the 4 plots without $\mathrm{N}$. Also, smaller $\mathrm{N}$ levels would be used excessively under a 12-plot design because only $1.25 \mathrm{~N} *$ is allocated to 4 plots while 10 plots are allocated $1.5 \mathrm{~N} *(16.67 \%$ more of excess $\mathrm{N})$ under the 30-plot design. These results are consistent with the 30-plot experimental design by quit period and not by magnitude of their MQNPVs because of different price regimes in which they are considered. Table 3.7 shows sensitivity analysis results when the price of either corn or $\mathrm{N}$ doubles, holding the other's constant.

\section{\{Table 3.7\}}

As expected, average-corn-quit levels do not substantially differ from the main 30-plot experimental design. However, when corn price doubles holding $\mathrm{N}$ price constant, profit maximizing levels of $\mathrm{N}$, average corn-quit levels increase by less than $100 \%$. The average cost of experimentation is generally lower under a 12-plot experimental design than a 30-plot design 
perhaps because of the fewer experimental units under the 12-plot design. The MQNPVs for both designs are shown in figure 3.7.

\section{\{Figure 3.7\}}

Results suggest that a 12-plot experimental design would be more profitable (with MQNPV of $\$ 6,053.40 /$ acre) than a 30-plot experimental design whose MQNPV is $\$ 5,972.70 /$ acre. Results also indicate that under both designs, it would be more profitable to quit experimentation in year 2, a finding which is consistent with the 30-plot sampling procedure.

When only the price of $\mathrm{N}$ is doubled (shown in the last panel of table 3.7), average profit maximizing $\mathrm{N}$ levels substantially decline from 175.50 per $\mathrm{lb}$. in year 1 to around $150 \mathrm{lb}$./acre. Additionally, corn-quit levels for both 30-plot and 12-plot designs average around 154bu./acre while average actual and quit-profit decline by less than $100 \%$, which is consistent with economic theory that the profit function is decreasing in input prices. As before, under other designs considered previously, the average cost of experimentation is lower under a 12-plot design than under a 30-plot design. In terms of their MQNPVs (shown in figure 3.8), I find that a 12-plot experimental design would be a better procedure than a 30-plot design since it has a higher MQNPV (i.e., \$2,250.70/acre) than that of a 30-plot experimental design whose MQNPV is $\$ 2,217.9 /$ acre. In terms of the optimal quit period, results still suggest both designs would be most profitable if they are quit in year 2, a result that is also consistent with those found when a 30-plot experimental design was investigated at initial prices.

\section{\{Figure 3.8\}}

\section{Conclusions}

Agronomic experiments have been a source of input management recommendations to both researchers and agricultural producers for many years. While such technology has been present in 
in the U.S. and other countries across the world, agronomic experiments have largely been conducted on small plots without taking advantage of using large-scale farm machinery. Consequently, this has led to among other things, continuous search for appropriate crop input response functions, some of which are associated with large standard errors and uncertainty (Rodriguez 2014; Bullock and Mieno 2017). To avoid these drawbacks, a movement toward conducting large-scale, on-farm field experiments is underway. Such experiments are expected to be adequate for "big data statistical analyses" which could lead to improved input management recommendations for agricultural producers in the long-run. But the best way to conduct such experiments is yet to be known. This article attempts to address this gap.

Assuming a stochastic plateau production function from one field, this article employs a fully Bayesian decision-theoretic approach to determine an optimal experimental design for largescale, on-farm field trials. Data are from Monte Carlo simulations. The analysis spans over 10 years of experimentation with 250 replications. The main experimental design assumed is a $30-$ plot experimental design with each 10 plots allocated zero $\mathrm{N}$, half optimal $\mathrm{N}\left(\mathrm{N}^{*}=156 \mathrm{lb} . / \mathrm{acre}\right)$, $150 \%$ of $\mathrm{N}^{*}$, and the 70 plots are allocated with $\mathrm{N}^{*}$, which is computed sequentially. This procedure differs from previous related research (e.g., Bullock and Mieno 2013) that focus on determining the value of information from large-scale, on-farm experiments without explicitly accounting for the effect of year random and corn plateau random effects. My approach is theoretically sound and can be easily extended to other theoretical and applied economics settings.

Results indicate that when corn price is $\$ 2.95 / \mathrm{bu}$. And $\mathrm{N}$ costs $\$ 0.45 / \mathrm{lb}$., the best experimental design for conducting large-scale, on-farm field experiments for continuous corn is varying $30 \%$ of the plots, by equally distributing the number of plots with zero N, $96.882 \mathrm{lb}$./acre, 
and with $290.64 \mathrm{lb}$./acre with the rest of the plots allocated the optimal level of $\mathrm{N}=193.76 \mathrm{lb}$./acre. These results would be obtained by beginning in year 1 to conduct such experiments with a 30plot experimental design consisting of 10 plots without $\mathrm{N}, 10$ plots with half $\mathrm{N}^{*}$ of $156 \mathrm{lb}$./acre, 10 plots with $1.5 \times \mathrm{N}^{*}$ (i.e., $234 \mathrm{lb} . / \mathrm{acre}$ ), and the rest 70 plots allocated with $156 \mathrm{lb}$./acre. I find that the best way to quit these trials would be in year 2 - when the Mean Quit-Net Present Value (MQNPV) of conducting these experiments is maximum. But these results may change as shown in sensitivity analysis.

Sensitivity analyses indicate that the profitability of an experimental design for large-scale, on-farm field experiments depends on how many plots receive variable N. Experimental designs with less than 30 plots upon which $\mathrm{N}$ is varied would be more profitable than the main 30-plot experimental design considered here. For example, other factors held constant, I find a 6-plot experimental design to be the best design among those that consider zero $\mathrm{N}$ levels, half of $\mathrm{N}^{*}$, and $1.5 \mathrm{~N}^{*}$ to be allocated equally to experimental plots. On average, the optimal quit period for such designs was found to be year 2 though a 6-plot experimental design would be best quit in year 6 the only finding different than those from a 30-plot experimental design. The reason put forward is that plots under a 6-plot experimental design would be subjected to lower loss of both yield and $\mathrm{N}$ than those with more than 6 plots subjected to experimentation in similar conditions.

But results discussed above are amenable to change once I consider designs that do not allocate zero $\mathrm{N}$ to field plots. For example, sensitivity analysis further shows that a 12-plot-new experimental design would be most profitable among all the sampling procedures considered in this article. A 12 -plot-new design is the only design that allows allocation of $0.5 \mathrm{~N}^{*}$ to 4 plots, $0.75 \mathrm{~N}^{*}$ to 4 plots, and $1.25 \mathrm{~N}^{*}$ to other 4 plots - which is different than the rest of the designs 
discussed above. Plausibly, a 12-plot-new sampling procedure performed better than other procedures because it would avoid substantial loss of both $\mathrm{N}$ and yield since each plot is allocated non-zero $\mathrm{N}$ compared to other previously discussed designs. Even the optimal quit period under the 12-plot-new design changes to 6 years, which is different from the optimal quit period associated with other designs with the exception of the 30-plot-new experimental design. Thus, the optimal period to quit experimenting basically depends on the experimental design chosen.

Doubling both corn and N prices showed that between a 12-plot and 30-plot experimental designs, a 12-plot design would be more profitable and that both corn-quit supply and $\mathrm{N}$ demand functions are homogenous of degree zero in corn and $\mathrm{N}$ prices. A $100 \%$ increase in either corn or $\mathrm{N}$ price still suggests a 12-plot experimental design would be more profitable than a 30-plot design. This provides further evidence that conducting field experiments on fewer plots is more profitable than otherwise. The idea holds true even when either the input or output prices change. In terms of when it is most profitable to quit experimenting, both the 12-plot and 30-plot designs would be most profitably quit in year 2 even when either corn or $\mathrm{N}$ price or both prices change. This implies that possible changes in input and output prices barely affect the optimal quit period of experimenting while the question as to when it is most profitable to quit experimenting depends on the design of the experiment one chooses

The finding that the optimal period to quit experimentation does not depend on the number of plots does not agree with Bullock and Mieno (2013) who find that the optimal length of onfarm experiments decreases with field size. This could be because Bullock and Mieno (2013) and the present study employ completely divergent assumptions and methods. Findings from both main and sensitivity analyses have consistently shown that large-scale, on-farm field trials are best conducted by varying $\mathrm{N}$, but only over a small number of plots. That is, they are more profitable 
when conducted using experimental designs with fewer number of plots upon which $\mathrm{N}$ levels are varied than otherwise. One other important finding consistent in the estimations is that the profit maximizing $\mathrm{N}$ levels decline in subsequent years while optimal profits remain afloat. This suggests that as more information is gained in successive years of experimentation, experimenters would have to reduce $\mathrm{N}$ levels in subsequent years while still being able to realize similar profit levels as before.

While I recognize the caveat in assuming the same stochastic plateau production function without considering spatial correlation between errors, this study makes a novel contribution by being the first to employ these rigorous techniques that have received little attention in agricultural economics research. Employing spatial correlation between errors in these methods is a significant challenge for future research. 
Table 3.1: Experimental Designs Used in Sensitivity Analyses

\begin{tabular}{|c|c|c|c|c|c|c|}
\hline Design & Price of corn $\$ / \mathrm{bu}$. & Price of $\mathrm{N} \$ / \mathrm{lb}$. & & Levels of $\mathrm{N}$ & /acre) & \\
\hline 1 & 5.90 & 0.90 & 10 plots with zero of $\mathrm{N}^{*}$ & 10 plots with half $\mathrm{N}^{*}$ & 10 plots with $1.5 \times \mathrm{N}^{*}$ & 70 plots with $\mathrm{N}^{*}$ \\
\hline 2 & 5.90 & 0.90 & 4 plots with zero of $\mathrm{N}^{*}$ & 4 plots with half $\mathrm{N}^{*}$ & 4 plots with $1.50 \times \mathrm{N}^{*}$ & 88 plots with $\mathrm{N}^{*}$ \\
\hline 3 & 2.95 & 0.45 & 8 plots with zero of $\mathrm{N}^{*}$ & 8 plots with half $\mathrm{N}^{*}$ & 8 plots with $1.5 \times \mathrm{N}^{*}$ & 76 plots with $\mathrm{N}^{*}$ \\
\hline 4 & 2.95 & 0.45 & 6 plots with zero of $\mathrm{N}^{*}$ & 6 plots with half $\mathrm{N}^{*}$ & 6 plots with $1.5 \times \mathrm{N}^{*}$ & 82 plots with $\mathrm{N}^{*}$ \\
\hline 5 & 2.95 & 0.45 & 4 plots with zero of $\mathrm{N}^{*}$ & 4 plots with half $\mathrm{N}^{*}$ & 4 plots with $1.5 \times \mathrm{N}^{*}$ & 88 plots with $\mathrm{N}^{*}$ \\
\hline 6 & 2.95 & 0.45 & 2 plots with zero of $\mathrm{N}^{*}$ & 2 plots with half $\mathrm{N}^{*}$ & 2 plots with $1.5 \times \mathrm{N}^{*}$ & 94 plots with $\mathrm{N}^{*}$ \\
\hline 7 & 2.95 & 0.45 & 10 plots with 0.75 of $\mathrm{N}^{*}$ & 10 plots with half $\mathrm{N}^{*}$ & 10 plots with $1.25 \times \mathrm{N}^{*}$ & 70 plots with $\mathrm{N}^{*}$ \\
\hline 8 & 2.95 & 0.45 & 4 plots with 0.75 of $\mathrm{N}^{*}$ & 4 plots with half $\mathrm{N}^{*}$ & 4 plots with $1.25 \times \mathrm{N}^{*}$ & 88 plots with $\mathrm{N}^{*}$ \\
\hline 9 & 2.95 & 0.90 & 10 plots with zero of $\mathrm{N}^{*}$ & 10 plots with half $\mathrm{N}^{*}$ & 10 plots with $1.5 \times \mathrm{N}^{*}$ & 70 plots with $\mathrm{N}^{*}$ \\
\hline 10 & 2.95 & 0.90 & 4 plots with zero of $\mathrm{N}^{*}$ & 4 plots with half $\mathrm{N}^{*}$ & 4 plots with $1.50 \times \mathrm{N}^{*}$ & 88 plots with $\mathrm{N}^{*}$ \\
\hline 11 & 5.90 & 0.45 & 10 plots with zero of $\mathrm{N}^{*}$ & 10 plots with half $\mathrm{N}^{*}$ & 10 plots with $1.5 \times \mathrm{N}^{*}$ & 70 plots with $\mathrm{N}^{*}$ \\
\hline 12 & 5.90 & 0.45 & 4 plots with zero of $N^{*}$ & 4 plots with half $\mathrm{N}^{*}$ & 4 plots with $1.50 \times \mathrm{N}^{*}$ & 88 plots with $\mathrm{N}^{*}$ \\
\hline
\end{tabular}


Table 3.2: Bayesian Parameter Estimates of the Stochastic Plateau Corn Yield Response

\begin{tabular}{lccccc} 
& True & Median & SD & \multicolumn{2}{c}{ 95\% Credible Interval } \\
\hline Intercept & 39.84 & 40.815 & 1.686 & 37.563 & 44.137 \\
Slope & 0.86 & 0.916 & 0.020 & 0.876 & 0.954 \\
Plateau & 157.93 & 167.313 & 8.062 & 150.501 & 182.399 \\
Variance of plateau & 625 & 526.315 & 934.579 & 236.6136 & 2714.072 \\
Variance of year random effect & 100 & 25.641 & 14.084 & 6.613 & 300.080 \\
Variance of the error term & 289 & 300.947 & 6678.028 & 276.176 & 329.435 \\
\hline
\end{tabular}


Table 3.3: Monte Carlo Standard Errors

\begin{tabular}{lcc}
\hline & MCSE & MCSE/SD (\%) \\
\hline Intercept & 0.027 & 1.600 \\
Slope & 0.000 & 1.600 \\
Plateau & 0.080 & 10.000 \\
Variance of plateau & 0.000 & 2.000 \\
Variance of the year random effect & 0.001 & 1.700 \\
Variance of the error term & 0.000 & 0.700 \\
Average & 0.018 & 2.933 \\
\hline
\end{tabular}


Table 3.4: Expected Profit Maximizing N, Corn-Quit, Quit and Actual Profit, and Mean Cost of Experimenting Across Years

\begin{tabular}{|c|c|c|c|c|c|c|c|c|c|c|c|}
\hline Variable & & & & & & $\mathrm{Ye}$ & & & & & \\
\hline & 0 & 1 & 2 & 3 & 4 & 5 & 6 & 7 & 8 & 9 & 10 \\
\hline Expected profit maximizing $\mathrm{N}$ (lb./acre) & 208.74 & 208.74 & 193.76 & 182.37 & 178.64 & 173.80 & 172.08 & 169.69 & 169.18 & 167.99 & 167.25 \\
\hline Mean corn-quit (bu./acre) & 157.20 & 157.51 & 157.34 & 156.07 & 155.89 & 155.29 & 157.06 & 156.28 & 156.33 & 155.50 & \\
\hline Mean quit-profit (\$/acre) & 369.70 & 370.74 & 376.98 & 378.36 & 379.48 & 379.89 & 385.89 & 384.67 & 385.96 & 383.15 & \\
\hline Mean actual profit (\$/acre) & 335.14 & 335.38 & 340.25 & 345.95 & 340.30 & 343.15 & 342.73 & 344.40 & 349.48 & 342.76 & 346.85 \\
\hline Mean cost of experimenting (\$/acre) & & -34.32 & -30.48 & -31.02 & -38.05 & -36.32 & -37.16 & -41.49 & -35.19 & -42.29 & -36.30 \\
\hline
\end{tabular}


Table 3.5: Sensitivity Analysis Results for Different Experimental Designs When Corn Price is $\$ 2.95 / \mathrm{bu}$. And N Price is 0.45/lb.

\begin{tabular}{|c|c|c|c|c|c|c|c|c|c|c|c|c|}
\hline \multirow{2}{*}{ Experimental Design } & \multirow{2}{*}{ Variable } & \multicolumn{11}{|c|}{ Year } \\
\hline & & 0 & 1 & 2 & 3 & 4 & 5 & 6 & 7 & 8 & 9 & 10 \\
\hline \multirow[t]{5}{*}{ 24-plot experimental design } & Profit maximizing N (lb./acre) & 208.74 & 208.74 & 193.67 & 183.11 & 178.54 & 173.53 & 172.18 & 170.08 & 169.18 & 168.10 & 167.33 \\
\hline & Mean corn-quit (bu./acre) & 157.16 & 157.51 & 157.26 & 155.92 & 155.78 & 155,24 & 157.04 & 156.24 & 156.38 & 155.44 & \\
\hline & Mean quit-profit (\$/acre) & 369.70 & 370.74 & 376.76 & 377.56 & 379.21 & 379.87 & 385.78 & 384.37 & 385.20 & 382.92 & \\
\hline & Mean actual profit \$/acre) & 341.87 & 341.90 & 346.92 & 352.87 & 348.14 & 350.40 & 350.40 & 352.31 & 357.18 & 350.46 & 354.53 \\
\hline & Mean CE (\$/acre) & & -27.80 & -23.82 & -23.89 & -29.41 & -28.29 & -29.46 & -33.47 & -27.19 & -34.74 & -28.39 \\
\hline \multirow[t]{5}{*}{ 18-plot experimental design } & Profit maximizing N (lb./acre) & 208.74 & 208.74 & 193.19 & 182.56 & 178.41 & 173.20 & 172.02 & 169.70 & 168.92 & 167.59 & 166.94 \\
\hline & Mean corn-quit (bu./acre) & 157.16 & 157.51 & 157.18 & 155.99 & 155.84 & 155.13 & 157.02 & 156.14 & 156.25 & 155.29 & \\
\hline & Mean quit-profit (\$/acre) & 369.70 & 370.74 & 376.74 & 378.04 & 379.45 & 379.71 & 385.81 & 384.26 & 384.94 & 382.70 & \\
\hline & Mean actual profit (\$/acre) & 348.59 & 348.42 & 353.97 & 360.64 & 355.54 & 358.23 & 357.91 & 360.24 & 365.59 & 358.02 & 362.55 \\
\hline & Mean CE (\$/acre) & & -21.28 & -16.77 & -16.10 & -22.49 & -21.21 & 21.79 & -25.57 & -18.66 & -26.92 & -26.92 \\
\hline \multirow[t]{5}{*}{ 12-plot experimental design } & Profit maximizing N (lb./acre) & 208.74 & 208.74 & 191.39 & 181.95 & 177.51 & 172.36 & 171.58 & 169.53 & 168.70 & 167.52 & 166.98 \\
\hline & Mean corn-quit (bu./acre) & 157.16 & 157.51 & 156.92 & 156.03 & 155.70 & 154.94 & 156.80 & 156.04 & 156.08 & 155.13 & \\
\hline & Mean quit-profit (\$/acre) & 369.70 & 370.74 & 376.81 & 378.42 & 379.43 & 379.52 & 385.37 & 384.04 & 384.52 & 382.25 & \\
\hline & Mean actual profit (\$/acre) & 355.32 & 354.95 & 361.67 & 368.76 & 362.61 & 366.24 & 365.05 & 367.48 & 373.70 & 365.83 & 370.17 \\
\hline & Mean CE (\$/acre) & & -14.75 & -9.07 & -8.04 & -15.80 & -13.19 & -14.47 & -17.88 & -10.33 & -18.69 & -12.08 \\
\hline \multirow[t]{5}{*}{ 6-plot experimental design } & Profit maximizing N (lb./acre) & 208.74 & 208.74 & 193.73 & 182.05 & 179.10 & 173.78 & 172.27 & 169.80 & 168.86 & 167.51 & 166.55 \\
\hline & Mean corn-quit (bu./acre) & 157.16 & 157.51 & 157.08 & 155.96 & 155.68 & 155.03 & 156.79 & 156.10 & 156.01 & 155.32 & \\
\hline & Mean quit-profit (\$/acre) & 369.70 & 370.74 & 376.22 & 378.16 & 378.68 & 379.16 & 385.03 & 384.09 & 384.25 & 382.81 & \\
\hline & Mean actual profit (\$/acre) & 362.04 & 361.47 & 367.49 & 374.25 & 370.26 & 372.77 & 371.96 & 375.90 & 381.29 & 373.69 & 377.96 \\
\hline & Mean CE (\$/acre) & & -8.23 & -3.24 & -1.97 & -7.90 & -5.90 & -7.19 & -9.13 & -2.80 & -10.55 & -4.85 \\
\hline \multirow{5}{*}{$\begin{array}{l}\text { 30-plot-new experimental } \\
\text { design }\end{array}$} & Profit maximizing N (lb./acre) & 208.74 & 208.74 & 189.48 & 182.61 & 179.09 & 174.14 & 172.70 & 170.30 & 169.45 & 168.56 & 167.64 \\
\hline & Mean corn-quit (bu./acre) & 157.16 & 157.51 & 157.10 & 156.00 & 155.87 & 155.37 & 157.10 & 156.30 & 156.38 & 155.63 & \\
\hline & Mean quit-profit (\$/acre) & 369.70 & 370.74 & 378.17 & 378.04 & 379.22 & 379.99 & 385.73 & 384.45 & 385.09 & 383.26 & \\
\hline & Mean actual profit (\$/acre) & 364.52 & 364.39 & 368.92 & 373.36 & 367.05 & 370.15 & 369.19 & 371.45 & 376.29 & 368.98 & 373.45 \\
\hline & Mean CE (\$/acre) & & -5.31 & -1.81 & -4.81 & -10.99 & -9.07 & -10.80 & -14.27 & -8.15 & -16.11 & -9.81 \\
\hline \multirow{5}{*}{$\begin{array}{l}\text { 12-plot-new } \\
\text { design }\end{array}$} & Profit maximizing N (lb./acre) & 208.74 & 208.74 & 185.67 & 180.06 & 177.65 & 174.20 & 171.86 & 169.50 & 169.08 & 168.13 & 167.54 \\
\hline & Mean corn-quit (bu./acre) & & 157.51 & 156.77 & 155.66 & 155.74 & 155.11 & 156.81 & 156.13 & 155.99 & 155.42 & \\
\hline & Mean quit-profit (\$/acre) & 369.70 & 370.74 & 378.93 & 378.17 & 379.50 & 379.18 & 385.24 & 384.31 & 384.09 & 382.84 & \\
\hline & Mean actual profit (\$/acre) & 367.07 & 366.55 & 374.57 & 379.20 & 373.70 & 376.96 & 375.70 & 378.26 & 384.16 & 376.06 & 380.88 \\
\hline & Mean CE (\$/acre) & & -3.15 & 3.83 & 0.27 & -4.46 & -2.54 & -3.48 & -6.98 & -0.15 & -8.03 & -1.96 \\
\hline
\end{tabular}


Table 3.6: Sensitivity Analysis Results for Experimental Designs When Corn and N Prices Double

\begin{tabular}{|c|c|c|c|c|c|c|c|c|c|c|c|c|}
\hline \multicolumn{12}{|l|}{ Experimental Design } & \\
\hline \multirow{4}{*}{$\begin{array}{l}\text { 30-plot experimental } \\
\text { design }\end{array}$} & & 0 & 1 & 2 & 3 & 4 & 5 & 6 & 7 & 8 & 9 & 10 \\
\hline & Profit maximizing $\mathrm{N}$ (lb./acre) & 208.74 & 208.74 & 194.77 & 182.02 & 178.31 & 173.91 & 171.69 & 170.25 & 169.23 & 168.20 & 167.68 \\
\hline & Mean corn-quit (bu./acre) & 155.84 & 157.51 & 157.57 & 156.10 & 155.87 & 155.28 & 157.07 & 156.32 & 156.31 & 155.54 & \\
\hline & Mean quit-profit (\$/acre) & 739.41 & 741.48 & 754.42 & 757.29 & 759.18 & 760.00 & 771.95 & 769.55 & 770.16 & 766.31 & \\
\hline \multirow{7}{*}{$\begin{array}{l}\text { 12-plot experimental } \\
\text { design }\end{array}$} & Mean actual profit (\$/acre) & 670.29 & 670.76 & 680.73 & 692.17 & 680.53 & 686.24 & 685.31 & 688.92 & 698.81 & 685.64 & 693.79 \\
\hline & Mean CE (\$/acre) & & -68.65 & -60.74 & -62.25 & -76.75 & -72.93 & -74.69 & -83.03 & -70.73 & -84.51 & -72.88 \\
\hline & Profit maximizing $\mathrm{N}$ (lb./acre) & 208.74 & 208.74 & 191.05 & 182.43 & 177.77 & 172.91 & 171.94 & 169.275 & 168.67 & 167.66 & 166.79 \\
\hline & Mean corn-quit (bu./acre) & 157.17 & 157.47 & 155.98 & 156.96 & 156.37 & 155.98 & 157.35 & 156.92 & 155.28 & 155.86 & \\
\hline & Mean quit-profit (\$/acre) & 739.41 & 741.24 & 748.35 & 761.91 & 762.62 & 764.66 & 773.64 & 773.48 & 764.35 & 768.72 & \\
\hline & Mean actual profit (\$/acre) & 710.64 & 709.90 & 723.887 & 736.37 & 726.11 & 732.27 & 730.07 & 735.39 & 747.52 & 731.53 & 740.68 \\
\hline & Mean CE (\$/acre) & & -29.51 & -17.36 & -11.97 & -35.80 & -30.35 & -34.59 & -38.24 & -25.95 & -32.81 & -28.04 \\
\hline
\end{tabular}


Table 3.7: Sensitivity Analysis Results for Different Experimental Designs When Either Corn Price or N Price Doubles

\begin{tabular}{|c|c|c|c|c|c|c|c|c|c|c|c|c|}
\hline \multirow[t]{2}{*}{ Experimental Design } & \multirow[t]{2}{*}{ Variable } & \multicolumn{11}{|c|}{ Year } \\
\hline & & 0 & 1 & 2 & 3 & 4 & 5 & 6 & 7 & 8 & 9 & 10 \\
\hline \multicolumn{13}{|c|}{ Corn price doubles $(5.90 / \mathrm{bu}$.) but $\mathrm{N}$ price remains constant $(\$ 0.45 / \mathrm{lb}$.) } \\
\hline \multirow{5}{*}{$\begin{array}{l}\text { 30-plot-new experimental } \\
\text { design }\end{array}$} & Profit maximizing N (lb./acre) & 243.47 & 243.47 & 225.20 & 206.98 & 198.50 & 191.58 & 188.52 & 185.14 & 183.37 & 182.10 & 181.00 \\
\hline & Mean corn-quit (bu./acre) & & 157.54 & 157.95 & 156.86 & 156.46 & 156.17 & 158.04 & 157.17 & 157.21 & 156.57 & \\
\hline & Mean quit-profit (\$/acre) & 820.38 & 819.94 & 830.58 & 832.37 & 833.79 & 835.20 & 847.60 & 843.98 & 845.03 & 841.86 & \\
\hline & Mean actual profit $\$ /$ acre) & 749.98 & 750.32 & 754.93 & 765.01 & 752.86 & 757.13 & 755.92 & 759.34 & 769.55 & 757.12 & 762.74 \\
\hline & Mean CE (\$/acre) & & -70.06 & -65.00 & -65.56 & -79.51 & -76.66 & -79.27 & -88.25 & -74.43 & -87.91 & -79.12 \\
\hline \multirow{5}{*}{$\begin{array}{l}\text { 12-plot-new experimental } \\
\text { design }\end{array}$} & Profit maximizing N (lb./acre) & 243.47 & 243.47 & 224.12 & 206.47 & 197.27 & 190.58 & 188.84 & 185.11 & 183.56 & 181.82 & 181.01 \\
\hline & Mean corn-quit (bu./acre) & 157.61 & 157.54 & 157.96 & 156.78 & 156.49 & 156.00 & 157.81 & 157.11 & 157.10 & 156.27 & \\
\hline & Mean quit-profit (\$/acre) & 820.38 & 819.94 & 831.14 & 832.09 & 834.50 & 834.67 & 846.13 & 843.64 & 844.30 & 840.20 & \\
\hline & Mean actual profit (\$/acre) & 791.12 & 790.24 & 799.46 & 811.84 & 800.42 & 806.50 & 803.16 & 808.41 & 821.64 & 805.68 & 812.41 \\
\hline & Mean CE (\$/acre) & & -30.14 & -20.48 & -19.29 & -31.67 & -27.99 & -31.51 & -37.72 & -22.00 & -38.61 & -27.78 \\
\hline \multicolumn{13}{|c|}{ Corn price is constant (2.95/bu.) but $\mathrm{N}$ price doubles $(\$ 0.90 / \mathrm{lb}$.) } \\
\hline \multirow{5}{*}{$\begin{array}{l}\text { 30-plot-new experimental } \\
\text { design }\end{array}$} & Profit maximizing N (lb./acre) & 175.50 & 175.50 & 163.63 & 158.69 & 157.54 & 154.93 & 154.22 & 152.74 & 152.53 & 151.83 & 151.23 \\
\hline & Mean corn-quit (bu./acre) & & 156.79 & 154.96 & 153.85 & 153.74 & 152.93 & 154.63 & 153.71 & 153.91 & 152.76 & \\
\hline & Mean quit-profit (\$/acre) & 303.43 & 304.59 & 309.87 & 311.03 & 311.75 & 311.71 & 317.37 & 316.00 & 316.78 & 314.01 & \\
\hline & Mean actual profit (\$/acre) & 271.50 & 272.21 & 277.86 & 283.04 & 277.97 & 280.37 & 279.89 & 281.37 & 286.21 & 280.18 & 284.91 \\
\hline & Mean CE (\$/acre) & & -31.21 & -26.73 & -26.83 & -33.06 & -31.37 & -31.82 & -35.99 & -29.78 & -36.59 & -29.09 \\
\hline \multirow{5}{*}{$\begin{array}{l}\text { 12-plot-new experimental } \\
\text { design }\end{array}$} & Profit maximizing N (lb./acre) & 175.50 & 175.50 & 162.20 & 158.34 & 156.06 & 153.90 & 153.42 & 151.89 & 151.39 & 151.18 & 150.79 \\
\hline & Mean corn-quit (bu./acre) & 156.40 & 156.79 & 154.50 & 153.55 & 153.28 & 152.50 & 154.16 & 153.26 & 153.45 & 152.28 & \\
\hline & Mean quit-profit (\$/acre) & 303.43 & 304.59 & 309.80 & 310.45 & 311.72 & 311.37 & 316.70 & 315.41 & 316.43 & 313.18 & \\
\hline & Mean actual profit (\$/acre) & 289.95 & 290.16 & 296.44 & 302.95 & 296.73 & 299.32 & 298.68 & 300.05 & 306.28 & 2.99 .04 & 304.70 \\
\hline & Mean CE (\$/acre) & & -6.13 & -8.15 & -6.85 & -13.72 & -12.39 & -12.69 & -16.65 & -9.12 & -17.39 & -8.47 \\
\hline
\end{tabular}




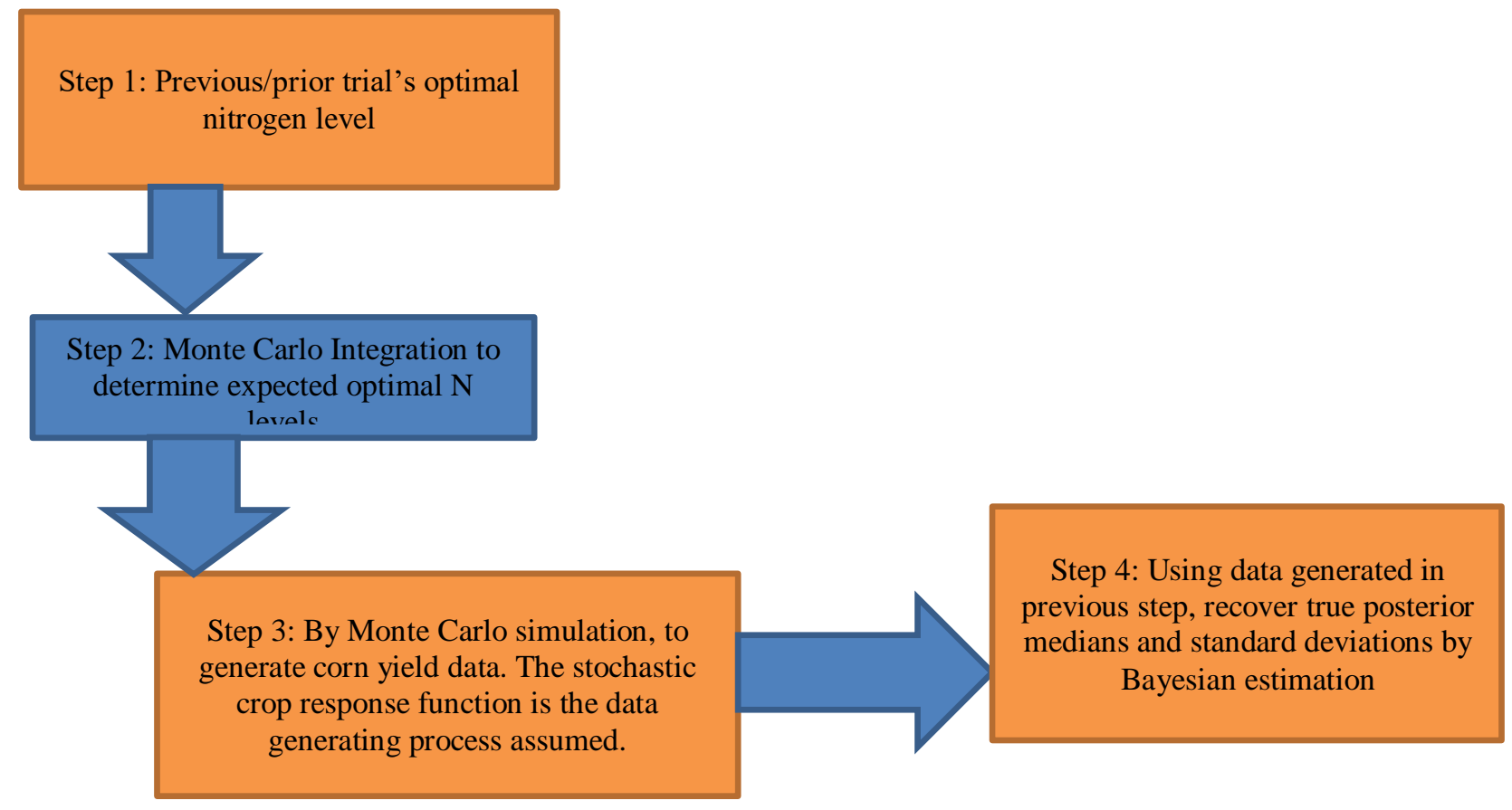

Figure 3.1: Flowchart summarizing the approach used 

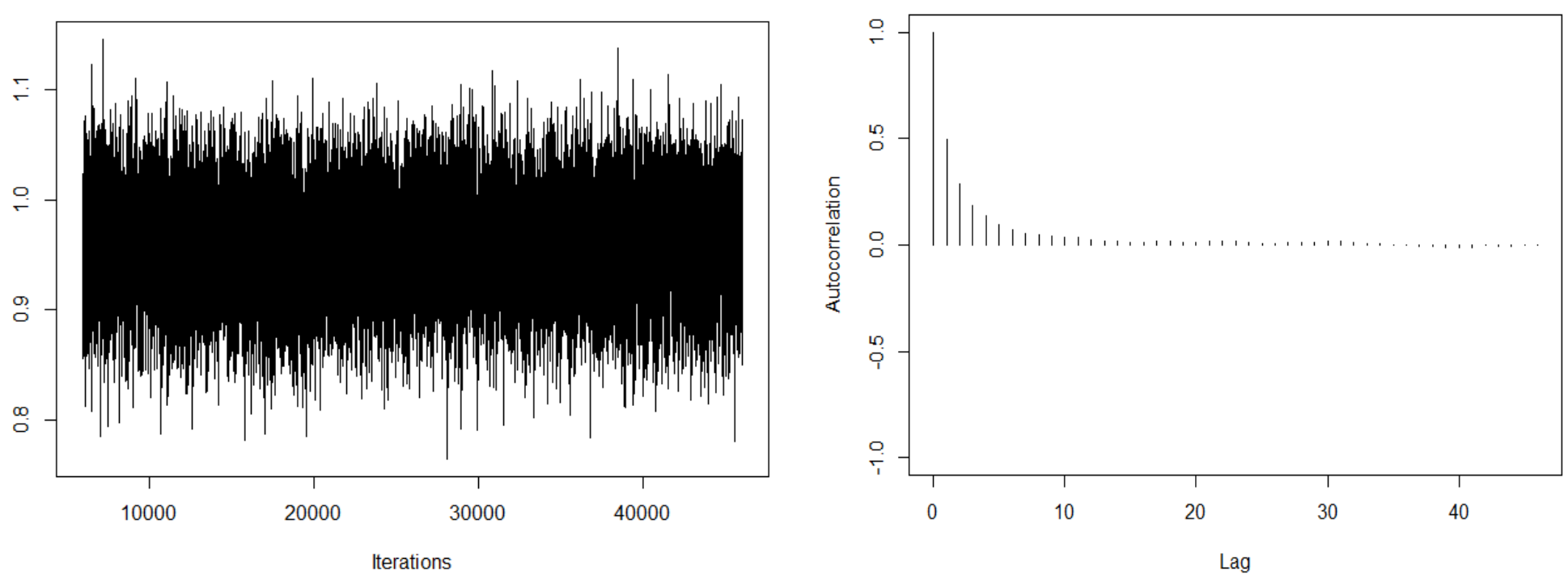

Figure 3.2: The trace and autocorrelation graphs for $\beta_{1}$. 


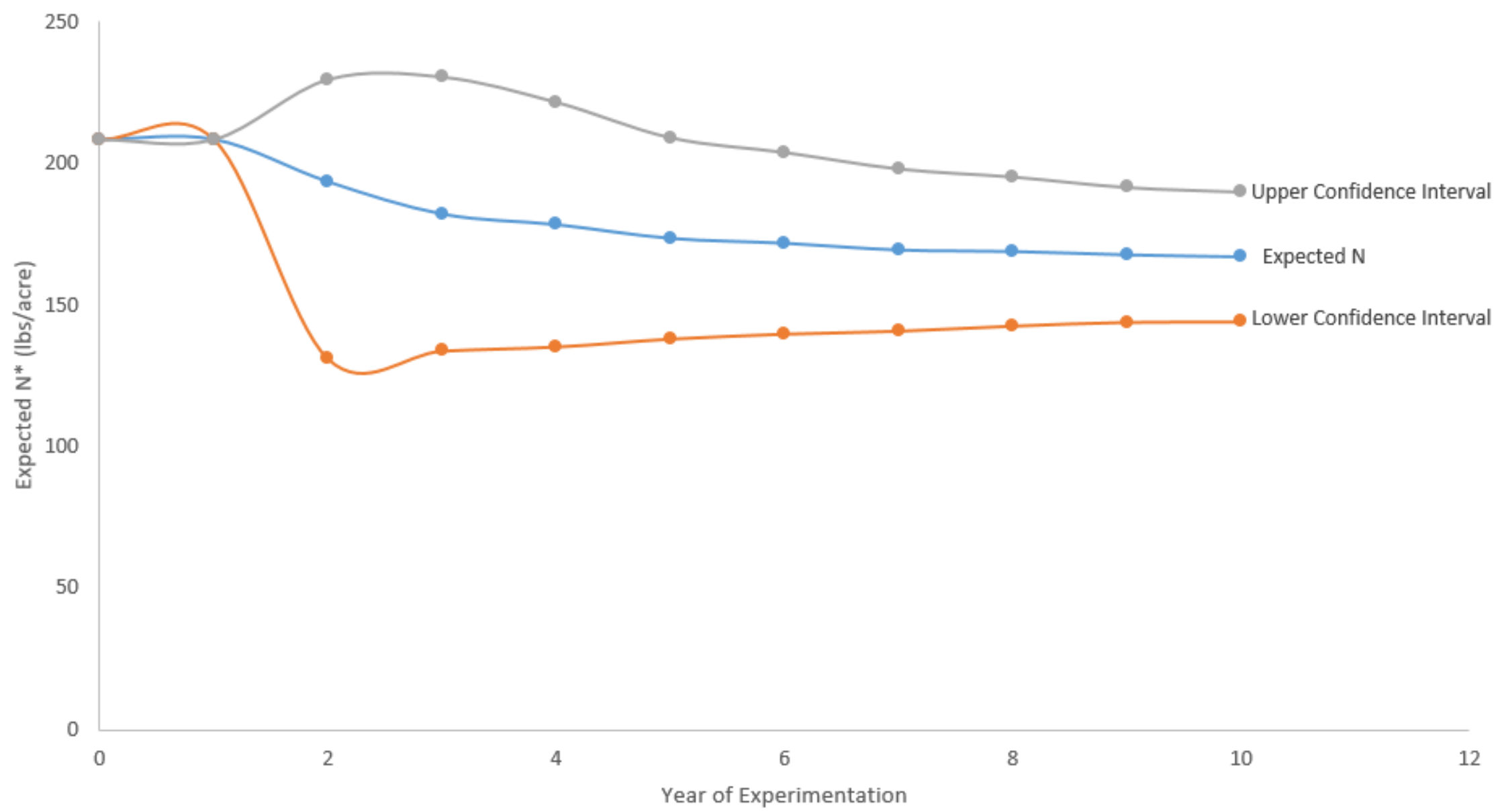

Figure 3.3: A Plot of Expected Profit Maximizing Levels of $\mathbf{N}$ in lb./acre in Each Year of Experimentation 


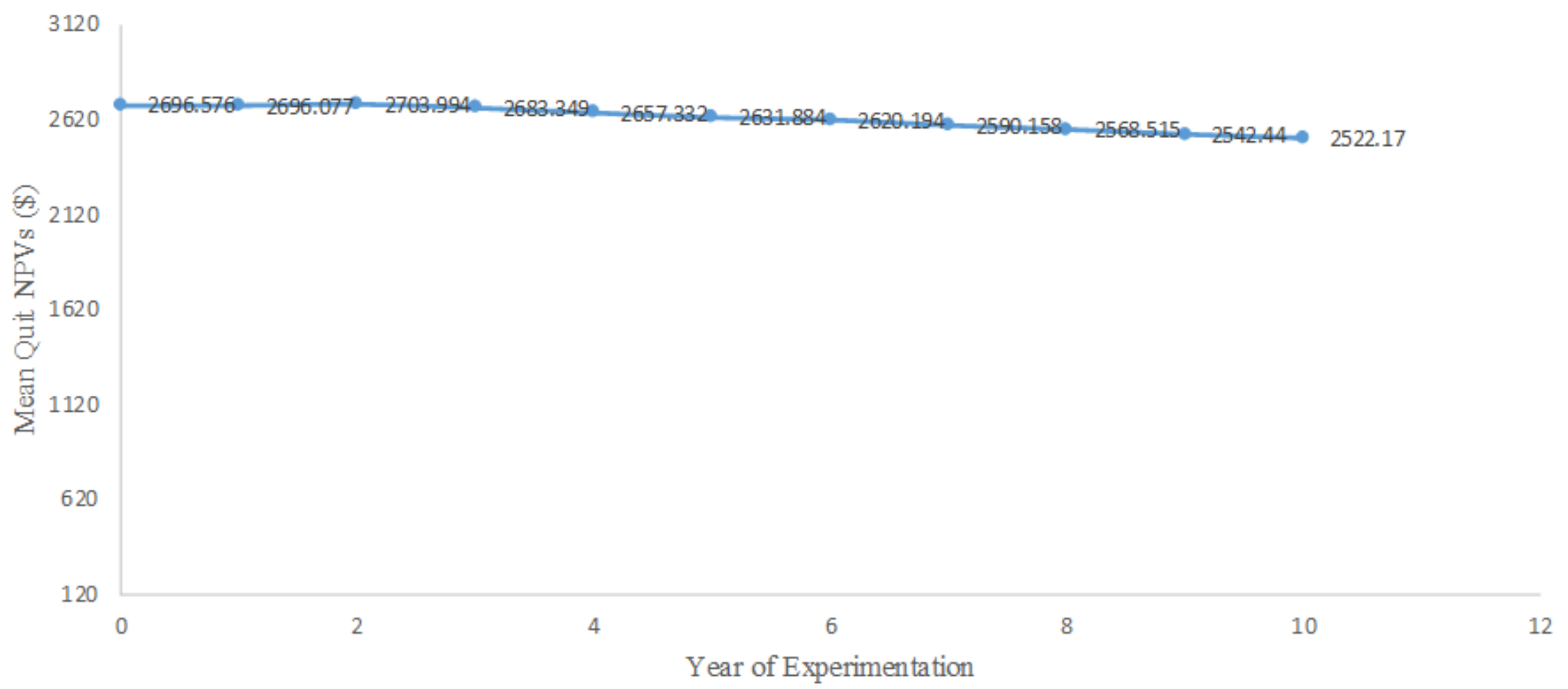

Figure 3.4: A Plot of Mean Quit NPV against Year of Experimentation 


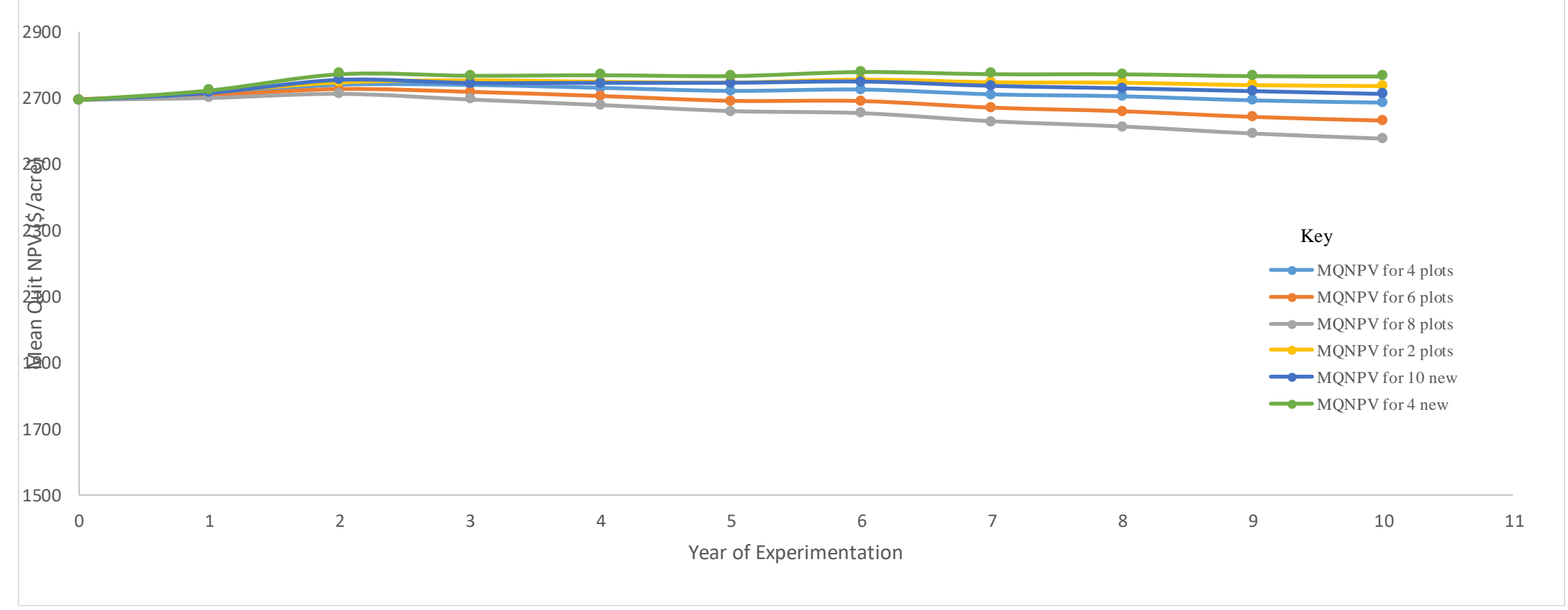

Figure 3.5: A Plot of Mean Quit NPV against Year of Experimentation for 2, 4, 6, 8 Plots, and 4 and 10 Plots with 0.5 N*, $0.75 N^{*}$, and $1.25 \mathrm{~N} *$ 


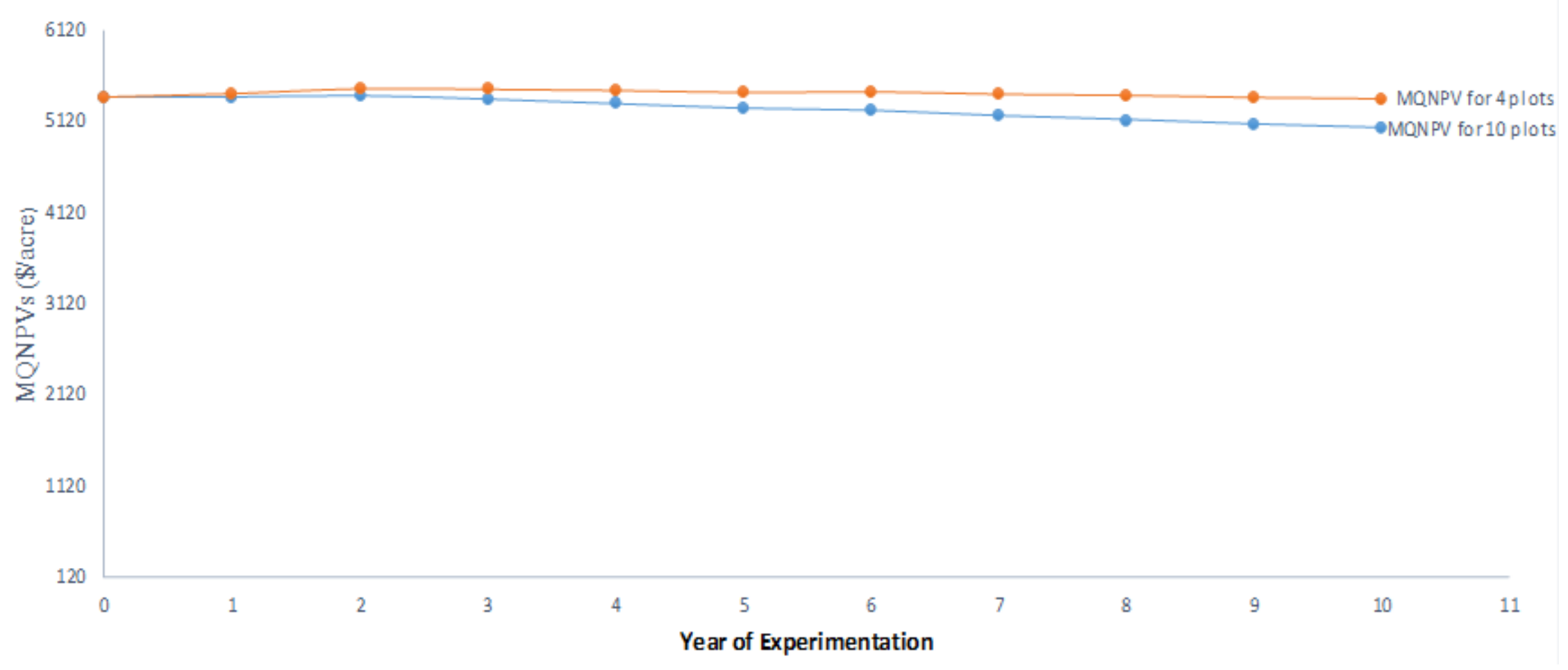

Figure 3.6: A Plot of Mean Quit NPV against Year of Experimentation for 10 and 4 Plot Designs When Corn and N Prices Double. 


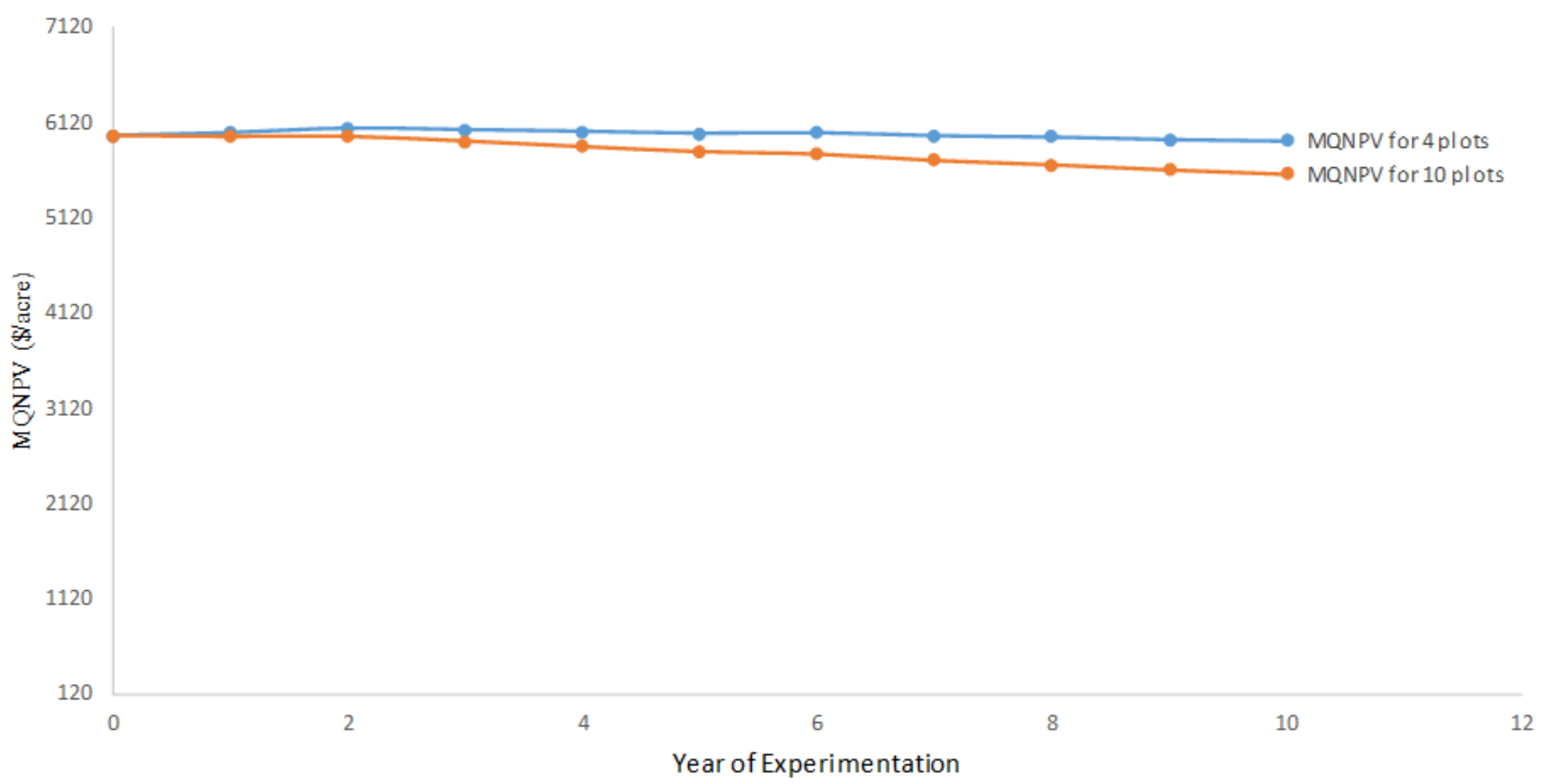

Figure 3.7: A Plot of Mean Quit NPV against Year of Experimentation for 12-Plot and 30-Plot Designs When Only Corn Price Doubles. 


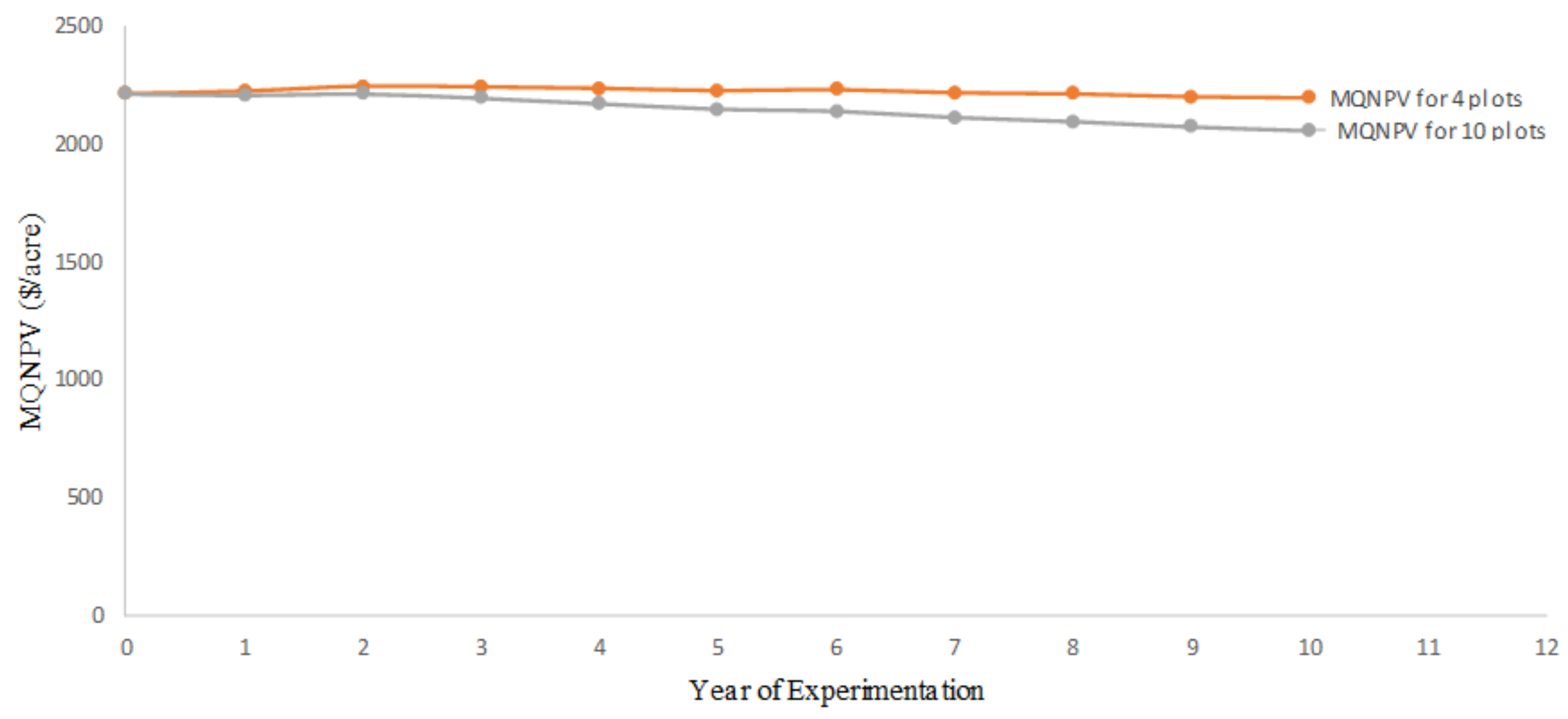

Figure 3.8: A Plot of Mean Quit NPV against Year of Experimentation for 12-Plot and 30-Plot Designs When Only N Price Doubles. 


\section{References}

Ackello-Ogutu, C., Q. Paris., and W.A. Williams 1985. Testing a von Liebig Crop Response Function against Polynomial Specifications. American Journal of Agricultural Economics 67(4):873-880.

Adjei, E.O., S.H.M. Aikins, P. Boahen, K. Chand, I. Dev, M. Lu, V. Mkrtumysn, S.D. Samaraweera, and T. Amare. 2003. Combining mechanisation with conservation and agriculture in the transitional zone of Brong Ahafo Region, Ghana. ICRA Working Documents Series 108. Wageningen, the Netherlands: International Centre for Development Oriented Research in Agriculture.

Aikins, S.H.M., A. B. Plange, and S.O. Baffour. 2010. Performance evaluation of jab planters for maize planting and inorganic fertilizer application. ARPN J. of Agricultural and Biological Science 5(1):29-33.

Babcock, B.A., and G.R. Pautsch. 1998. Moving from Uniform to Variable Fertilizer Rates on Iowa Corn: Effects on Rates and Returns. Journal of Agricultural and Resource Economics $385-400$

Bates, B, M. Maechler, B. Bolker, and S. Walker. 2015. Fitting linear mixed-effects models using lme4. J. of Statistical Software 67(1):1-47.

Berger, J. O. 2013. Statistical Decision Theory and Bayesian Analysis. New York, NY: SpringerVerlag.

Biermacher, J.T., B.W. Brorsen, F.M. Epplin, J.B. Solie, and W.R. Raun. 2009. The economic potential of precision nitrogen application with wheat based on plant sensing. Agric. Economics 40(4):397-407.

Borlaug, N. 2007. Feeding a hungry world. Science 318:359.

Bourguignon F., M. Fournier, and M. Gurgand. 2007. Selection bias corrections based on the multinomial logit model: monte carlo comparisons. J. of Economic Surveys 21(1):174-205.

Bouwman, A. F., and L.J.M. Boumans. 2002. Estimation of global NH3 volatilization loss from synthetic fertilizers and animal manure applied to arable lands and grasslands. Global Biogeochemical Cycles 16(2):1-13.

Boyer, C.N., J.A. Larson, R.K. Roberts, A.T. McClure, D.D. Tyler., and V. Zhou. 2013. 
Stochastic Corn Yield Response Functions to Nitrogen for Corn after Corn, Corn after Cotton, and Corn after Soybeans. Journal of Agricultural and Applied Economics 45(13792016-113848):669.

Bullock, D., and T. Mieno. 2017. An Assessment of the Value of Information from On-Farm Field Trials. Unpublished Working Paper, University of Illinois, Champaign, IL.

Bullock, D. S., and T. Mieno. 2019. The Economic Value of On-Farm Precision

Experimentation. In Precision Agriculture'19 (pp. 327-342). Wageningen Academic Publishers.

Brorsen, B.W., and F.G.C. Richter. 2012. Experimental Designs for Estimating Plateau-Type

Production Functions and Economically Optimal Input Levels. Journal of Productivity Analysis 38(1):45-52.

Cairns, J.E., J. Hellin, K. Sonder, J.L. Araus, J.F. MacRobert, C. Thierfelder, and B.M. Prasanna. 2013. Adapting maize production to climate change in sub-Saharan Africa. Food Security 5(3):345-360.

Casanoves, F., R. Macchiavelli., and M. Balzarini. 2007. Models for Multi-Environment Yield Trials with Fixed and Random Block Effects and Homogeneous and Heterogeneous Residual Variances. The Journal of Agriculture of the University of Puerto Rico 91(34):117-131.

Cerrato, M.D., and A.M. Blackmer. 1990. “Comparison of Models for Describing Corn Yield Response to Nitrogen Fertilizer. Agronomy Journal 82:138-143

Chim, B.K., P. Omara, N. Macnack, J. Mullock, S. Dhital, and W. R. Raun. 2014. Effect of seed distribution and population on maize (Zea Mays L.) grain yield. International J. of Agronomy 145(8):166-173.

Cha, W., and Melstrom, R. T. 2018. Catch-and-Release Regulations and Paddlefish Angler Preferences. Journal of Environmental Management 214: 1-8.

Denwood, M.J. 2016. runjags: An R Package Providing Interface Utilities, Model Templates, Parallel Computing Methods and Additional Distributions for MCMC Models in JAGS. Journal of Statistical Software 71(9):1-25. doi:10.18637/jss.v071.i09

Dhakal, C., K. Lange., M.N. Parajulee., and E. Segarra. 2019. Dynamic Optimization of Nitrogen in Plateau Cotton Yield Functions with Nitrogen Carryover Considerations. Journal of Agricultural and Applied Economics 1-17.

Dhillon, J.S., B. Figueiredo, L. Aula, T. Lynch, R.K. Taylor, and W.R. Raun. 2017. 
Evaluation of drum cavity size and planter tip on singulation and plant emergence in maize (Zea mays L.). J. of Plant Nutrition 40(20):2829-2840.

Dhillon, J.S., P. Omara, E. Nambi, E. Eickhoff, F. Oyebiyi, G. Wehmeyer, A. Fornah, E.N. Ascenio, B.M.. Figueriedo, R. Lemings, T. Lynch, J. Ringer, W. Kiner, R.K. Taylor, and W.R. Raun. 2018. Hand planter for the developing world: factor testing and refinement. Agrosystems, Geosciences, and Environment 1(1)

Drovandi, C. C., and M.N, Tran. 2018. Improving the Efficiency of fully Bayesian Optimal Design of Experiments Using Randomised Quasi-Monte Carlo. Bayesian Analysis 13(1): 139-162.

Eliaz, K., and R. Spiegler. 2011. "Consideration Sets and Competitive Marketing." Review of Economic Studies 78(1):235-262.

Epplin, F. M., N. Z. F. Fofana, T. F. Peeper and J.B. Solie. 1996. Optimal wheat seeding rates for conventional and narrow rows for cheat-free and cheat-infested fields. J. of Production Agriculture 9(2):265-270.

Fisher, M. 2016. Greenseeder: Hand planter could boost productivity for world's poorest farmers. Crops, Soils, Agronomy News 61(3):4-8

Freund, R.J., and W.J. Wilson. 2003. Statistical method. $2^{\text {nd }}$ Edition. New York: Elsevier Science.

Funderburg, E. 2009. Nitrogen Losses from Urea. Noble Research Institute: Accessed on Dec. 20, 2018, from https://www.noble.org/news/publications/ag-news-andviews/2009/may/nitrogen-losses-from-urea/

Gelman, A., H.S. Stern., J.B. Carlin., D.B. Dunson., A. Vehtari, D.B. Rubin. 2013. Bayesian Data Analysis, Third Ed. Chapman and Hall/CRC.

Gelman, A., and D.B. Rubin. 1992. Inference from Iterative Simulation Using Multiple Sequences. Statistical Science 7(4):457-472.

Griffin, T., G.J. Fitzgerald., D. Lambert., J. Lowenberg-Deboer., E.M. Barnes., and R. Roth. 2005. Testing Appropriate On-Farm Trial Designs and Statistical Methods for Cotton Precision Farming. In National Cotton Council Beltwide Cotton Conferences, New Orleans, Louisiana, January 4-7, 2005. 1:383-392.

Guevara, C.A., Ben-Akiva, M., 2013. "Sampling of Alternatives in Logit Mixture Models." Transportation Research Part B Methodology. 58, 185e198. 
Greene, W.H., 2003. "Econometric Analysis." Pearson Education, India.

Haab, T.C., and R.L. Hicks. 1997. "Accounting for Choice Set Endogeneity in Random Utility Models of Recreation Demand." Journal of Environmental Economics and Management 34(2):127-147.

Haggblade, S., and G.Tembo. 2003. Development, diffusion and impact of conservation conservation farming. Working Paper No. 8, Food Security Research Project, Lusaka, Zambia. Available at: http://www.aec.msu.edu/agecon/fs2/zambia/index.htm.

Han, C., and K. Chaloner. 2004. Bayesian Experimental Design for Nonlinear Mixed-Effects Models with Application to HIV Dynamics. Biometrics 60(1):25-33.

Horowitz, J.L., and J.J. Louviere. 1995. "What is the Role of Consideration Sets in Choice Modeling?" Journal of Choice Modeling 12:39-54.

Hossain, I., F.M. Epplin, G.W. Horn, and E.G. Krenzer Jr. 2004. "Wheat Production and Management Practices Used by Oklahoma Grain and Livestock Producers.” Oklahoma Agricultural Experiment Station Bulletin B-818.

Jama, B., Kimani, D., Harawa, R., Mavuthu, A.K. and G.W. Sileshi. 2017. Maize yield response, nitrogen use efficiency and financial returns to fertilizer on smallholder farms in southern Africa. Food Security 9(3):577-593.

Jehle, G.A., and P.J. Reny. 2001. Advanced Microeconomic Theory. Boston, MA: AddisonWesley.

Jones, C.A., and F. Lupi. 1999. "The Effect of Modeling Substitute Activities on Recreational Benefit Estimates.” Marine Resource Economics 14(1):357-374.

Koehler, E., Brown, E., and Haneuse, S.J.P., 2009. "On the Assessment of Monte Carlo Error in Simulation-based Statistical Analyses." The American Statistician 63(2):155-162.

Kyveryga, P. M., T. A. Mueller., D. S. Mueller. 2018. On-Farm Replicated Strip Trials. In: D.K. Shannon, D.E. Clay, and N.R. Kitchen, Precision Agriculture Basics, ASA, CSSA, and SSSA, Madison, WI. p. 189-208. doi:10.2134/precisionagbasics.2016.0096

Lambert, B. 2018. A Student's Guide to Bayesian Statistics, $1^{\text {st }}$ Ed. Thousand Oaks, CA: Sage Publications.

Lenth, V.R. 2016. Least-squares means: the R package lsmeans. J. of Statistical Software 
69(1), 1-33.

Lindley, D.V., 1972. Bayesian Statistics, A Review. Philadelphia, USA: SIAM.

Lessley, B. V., and D. Holik. 1987. Determining the cost of owning or custom hiring machinery services. Maryland Coop. Ext., University of Maryland. MD, USA.

Li, L., W. Adamowicz, and J. Swait. 2015. “The Effect of Choice Set Misspecification on Welfare Measures in Random Utility Models." Resource and Energy Economics 42:71-92.

Llewelyn, R.V., and A. M. Featherstone. 1997. A Comparison of Crop Production Functions Using Simulated Data for Irrigated Corn in Western Kansas. Agricultural Systems 54:521-538.

Manski, C.F. 1977. "The Structure of Random Utility Models." Theory and Decision $8(3): 229-254$.

Martin, K.L., P.J. Hodgen, K.W. Freeman, R. Melchiori, D.B. Arnall, R.K. Teal, R.W. Mullen, K. Desta, S.B. Phillips, J.B. Solie, M.L. Stone, O. Caviglia, F. Solari, A. Bianchini, D.D. Francis, J.S. Schepers, J.L. Hatfield, and W.R. Raun. 2005. Plantto-plant variability in corn production. Agron. J. 97(6):1603-1611.

Masasi, B., and J. N. Ng'ombe. 2019. Does A Market Systems Approach Revitalize Smallholder Irrigation Schemes? Evidence from Zimbabwe. Sustaianble Agriculture Research 8(2):36-45 doi:10.5539/sar.v8n2p36

Mas-Colell, A., M.D. Whinston., and J.R. Green. 1995. Microeconomic Theory (Vol. 1). New York: Oxford University Press.

McFadden, B.R., B.W. Brorsen., and W.R, Raun. 2018. Nitrogen Fertilizer Recommendations Based on Plant Sensing and Bayesian Updating. Precision Agriculture 19(1):79-92.

McFadden, D., 1978. "Modeling the Choice of Residential Location.” In: Karlgvist, A., et al. (Eds.), Spatial Interaction Theory and Planning Models. North-Holland, Amsterdam.

Meaney, C. and Moineddin, R. 2014. "A Monte Carlo Simulation Study Comparing Linear Regression, Beta Regression, Variable-Dispersion Beta Regression and Fractional Logit Regression at Recovering Average Difference Measures in a Two Sample Design." BMC Medical Research Methodology 14(1):14.

Mukembo, S., J. Dhillion, D. K. Alliddekki, W. Kiner, R. Taylor, and W. R. Raun. 2016. 
The greenseeder hand planter, and planter power point presentation, Oklahoma State University, OK, 28 January. http://www.nue.okstate.edu/Hand Planter/PowerPoint Pres.htm

Ng'ombe, J.N. 2017. Technical efficiency of smallholder maize production in Zambia: A Stochastic meta-frontier approach. Agrekon 56(4):347-365.

Ng'ombe, J. N., Kalinda, T. H., and Tembo, G. 2017. Does adoption of conservation farming practices result in increased crop revenue? Evidence from Zambia. Agrekon, 56(2), 205-221.

Ng'ombe, J. N., and Boyer, T. A. 2019. Determinants of Earthquake Damage Liability Assignment in Oklahoma: A Bayesian Tobit Censored Approach. Energy Policy, 131, 422-433.

Nuthall, P.L. 2011. Farm business management: analysis of farming systems.

Massachussets: CABI.

Ntzoufras, I., 2011. Bayesian Modeling Using WinBUGS (Vol. 698). New York, NY: John Wiley \& Sons.

Omara, P., L. Aula, B. Raun, R. Taylor, A. Koller, E. Lam, J. Ringer, J. Mullock, S. Dhital, and N. Macnack. 2015. Hand planter for maize (Zea mays L.) in the developing world. J. of Plant Nutrition 39(9):1233-1239.

Oklahoma State University’s Nitrogen Use Efficiency website (www.nue.okstate.edu). Ouedraogo, F. and B.W. Brorsen. 2018. Hierarchical Bayesian Estimation of a Stochastic Plateau Response Function: Determining Optimal Levels of Nitrogen Fertilization. Canadian Journal of Agricultural Economics 66(1):87-102.

Overstall, A.M., and D.C. Woods, 2017. Bayesian Design of Experiments Using Approximate Coordinate Exchange. Technometrics 59(4):458-470.

Paris, Q. 1992. “The von Liebig Hypothesis.” American Journal of Agricultural Economics 74:1019-1028

Parsons, G.R., and A.B. Hauber. 1998. "Spatial Boundaries and Choice Set Definition in a Random Utility Model of Recreation Demand” Land Economics 74(1):32-48.

Parsons, G.R., A.J. Plantinga, and K.J. Boyle. 2000. "Narrow Choice Sets in a Random Utility Model of Recreation Demand Narrow Choice Sets in a Random Utility Model of Recreation Demand." Land Economics 76(1):86-99.

Paulsrud, B.P., Martin, D., Babadoost, M., Malvick, D., Weinzierl, R., Lindholm, D.C., 
Steffey, K., Pederson, W., and M. Reed. 2001. Seed treatment. Oregon pesticide applicator training manual seed treatment, University of Illinois, Urbana, IL, USA. Peters, T., and W.L. Adamowicz. 1995. "Influence of Choice Set Considerations in Modeling the Benefits from Improved Water Quality." Water Resources Research 31(7):1781-1787.

Plastina, A., and S.H. Lence, S. H. 2019. Theoretical Production Restrictions and Agricultural Technology in the United States. American Journal of Agricultural Economics, 101(3):849-869.

Posada, D., and T.R. Buckley. 2004. "Model Selection and Model Averaging in Phylogenetics: Advantages of Akaike Information Criterion and Bayesian Approaches over Likelihood Ratio Tests." Systematic Biology 53(5):793-808.

Pramono, A., and H. Oppewal. 2012. "Accessibility and the Role of the Consideration Set in Spatial Choice Modelling : A Simulation Study." Journal of Choice Modeling $5(1): 46-63$.

R Core Team. 2018. "R: A Language and Environment for Statistical Computing. R Foundation for Statistical Computing." Vienna, Austria.

Rodriguez, D. 2014. "Testing Two Existing Fertilizer Recommendation Algorithms: Stanford's 1.2 Rule for Corn and Site-Specific Nutrient Management for Irrigated Rice." PhD dissertation, University of Illinois, Department of Agricultural and Consumer Economics, Urbana-Champaign, Illinois.

Rutto, E., C. Daft, J. Kelly, B.K. Chim, J. Mullock, G. Torres, and W. Raun. 2014. Effect of delayed emergence on corn (Zea mays L.) grain yield. J. of Plant Nutrition 37(2):198-208.

Ryan, E. G., C.C. Drovandi, J.M. McGree., and A. N. Pettitt. 2016. A Review of Modern

Computational Algorithms for Bayesian Optimal Design. International Statistical Review $84,128-154$.

Shiferaw, B., B.M. Prasanna, J. Hellin and M. Bänziger. 2011. Crops that feed the world 6. Past successes and future challenges to the role played by maize in global food security. Food Security 3(3):307-327.

Swait, J., and M. Ben-Akiva. 1987. "Empirical Test of a Constrained Choice Discrete Model: Mode Choice in Sao Paulo, Brazil.” Transportaiton Research B 218(2):103- 
115.

Tembo, G., B.W. Brorsen, F.M. Epplin., and E. Tostão. 2008. Crop Input Response Functions with Stochastic Plateaus. American Journal of Agricultural Economics 90(2):424-434.

Terry M. Therneau, Patricia M. Grambsch (2000). Modeling Survival Data: Extending the Cox Model_. Springer, New York. ISBN0-387-98784-3.

Therneau, T. 2015._A Package for Survival Analysis in $S_{\_}$. version 2.38, <URL: https://CRAN.R-project.org/package=survival $>$.

Thiene, M., J. Swait, and R. Scarpa. 2017. "Choice Set Formation for Outdoor Destinations : The Role of Motivations and Preference Discrimination in Site Selection for the Management of Public Expenditures on Protected Areas." Journal of Environmental Economics and Management 81:152-173.

Tumusiime, E., B.W. Brorsen, J. Mosali, J. Johnson, J. Locke., and J.T, Biermacher. 2011. "Determining Optimal Levels of Nitrogen Fertilizer Using Random Parameter Models." Journal of Agricultural and Applied Economics 43(1379-2016-113680):541.

Train K.E. 2009. Discrete Choice Methods with Simulation. Cambridge, U.K: Cambridge University Press.

von Haefen, R. H. and Domanski, A. 2018. "Estimation and Welfare Analysis from Mixed Logit Models with Large Choice Sets', Journal of Environmental Economics and Management 90: 101-118.

Wackerly, D., W. Mendenhall., and R.L. Scheaffer. 2014. Mathematical Statistics with Applications. Cengage Learning. Belmont: Brooks/Cole.

Walter, E., and L. Pronzato. 1985. How to Design Experiments That Are Robust to Parameter Uncertainty. IFAC Proceedings Volumes 18(5): 921-926.

West, B. T., Welch, K. B., and Galecki, A. T. (2014). Linear mixed models: a practical guide using statistical software. CRC Press.

White, I.R. 2010."simsum: Analyses of Simulation Studies Including Monte Carlo Error. Stata Journal 10(3):369.

Whitehead, J. C. and Haab, T.H. 1999. "Southeast Marine Recreational Fishery Statistics Survey: Distance and Catch Based Choice Sets," Marine Resource Economics 14:283-298, 1999.

Wichmann, B., M. Chen, and W. Adamowicz. 2016. "Social Networks and Choice Set 
Formation in Discrete Choice Models." Econometrics 4(42):1-26.

Wu, F., and Z. Guan. 2018. Efficient Estimation of Risk Preferences. American Journal of Agricultural Economics 100(4):1172-1185.

Zambia National Farmers' Union (ZNFU). 2015. Smallholder maize enterprise budget.

Farmers' village, show grounds, Lusaka, Zambia.

Zhang, J., L, Zeng., C, Chen., D, Chen., and L. Wu. 2015. "Efficient Bayesian Experimental Design for Contaminant Source Identification. Water Resources Research 51(1), 576-598 
VITA

John Nedson Ng'ombe

Candidate for the Degree of

Doctor of Philosophy

Thesis: ECONOMICS OF THE GREENSEEDER HAND PLANTER, DISCRETE CHOICE MODELLING, AND ON-FARM FIELD EXPERIEMENTATION

Major Field: Agricultural Economics

Biographical:

Education:

Completed the requirements for the Doctor of Philosophy in Agricultural

Economics at Oklahoma State University, Stillwater, Oklahoma in July, 2019.

Completed the requirements for the Master of Science in Agricultural Economics at University of Zambia, Lusaka, Zambia in 2013.

Completed the requirements for the Bachelor of Science in Agricultural Economics at University of Zambia, Lusaka, Zambia in 2010.

Experience:

Graduate Research Assistant, Department of Agricultural Economics, Oklahoma State University, 2015-2019.

Lecturer, Department of Agricultural Economics and Extension, University of Zambia, 2014-Present

Adjunct Lecturer, School of Business, University of Lusaka, 2014-2015

Adjunct Lecturer, Department of Economics, Cavendish University-Zambia, 2010-2012.

Professional Memberships:

Agricultural and Applied Economics Association (AAEA)

Southern Agricultural Economics Association (SAEA)

Midwest Economics Association (MEA)

International Society for Bayesian Analysis (IABA) 